\title{
Transformative Learning Networks: Guidelines and Insights for Netweavers
}

RESEARCH TEAM LEADER:

BRUCE EVAN GOLDSTEIN, ASSOCIATE PROFESSOR, PROGRAM IN ENVIRONMENTAL DESIGN, UNIVERSITY OF COLORADO BOULDER

RESEARCH TEAM MEMBERS:

CLAIRE S. CHASE, UNIVERSITY OF COLORADO BOULDER

LEE FRANKEL-GOLDWATER, UNIVERSITY OF COLORADO BOULDER

JEREMIAH OSBORNE-GOWEY, UNIVERSITY OF COLORADO BOULDER

JULIE RISIEN, OREGON STATE UNIVERSITY

SARAH SCHWEIZER, UNIVERSITY OF COLORADO DENVER

A REPORT FROM THE NETWORK OF STEM EDUCATION CENTERS, HTTP://SERC.CARLETON.EDU/STEMEDCENTERS/INDEX.HTML.

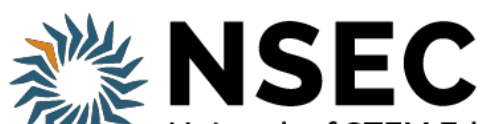

Network of STEM Education Centers
CENTER O, FOR SCIENCE \& TECHNOLOGY POLICY RESEARCH
University of Colorado
Boulder 


\section{Contents}

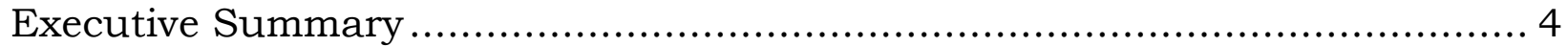

Purpose and Audience........................................................................ 4

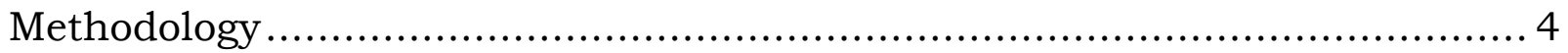

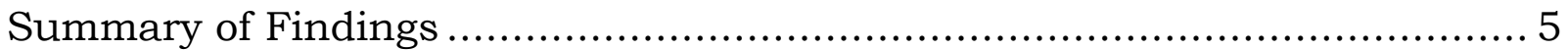

Learning Network: Their Promise and Challenges .................................... 7

Case Study Introduction .............................................................. 9

Project Summary and Conclusions ................................................. 12

Network Facilitation .................................................................. 12

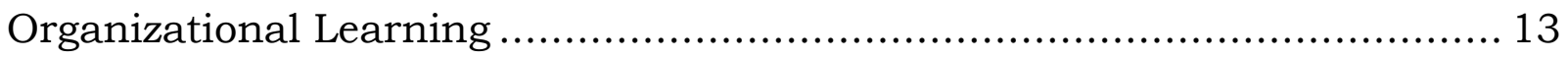

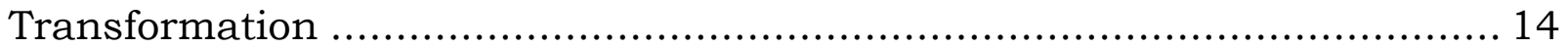

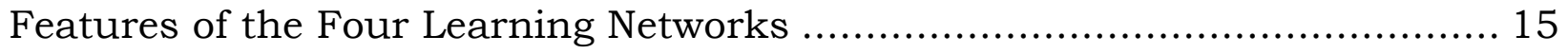

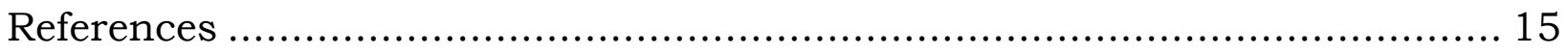

CASE STUDY - The National Alliance for Broader Impacts by Julie Risien,

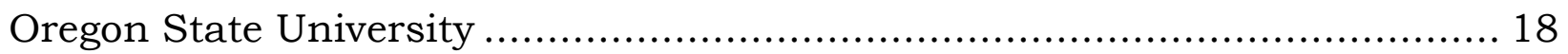

PART 1 - Case Introduction and Profile ........................................... 18

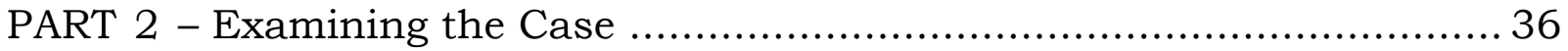

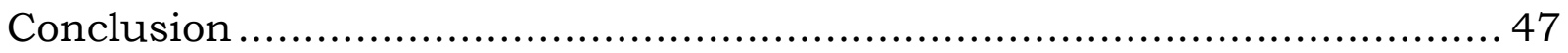

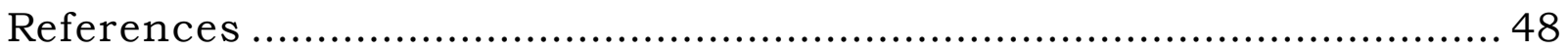

CASE STUDY - 100 Resilient Cities by Claire S. Chase \& Lee Frankel-Goldwater, University of Colorado Boulder ................................................... 52

PART 1 - Case Introduction and Profile .............................................. 52

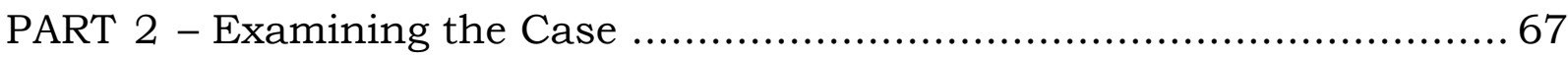

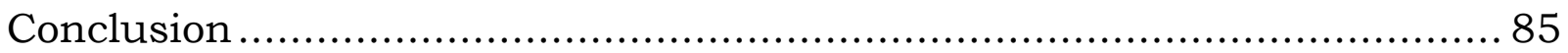

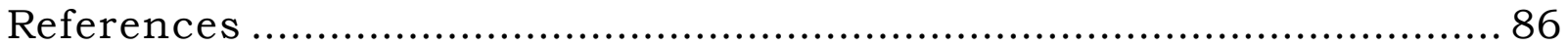

CASE STUDY - The Fire-Adapted Communities Learning Network by Jeremiah Osborne-Gowey, University of Colorado Boulder .................................... 89

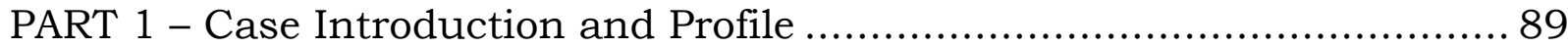

PART 2 - Examining the Case ...................................................... 109

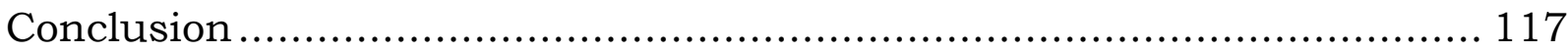

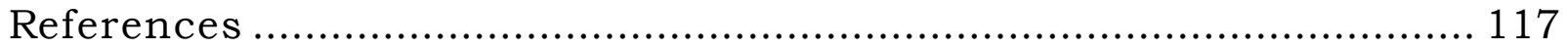


CASE STUDY - Global Change SysTem for Analysis, Research and Training by Sarah Schweizer, University of Colorado Denver ................................. 120

PART 1 - Case Introduction and Profile ......................................... 120

PART 2 - Examining the Case …............................................... 135

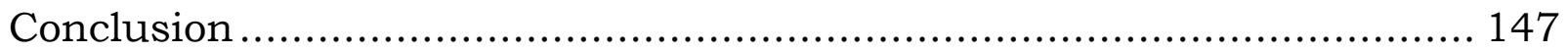

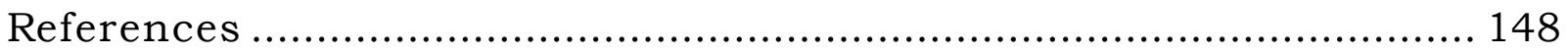

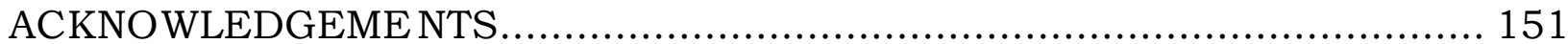


EXECUTIVE SUMMARY

\section{PURPOSE AND AUDIENCE}

The purpose of this report is to explore how a learning network can contribute to better learning outcomes and practices for their members and foster increased capacity to effect transformative change to address fundamental barriers. Here we define learning networks as inter-organizational voluntary collaboratives that nurture professional expertise. Learning networks are often systems-oriented and non- hierarchical and are attempted when deeply rooted obstacles to institutional change have proven resistant to both top-down or bottom-up change strategies.

Learning networks require a high level of engagement and commitment to identify deep-rooted problems and to coordinate disparate actors to implement solutions that are both site-specific and network-wide. This coordination and management is undertaken by netweavers or network leaders. Netweavers initiate activities that build community by forming relationships, circulating ideas and practices through the network, and promoting a shared identity that provides the foundation for common practice and purpose.

The audiences for this work are the designers and netweavers of STEM education networks and the broader community of network participants. The report provides specific guidance to netweavers on how netweaving practices can enable a network to become self-sustaining by supporting participants to identify as a community and view themselves as the change leaders.

\section{METHODOLOGY}

As STEM education centers increasingly serve as tools for advancing undergraduate educational missions of higher education institutions, the Network of STEM Education Centers (NSEC) has the potential to advance individual center capacity as well as systematically address collective national challenges in STEM education. NSEC can draw from key principles of other learning networks.

Researchers at the University of Colorado Boulder have prepared case studies of four learning networks: National Alliance for Broader Impacts (NABI), 100 Resilient Cities Network (100RC), Fire Adapted Community Learning Network (FACNet), START (Global Change SysTem for Analysis, Research \& Training). 
The project team (see bios at http://www.brugo.org) assembled the case studies using interviews with netweavers, document analysis (including media accounts and documentation), and literature review. In three of the four cases (FACLN, START, and NABI), the researchers were embedded in the network as members of the management team, which enabled them to engage in participant observation (in-person and in webinars and network management calls) and get participant feedback for their initial findings.

Each of the case studies explores how a learning network disrupted old habits and fostered new collaborative relationships, reinforcing participants' shared ties and purposes while providing freedom to experiment.

Each case is similarly structured. The first section describes the network's origin, design and approach to collaborative learning. The second section focuses on how the network contributes to organizational learning, network facilitation ("netweaving") both within sites and across different levels of the network, and transformative capacity building for systems change. A brief summary of key takeaways from the cases and some concluding remarks are provided for each case study.

\section{SUMMARY OF FINDINGS}

In the collection of case studies, we consider how four learning networks are designed, facilitated and their potential to build transformative capacity in the domains of city governance, wildfire protection, climate adaptation, and the broader impacts of scientific research. We focused on three core themes:

Netweaving

- Netweavers, who may be formally identified or may emerge from among network participants, performed a crucial nucleating role by supporting individual members and promoting overall network health.

- Netweavers who were more fluid in operating across the different network levels were more capable at facilitating information flow, forging social ties that enabled members to identify shared interests and challenges and engage in group learning.

- Netweaving requires an ability to operate flexibly within and across participating sites. When relationships are pre-determined and subordinated to a chain of command, tensions open up between locally emergent and centrally-prescribed identity and objectives. 
Organizational learning of the Network:

- Capacity to engage in organizational learning is essential to ongoing network adaptation, as needs and perspectives evolve and different participants come into the network.

- Three network features associated with organizational learning were:

○ multiple opportunities for communication and feedback between netweavers and members,

- encouragement to experiment with different approaches to network interaction, and

o whole-network meetings where network governance was explicitly addressed.

Transformative capacity:

- Transformative capacity emerges from a productive tension within and between network sites, a capacity that is neither the sum of similar efforts at different sites and scales nor the least common denominator between them. Mediating these tensions well often results in better learning, more innovative solutions, and more effective implementation of approaches to system transformation.

- In a multi-sited learning network that engages members within and across sites, there are many perspectives on transformation which may not be entirely coherent with one another, since they are grounded in different social and ecological conditions, informed by multiple epistemologies, and shaped by power-laden choices about the purpose of collective action. A well-designed learning network not only supports this heterogeneity across sites (individual members) and scales, it also mediates the relationship between sites, supporting expression and adoption of a new professional identity that can promote higher-order coherence.

Overall, we conclude that good netweaving employs a soft touch by mediating between different ideas about transformation ways of knowing, being, and organizing without collapsing them into one perspective.

Critically, a learning network must be a learning organization (Senge, 1990), not only performing efficiently over time, but also critically questioning its policies, objectives, and embedded values to continuously transform its structure and procedures. This facilitates developing an open culture of inquiry and trust that can foster collective identity and ongoing commitment among network participants. 
Learning networks are inter-organizational voluntary collaboratives that nurture professional expertise in fields such as environmental management, public health, and education (Goldstein and Butler 2010a; Dolle et al., 2013). Learning networks are often attempted when deeply rooted obstacles to institutional change have proven resistant to both top-down or bottom-up change strategies. These networks have a loose, light structure that allows them to learn and adapt as their membership becomes more confident and experienced, as new needs and opportunities are recognized, and as resources and institutional support require.

Learning networks rely on effective design and ongoing facilitation to function effectively. Network facilitators or "netweavers" may be formally identified or may emerge from among network participants. These netweavers collaborate with participants in identifying goals and an effective network topology and infrastructure.

Netweavers initiate activities that build community by forming relationships, circulating ideas and practices through the network, and promoting a shared identity that provides the foundation for common practice and purpose. This social capital can

Netweavers are network facilitators that initiate activities that build community by forming relationships and circulating ideas and practices through the network, promoting a shared identity that provides the foundation for common practice and purpose. enable learning networks to persist through the vicissitudes of sponsor funding and political climate, enabling them to influence transformative change. This bridging function of netweavers is especially important as transformative change is often slow moving or punctuated, only occurring when rare windows of opportunity for adaptation enable networks to rapidly mobilize resources and disseminate innovation across sites (Pelling, 2010).

Effective learning networks amplify the potential for transformative change by combining community-based innovation with community-spanning interaction and exchange (Goldstein \& Butler, 2009, 2010a, 2010b; Goldstein, 2012; Goldstein et al., 2013). Each participating site defines problems in its own way, accommodating local context and contingencies to generate distinct strategies and solutions. This autonomy is balanced with a network-wide coherence that advances collective action across organizational, temporal, and spatial scales. Learning networks can disrupt old habits and foster new collaborative 
relationships, reinforcing participants' shared ties and purpose, while providing freedom to experiment with innovative approaches. Fundamentally different kinds of learning take place within, between, and across network levels, and even across different network initiatives; it is the effective interweaving of these different kinds of learning that fosters transformative capacity. Learning networks can be thought of as bridging organizations in two different ways: they create bridges between different ways of knowing and operating and they bridge to desired alternative futures by fostering system-wide innovation and collective mobilization.

However, many of the features that provide learning networks with transformative potential also make them difficult to organize and maintain. Learning networks require a high level of engagement and commitment to identify deep-rooted problems and coordinate disparate actors to implement solutions that are both site-specific and network-wide. Maintaining this level of engagement in a learning network is especially difficult because they often are:

- Voluntary, and often not recognized as part of member's work responsibilities.

- Operate at multiple scales and rely on coordination among multiple approaches to maintain connection and dialogue.

- Promoting change during turbulent times, where opportunities to make change are shifting and fleeting.

- Reliant on support from multiple sponsors and supporting organizations, and so are lightly resourced and staffed, and highly vulnerable to changing funding priorities.

The learning network literature does not provide clear guidance on important initial design issues, such as how a specific network typology or connectivity could contribute to better learning outcomes and practices of members on their own campuses. Additionally, the literature does not provide clear guidance on how the initial design of the network impacts the capacity of the network to foster transformative change to address fundamental barriers, such as the tenure and promotion policies that are often indicated as a barrier to adoption of effective classroom practices for STEM education, Netweavers need more specific guidance on what membership guidelines and accountability standards could enable a transformative change network to become self-sustaining. 
The Network of STEM Education Centers (NSEC) commissioned these case studies to identify the opportunities and challenges of a learning network approach, with the purpose of informing NSEC's design to foster transformative capacity and ensure member ownership of their network. The network management team drew on available research on learning networks (e.g. Goldstein \& Butler, 2010a, 2010b; Goldstein, Wessells, Lejano, \& Butler, 2013) as well as on how successful networks support change in STEM instruction operating at the faculty level (e.g., Narum \& Manduca, 2012; Henderson, Beach, \& Finkelstein, 2011; Kezar \& Gerhke, 2014). The four learning networks that our project team examined, along with their transformation challenges, are:

- NABI (National Alliance for Broader Impacts): Connecting basic research to broader impacts to address the deep cultural divide between the academy and the public;

- 100 Resilient Cities Network: Fostering urban resilience in response to the inability of city governments to adequately address challenges to sustainability;

- Fire Adapted Community Learning Network: Creating fire adapted communities after 100 years of failed wildfire management policy; and

- START (Global Change SysTem for Analysis, Research \& Training): Addressing the knowledge and capacity deficit to address global change impacts in the developing world.

The project team (see bios at: www.brugo.org) assembled the case studies using interviews with netweavers, document analysis (including media accounts and documentation), and literature review. In three of the four cases (FACLN, START, and NABI), the researchers are embedded in the network as members of the management team, which enabled them to engage in participant observation (inperson and in webinars and network management calls) and get participant feedback for their initial findings. All of the studies were conducted under the terms of human subjects protocols approved by the University of Colorado Boulder.

The objective was to describe each network's origin, design and approach to collaborative learning, and then focus on organizational learning, cross-scale integration, netweaving, and transformative capacity building. Accordingly, each case is organized around two parts: 


\section{Part 1: Network Fundamentals}

Network Origins

- Core challenges that brought the network together, focusing on how netweavers framed possibilities for systems transformation

- Principal individuals and organizations involved in network formation, and what motivated them to participate

Network Design and History

- Initial network design, focusing on netweaving and cross-scale operation and transformative potential

- History of the network, focusing on major organizational/personnel changes, turning points, or crises that resulted in network redesign, growth, or decline

Introduction to Netweaving

- Who are the netweavers and how do they operate, with a focus on network accountability

Collaborative Learning

- How network collaboration supports learning, with detailed examples at different scales

\section{Part 2: Network Possibilities}

Organizational Learning

- Does organizational learning within the network occur through ongoing course correction, and/or through adaptation to external conditions?

- What kind of formal or informal monitoring and feedback is critical for organizational learning?

- Is the network evolving to be catalytic and temporary, or become a permanent part of system governance, and what difference does that make?

Network Facilitation ("netweaving") both within sites and across scales of the network:

- How does the netweaver integrate both across sites and with other institutional actors through boundary integration, boundary crossing, translating, and/or mediation?

- Do netweavers support creation of a shared network story, or common identity? 
- What are the core practices of netweavers that support organizational learning and transformative capacity building?

- How does the network balance its capacity for creativity and autonomy at the community scale (or comparable lowest unit) with coherence and coordination at the network scale?

- How does the network accommodate differences between sites? Does the network cultivate partial understandings, and coordination across difference?

- Given heterogeneity between communities/sites, what holds the network together?

- What is the network's common professional or activist identity, in terms of community, domain, and practice? Has it shifted over time?

- Does the network support the creation of a shared story? If so, to what degree does the story have different actors, timelines, plot arc or story development?

- Does the network offer any generalized principles or practices for design of a transformative learning network?

Transformative Capacity for System Change

- Has the network fostered transformative capacity at the individual, community and/or network scales, and how does capacity translate into transformation?

- What is the "secret sauce" that enables the network to build transformative capacity?

- Is there learning going on in the network, what kind of learning is it, and how does this support transformative capacity building? 
In this collection of case studies, we have considered how four learning networks (see Figure 1) are designed and facilitated; and their potential to build transformative capacity in the domains of city governance, wildfire protection, climate adaptation, and the broader impacts of scientific research. We have also explored how a learning network is a learning organization (Senge, 1990), not only performing efficiently over time, but also critically questioning its policies, objectives, and embedded values to continuously transform its structure and procedures.

Well-designed and facilitated learning networks develop an open culture of inquiry and trust, a willingness to take risks and extend opportunities to learn, and possess the transparency necessary to challenge embedded values and develop shared meaning and understanding. These characteristics can contribute to creation of collective identity and commitment among network participants (Goldstein \& Butler, 2009). In this conclusion, we briefly summarize what we have learned from these networks about the crosscutting themes of transformative capacity, netweaving, and organizational learning, and reflect on the implications of this study for thinking about learning networks.

\section{NETWORK FACILITATION}

In each network we examined, there were designated netweavers who performed a crucial nucleating role by supporting individual members and promoting overall network health. Netweavers operated at different scales of network action, from community-based netweaving by the 100RC CROs and Relationship Managers, to learning exchanges between communities in FACNet, to wholenetwork netweaving in NABI. While netweavers in three networks (NABI, FACNet, and START) were able to respond flexibly to the tension between supporting individual sites and promoting overall network objectives, netweaving in the 100RC network was relatively rigid, with relationships predetermined and subordinated to a chain of command. This exacerbated tensions between local and network-wide identity and objectives. Netweaving requires an ability to operate within and across participating sites without eliding differences between them. Netweavers who were more fluid in operating across the different network levels were more capable at facilitating information flow, forging social ties that enabled members to identify shared interests and challenges and engage in group learning, and promoting a shared professional identity. 
Capacity to engage in organizational learning was essential to ongoing network adaptation. Three network features associated with organizational learning were apparent:

1. multiple opportunities for communication and feedback;

2. encouragement to experiment with different approaches to network interaction; and

3. whole-network meetings where network governance was explicitly addressed.

Organizational learning was supported by opportunities for rapid feedback between netweavers and members, both through formal evaluation and regular and open communication. While all four cases observed instances where network procedures and practices were examined and altered, a communication "bottleneck" in 100RC inhibited organizational learning.

Networks that encouraged members to take the initiative to experiment with different ways to collaborate were observed to adapt their procedures more readily, such as in FACNet, where the coordinating team encouraged its members to develop additional partnerships and projects, such as subnetworks, and then once the approach showed promise encouraged other members to adopt and adapt it. Annual meetings that engaged network members in critical deliberation about network governance were more successful in addressing underlying tensions and getting agreement on new approaches. One example are the annual retreats involving START staff, Board of Directors, and regional representatives.

We believe that networks function best when they are designed and facilitated with a soft touch. People participate in learning networks to bring about change either in their own practice or within a larger system, so they need to have the freedom to bound and define their communities as they are, as well as how they think they ought to be. The sense-making process that participants engage is often more like storytelling than formal analysis, since network members not only define their place and purpose within their communities, they also identify their own role in bringing about a desired transformation. In a multi-sited and multi-level learning network, this is happening in many places at once, amidst many perspectives on how to bound a system and what actors and organizations to take into consideration. These perspectives will not be entirely coherent with 
one another, since they may be grounded in different social and ecological conditions, informed by multiple epistemologies, and/or shaped by power-laden choices about the purpose of the network's collective action (Goldstein et al. 2013). Prescribing a specific approach to professional practice across network membership can only short-circuit the process of discovery.

A learning network not only supports maintaining this heterogeneity across sites and scales, it also mediates the relationship between sites, connecting them in ways that can promote higher-order coherence as well as member autonomy. A key to this is maintaining coherence between the stories that people tell themsleves about their communities part and future and their role in it, which may otherwise have different starting points, alternative possible futures, key characters, and plot trajectories (Cronon, 1992). From this perspective, good netweaving employs a soft touch by mediating between different ways of knowing, being, and organizing without collapsing them into one perspective. At the network scale, organizational learning enables ongoing adaptation of the network's structure and functions, as needs and perspectives evolve and different participants come and go.

\section{TRANSFORMATION}

Transformative capacity emerges from the productive tension within and between network sites, an emergent capacity that is neither the sum of similar efforts at different sites and scales nor the least common denominator between them. For example, interaction between sites supported expression and adoption of a new professional identity. In the NABI network, the emergence of a specialty in expanding the broader societal impacts of research, along with an expression of its moral purpose, enabled members to identify best practices and support collective efforts to influence national research funding and oversight. FACNet also engaged its members in ways that supported a common identity of community fire adaptation organizer, grounded in a social-ecological perspective on community and place. START's focus on strengthening individual skills and capacities to address the impacts of climate change was notable for addressing entrenched power dynamics and the political constraints on collective action. In contrast to the other cases, we did not observe the potential for collective action and impact in the 100RC network, although Chief Resilience Officers (CROs) did develop an explicitly defined, shared identity. 


\begin{tabular}{|c|c|}
\hline & ORIGINS \\
\hline NABI & $\begin{array}{l}\text { - Began with a conference style summit in } 2013 \\
\text { - Funded as an NSF RCN in } 2014 \text {. } \\
\text { - Driving goal is to create a community of practice that fosters the } \\
\text { development of sustainable and scalable institutional capacity and } \\
\text { engagement in broader impacts activity. }\end{array}$ \\
\hline 100RC & $\begin{array}{l}\text { - Created to help cities account for sudden shocks and long term stresses } \\
\text { by supporting local Chief Resilience Officers (CRO). } \\
\text { - CRO develops a city resilience strategy and coordinates network of } \\
\text { resources and tools for resilience-oriented goals for cities. } \\
\text { - First round of } 34 \text { cities in December } 2013 \text {. }\end{array}$ \\
\hline FACLN & $\begin{array}{l}\text { Formed in 2013, growing out of (or in response to) and patterned after the } \\
\text { Fire Learning Network (formed in 2001-2002). } \\
\text { Goal was to broaden acceptance of fire-adapted principles to build } \\
\text { resilience to fire and in response to need to balance national policies with } \\
\text { local contexts. } \\
\text { - Work tends to focus from social (and ecological) communities into the } \\
\text { surrounding landscapes. }\end{array}$ \\
\hline START & $\begin{array}{l}1990 \text { meeting of the International Geosphere Biosphere Programme (IGBP) } \\
\text { in Bellagio, Italy concluded that a system of regional networks focusing on } \\
\text { analysis, research and training would be an effective way of ensuring } \\
\text { regional collaboration on global change science and research. } \\
\text { - START was launched in } 1992 \text { under the aegis of the International Council } \\
\text { for Science (ICSU) and its four international global change science } \\
\text { programs as the capacity building arm of the global change programs' } \\
\text { work in Africa and Asia-Pacific. }\end{array}$ \\
\hline
\end{tabular}

\begin{tabular}{l|l}
\hline \multicolumn{2}{l}{ STRUCTURE } \\
\hline NABI & - Distributed network with a steering committee that meets monthly \\
& - Subcommittees tackle specific needs of the network (e.g. training, finance, \\
& event planning, and membership development) \\
& - Non-governing advisory board. \\
& - PI manages overall operations \\
- Two partially committed staff members.
\end{tabular}




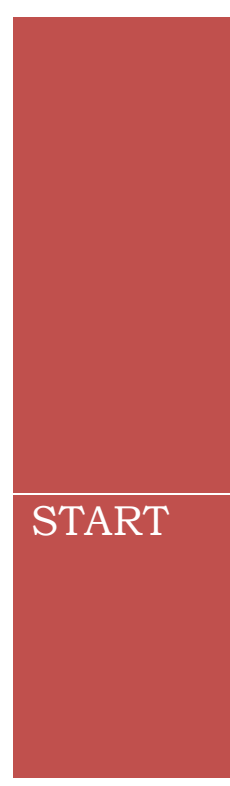

- National coordinating team (CT), in consultation with researchers and with input from network members, helps steer the network.

- Activities and logistical support coordinated by a small non-profit org in N. California.

- Network leads in each member community regularly interact with CT members.

- Accountability to funders is in part via CT team comprised of people from funding institutions. Accountability of project funding to members via member reporting to network.

- International START Secretariat, located in Washington, DC, coordinates programs and activities.

- Distributed system of regional centers and affiliates that aim to strengthen partnerships, programming, implementation capacities, and local legitimacy in the regions in which it works.

\begin{tabular}{|c|c|}
\hline & MEMBERSHIP \\
\hline NABI & $\begin{array}{l}\text { - }>450 \text { self-selected members representing }>60 \text { member institutions } \\
\text { prombership is by a request to the managing office and completion of a } \\
\text { - Members participate through annual conferences, listserv communication } \\
\text { and service on sub- committees. }\end{array}$ \\
\hline 100RC & $\begin{array}{l}\text { - } 100 \text { cities in the network. } \\
\text { M embers were competitively selected as part of an application process } \\
\text { that requires the matching of resources and financial support from city } \\
\text { governments. }\end{array}$ \\
\hline FACLN & $\begin{array}{l}\text { Membership is by invitation only but builds on existing fire-related } \\
\text { programs and capacities of local communities. } \\
\text { Members represent geographies (e.g., counties, cities, etc.), individuals, } \\
\text { or organizations. } \\
\text { - Potential members either approach the network seeking membership or } \\
\text { current members reach out to prospective members. } \\
\text { Two levels of membership: core and affiliate. Core members actively } \\
\text { disseminate lessons learned to other nodes of the network. }\end{array}$ \\
\hline START & $\begin{array}{l}\text { - Individual membership is based on START regional centers and affiliates } \\
\text { or through participation in START programs and activities. } \\
\text { - Engages 500-1000 early career scientists per year. }\end{array}$ \\
\hline
\end{tabular}

\section{PRIMARY ACTIVITIES}

NABI

- Nucleating activity is an annual conference.

- Connected by conversation on an email listserv.

- Trellis is used minimally as a digital platform and potential archive of documents, resources and conversation.

- Steering committee conducts monthly phone calls and biennial in person meetings. 


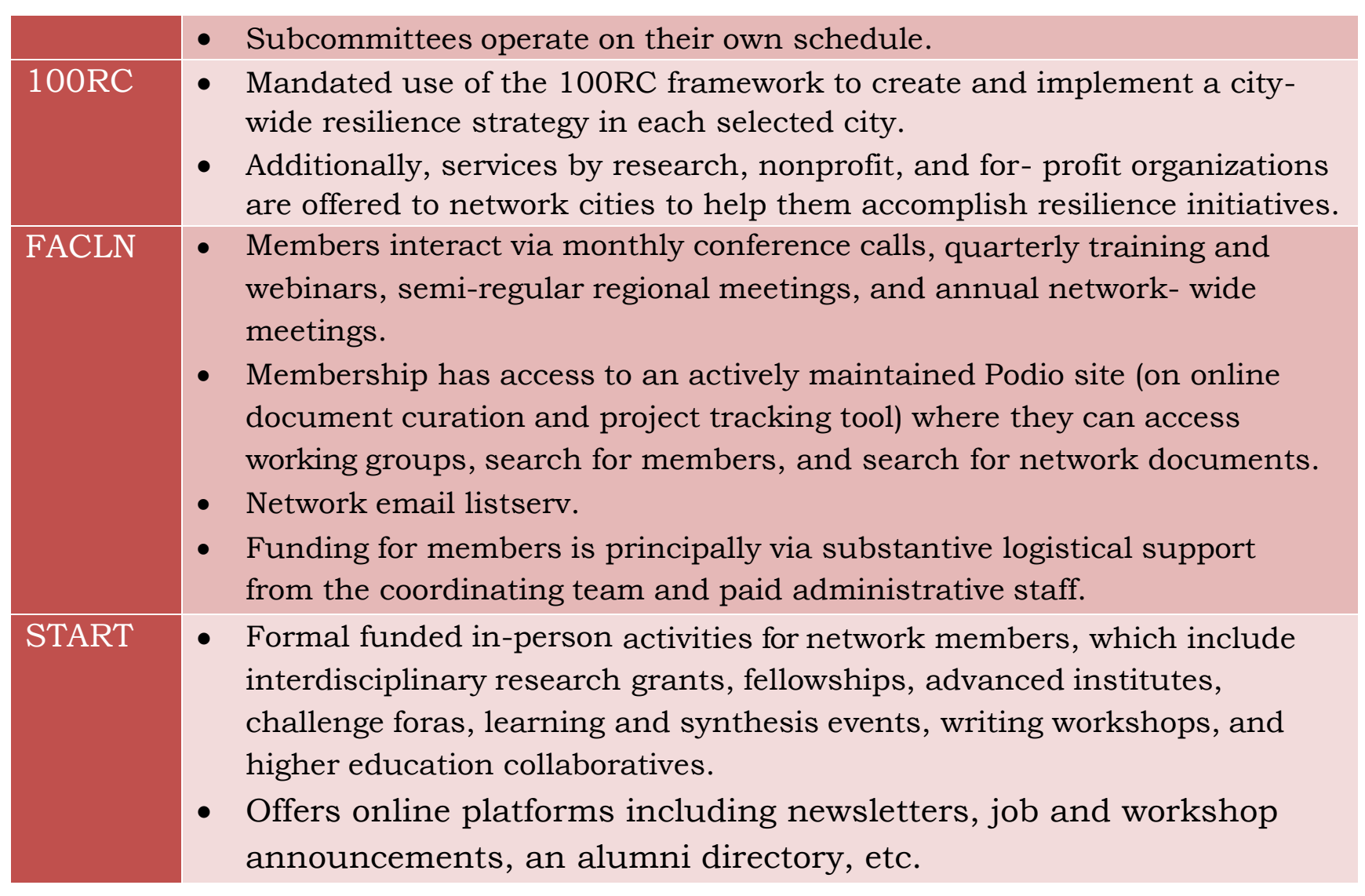

\begin{tabular}{|c|c|}
\hline & FUNDING \\
\hline NABI & $\begin{array}{l}\text { - NSF has provided 500k for five years to fund basic operations of the } \\
\text { Network including minimal time of PI and staff, steering committee and } \\
\text { advisory board travel to NABI meetings and complementary meetings } \\
\text { where NABI can build membership and awareness about broader impacts. }\end{array}$ \\
\hline 100RC & $\begin{array}{l}\text { 100RC grants } \$ 1 \text { million to cities selected as part of the } 100 \text { RC network } \\
\text { specifically earmarked for the hiring of a Chief Resilience Officer in the } \\
\text { selected city. } \\
\text { 100RC is one of seven resilience initiatives pioneered by the Rockefeller } \\
\text { Foundation. Rockefeller is the parent organization and funder for the } \\
\text { 100RC network. }\end{array}$ \\
\hline FACLN & $\begin{array}{l}\text { Funding comes from a multi-partner cooperative agreement (PERFACT) } \\
\text { between the USFS, TNC and natural resource agencies of the Dept. of } \\
\text { Interior with additional discretionary funds coming from agency or org } \\
\text { budgets of members who sit in other positions with agencies and orgs. } \\
\text { - TNC and USFS appear to provide most of the funding. } \\
\text { - PERFACT fund for FACLN are primarily used for paid staff to provide } \\
\text { substantial logistical and administrative support, to support regional and } \\
\text { national learning and training exchanges, as well as provide travel funds } \\
\text { for members. } \\
\text { - Funding is secure for two more years at which point the agreement will } \\
\text { be re-evaluated by all parties. }\end{array}$ \\
\hline START & - $\$ 1.5-3$ million annual budget \\
\hline
\end{tabular}


- Core operational and program funding for the International START Secretariat is through grants from the US Global Change Research Program (USGCRP), and grants and contracts from development assistance and other multilateral agencies.

- About half of START's total income is from US government grants.

- Half is from international NGOs, foreign government agencies, foundations and donations.

- Consistently partners with other organizations to secure resources for programmatic portfolio.

- Spends over $90 \%$ of its funds on program activities focused on core mission.

\section{TRAJECTORY}

NABI NABI steering committee and advisory board is in active conversation about the future membership and financial model of the network. There is a strong commitment to sustainability and it is likely that the membership structure will change in a substantial way.

100RC 100RC aims to create a "resilience revolution" across city governments throughout the world. Plans are still tentative as to what the network will look like after the funding periods for cities end.

FACLN - The network is still expanding membership but being more intentional about who it brings on, wanting to ensure "learning" across the network and the presence of existing capacities in potential members so as not to create financial strain and to leverage existing capacities, network connections, funding streams, etc.

START

- In 2009, START incorporated as START International, Inc. in the US as a 501 (c)(3) non-profit organization. The By-Laws of START International, Inc. define the overall governance and operating structure of START. The highest decision-making body of START International, Inc. is the Board of Directors, and the International START Secretariat is its operating arm. 
Cronon, W. (1992). A place for stories: Nature, history, and narrative. The Journal of American istory, 78(4), 1347-1376.

Dodgson, M. (1993). Organizational learning: a review of some literatures. Organization studies, 14(3), 375-394.

Dolle, J. R., Gomez, L. M., Russell, J. L., \& Bryk, A. S. (2013). More than a network: Building professional communities for educational improvement. National Society for the Study of Education Yearbook, 112(2), 443-463. http:/ / learndbir.org/resources / 14-Dolle-Gomez-Russell-Bryk-Ready.pdf

Goldstein, B. E. \& Butler, W. H. (2009). The network imaginary: coherence and creativity within a multiscalar collaborative effort to reform US fire management. Journal of Environmental Planning and Management, 52(8), 1013-1033.

Goldstein, B. E. \& Butler, W. H. (2010a). Expanding the scope and impact of collaborative planning: combining multi-stakeholder collaboration and communities of practice in a learning network. Journal of the American Planning Association, 76(2), 238-249.

Goldstein, B. E. \& Butler, W. H. (2010b). The US Fire Learning Network: Providing a narrative framework for restoring ecosystems, professions, and institutions. Society and Natural Resources, 23(10), 935-951.

Goldstein, B. E. (Ed.). (2012). Collaborative resilience: moving through crisis to opportunity. MIT Press.

Goldstein, B. E., Wessells, A. T., Lejano, R., \& Butler, W. (2013). Narrating resilience: transforming urban systems through collaborative storytelling. Urban Studies, 0042098013505653. Available at: http://usj.sagepub.com/content/early/2013/10/08/0042098013505653.a bstract

Goldstein, Bruce Evan, Wessells, Anne Taufen, Lejano, Raul P., and William Butler. 2015. Narrating Resilience: Transforming Cities Through Collaborative Storytelling. Urban Studies. 52(7): 1285-130.

Henderson, C., Beach, A., \& Finkelstein, N. (2011). Facilitating change in undergraduate STEM instructional practices: an analytic review of the literature. Journal of Research in Science Teaching, 48(8), 952-984.

Kezar , A. \& Gehrke, S. (2014). Lasting STEM Reform: Sustaining NonOrganizationally Located Communities of Practice Focused on STEM Reform. Paper prepared for the 2014 ASHE Annual Conference, Washington, DC.

Narum, J. and Manduca, C. (2012). Workshops and Networks in Bainbridge, W. S. (Ed.). (2011). Leadership in science and technology: A reference handbook. Sage Publications. ISBN 978-1-4129-7688-6 p. 443-451 
Pelling, M. (2010). Adaptation to climate change: from resilience to transformation. Routledge. Senge, P.M. (1990). The Fifth Discipline. London: Century Business.

Senge, P. (1990). The fifth discipline: The art and science of the learning organization. New York: Currency Doubleday. 


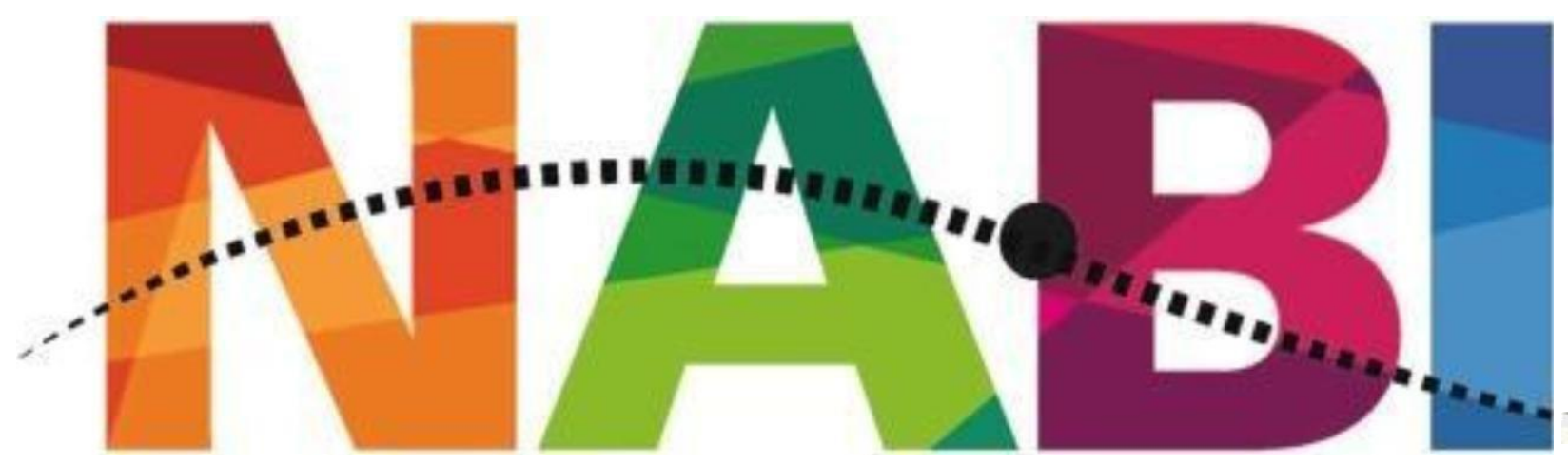

National Alliance for Broader In⿴囗十CLS

The National Alliance for Broader Impacts

Julie Risien, Oregon State University

Julie.Risien@oregonstate.edu 
CASE STUDY - THE NATIONAL ALLIANCE FOR BROADER IMPACTS BY JULIE RISIEN, OREGON STATE UNIVERSITY

PART 1 - CASE INTRODUCTION AND PROFILE

This chapter profiles the National Alliance for Broader Impacts (NABI), a relatively young network, established in part to address the challenge of better connecting publically funded research and societal benefits. The network has a strong focus on university-based activity across the country.

\section{Network Origins}

Federal research funding encompasses the majority of research expenditures at many large universities. Depending on the nature of topical strengths, many universities rely to a great degree on one agency, the National Science Foundation (NSF). But public, and specifically congressional, scrutiny has been increasing and the NSF frequently makes the news with conflated stories of wasteful spending. Since 2012, the agency has dedicated substantial energy to demonstrating their commitment to public returns on research investments. The primary path for doing so is strengthening and reaffirming their commitment to "broader impacts." Broader impacts (BI) can be summed up as the societal benefit associated with research investments and the "return" (in benefits) of those investments. They are inclusive of advancing discovery, promoting learning, enhancing infrastructure, and broadening participation of underrepresented groups in science (NSF, 2014a). In January 2014, in response to scrutiny and confusion in the research community, the agency considerably strengthened their Grant Proposal Guidelines document with respect to the BI merit review criteria (NSF, 2014b) ${ }^{1}$. Many federal and state agencies also increased their emphasis on broadening the impacts of research investments, reflecting a growing focus on BI across the research community.

The change in NSF policy and calls for shifts in university practice are situated amidst a complex debate about the role of institutions of higher education in civic society and the often competing neoliberal notions that increasingly drive management and structures at universities. It is argued that the post-WWII decline of social capital and civic engagement (Putnam, 2000) and associational culture (Skocpol, 2004), along with the increasing complexity of social problems

\footnotetext{
1 The America Creating Opportunities to Meaningfully Promote Excellence in Technology, Education, and Science or America COMPETES Act of 2007, 2010, and the reauthorization of 2015 address the NSF directly requiring many new reporting and public transparency mechanisms adopted by the agency
} 
requires organizations such as universities to transform and play a more active civic role (Sirianni, 2009). This is juxtaposed by an ascent in neoliberal management of higher education with a focus on universities as the key institutions in the knowledge economy (Olssen \& Peters, 2005) creating increasingly hierarchical structures (Kezar, 2014). Kezar hypothesizes that central actors such as those being developed through networks will play increasingly critical change agent roles on campuses affected by neoliberalism.

Pressure is building on universities to address BI at the institutional scale, to improve both their impacts on the knowledge economy and civic society. The focus on neoliberal outputs may drive the need for institutions to organize in a way that allows quantification of aggregate impacts associated with research spending. While the complexity of social problems pushes universities to be civic enablers using their resources to improve social conditions and public access to education and science, transformation is prerequisite on several fronts. Structurally, universities are working to offer researchers support in designing and delivering broader impacts infused with evidence based practices and organized with some economy of scale. Universities need the appropriate organizational structures and supports to track such impacts to report to funding agencies and the public on benefits associated with research spending.

There is also a well-known need for transformation in the university reward structure which often rewards research dollars and peer- reviewed publications with little (if any) attention on benefits to society; an effect especially present at high intensity research institutions. Academic research culture, in accord with this reward structure, can be resistant and ill-prepared to succeed with BI. There is a need to stimulate shifts in values and capabilities of researchers to appropriately connect their work with the public and contribute to solutions of social problems either directly or indirectly. Direct contributions might include research outcomes such as life-saving technologies or better predictions of perilous weather events whereas indirect outcomes might be related to inspiring young people to consider careers in science or engineering or engaging a community in citizen science programming. Both direct and indirect contributions would be better realized with support and brokerage services of a new kind of professional with a keen focus on advancing BI.

The National Alliance for Broader Impacts, known as NABI, was born of a recognized need to build capacity at universities to create institutional scale solutions to BI challenges. While many universities had taken steps towards institutional action to meet the updated guidelines, the sophistication and implementation of the BI criterion remains highly variable. The goal of NABI is 
to "create a community of practice that fosters the development of sustainable and scalable institutional capacity and engagement in broader impacts activity"2.

NABI represents one of many efforts to develop a geographically distributed network to address the changing needs of higher education institutions. The Association of Public and Land-grant Universities (APLU) is building a network focused on supporting and developing directors of independent STEM (Science, Technology, Engineering and Mathematics) education centers working towards improved undergraduate instructional practices at universities ${ }^{3}$. The American Associated Universities (AAU) also has a STEM initiative and network (https://stemedhub.org/groups/aau) as does the NSF-funded Center for Integration of Research, Teaching and Learning (CIRTL) (http://www.cirtl.net/). These networks share several qualities; they are university focused, national in scale, distributed in nature, and assert goals of helping universities implement transformational change (in terms of policy, practice, and culture) by facilitating networked support of social learning, building community, and by serving as a nucleus for collective voice and action. These networks also aspire to build professional competence and identity through engaging participants in communities of practice.

Contemporary challenges faced by universities are beginning to be addressed by a new kind of professional who can navigate both vertically and horizontally in a university (Whitchurch, 2008). These new professionals are often central actors who can, often without positional authority, influence policy, practice, culture (Kezar, 2014), and, in some cases, the very structure of university systems. NABI refers to these boundary-spanning professionals as BI professionals. They occupy new territory and roles that work with some degree of autonomy and agency across academic and administrative structures; such professionals are increasingly necessary for universities but not always valued (Whitchurch, 2009). NABI is particularly focused on learning and professional development opportunities for BI professionals because of their central roles in changing BI practices at universities. The proposal that initiated funding for the group summarized the need and intended design of the network in this way:

Broader impacts specialists at multiple institutions across the country are rising to the challenge of helping stakeholders address

\footnotetext{
2 This and more information about the network can be found on the NABI website http://broaderimpacts.net/about/.

${ }^{3}$ NABI and NSEC have some overlapping members and are coordinating efforts and communicating about network practice, design and management.
} 
BI. To date, this has been happening in a non-systematic way, best characterized as "islands of practice." We have now reached a critical juncture in the evolution and maturation of the BI field where we must replace these "islands of practice" with a "community of practice." This community is ready to professionalize, collaborate on, and put into place mechanisms for sharing resources and promising approaches. The time is right for [NABI] to support these efforts and to catalyze the systematic organization of BI professionals.

\section{Network Design}

NABI is a geographically distributed network of both self-identified and institutionally appointed participants from a variety of higher education institutional types (e.g., public, private, minority- serving) with a small number of members from outside the realm of higher education. There is a dominance of high intensity research institutions with an intentional emphasis on supporting institutions in jurisdictions covered by the NSF Experimental Program to Stimulate Competitive Research (EPSCoR) ${ }^{4}$. The network has a goaldirected intentional design with a focus on overall improvement of broader impacts as an outcome; this is distinct from well-studied private sector interorganizational networks which often emerge from an incidental need to create a specific output (Raab \& Kenis, 2009). The network leaders conceived NABI as a distributed community of practice with implicit intent to build professional competence in a boundary where no previous coherent conception of competence exists (Wenger, 1998; Wenger-Trayner et al., 2015). The network's role is to innovate, through member connections, a set of professional practices to support BI. The boundaries in this context are not associated with objective social differences, but rather concerned with the dynamic dimensions of social relations.

Boundaries can be a tool across which members come to agree, establish feelings of similarity and acquire resources (LaMont \& Molnar, 2002) to collectively address issues where individual, rather than collective, mobility is less likely to be successful. In the university context, several symbolic

\footnotetext{
${ }^{4}$ EPSCoR, or the Experimental Program to Stimulate Competitive Research is a jurisdictionally restricted NSF program with a mission, "to advance excellence in science and engineering research and education in order to achieve sustainable increases in research, education, and training capacity and competitiveness that will enable EPSCoR jurisdictions to have increased engagement in areas supported by the NSF."
} 
boundaries and professional identities exist and are neither stable nor consistent. For example, boundaries between differing beliefs about the role of an institution (teaching versus research or knowledge economy versus. civic society), or actors' primary identification with a discipline versus an institution are both commonly present in university discourse (Clarke et al., 2013).

Like many other networks, NABI is designed around characteristics of a collaborative network where interdependent members share the common problem of ambiguity about BI policy and practice, and members make commitments to be part of evolving ways of thinking and behaving (Innes \& Booher, 2010; Mandell \& Keast, 2009). To call the network a collaborative does not, however, indicate emphasis on collaboration between members or member organizations, rather it is recognition that collaboration across boundaries in general is necessary to achieve shared network goals and collective outcomes. Among NABI members, several boundaries exist and must be skillfully navigated. These include boundaries of geography, institutional type, and faculty type that create differing status within a university (e.g., tenured, professional, extension, administrative), disciplinary identities, where one is situated within their institution (e.g., a research office, provost office, college), and differing approaches and expertise with regard to broader impacts.

The network is led by a steering committee made up of those partners invited and named on the initial application for funding to the NSF as a Research Coordination Network (RCN) and two vetted "at large members." Primary responsibility for the network is held by the Principal Investigator, referred to throughout this case study as the network leader, who serves as the primary netweaver or nucleating actor in the network. The netweaver navigates the tensions of organizations in flux by facilitating the flow of information and building social ties that enable learning (Reed et al., 2010), initiating activities that build community and promote a shared professional identity as the foundation for common practice and purpose.

Initial network design has focused on facilitating the flow of information. Prior to the existence of NABI information about the NSF BI criteria, evaluation and accountability was primarily shared in an ad-hoc way between discipline based NSF program managers and departmentally based (i.e. disciplinarily oriented) individual researchers (Figure 1). Communications between the NSF and the universities with regard to BI occurred in two primary ways: 1) researchers communicate with program managers as they prepare their own proposals for research funding or receive reviews on their proposals; and 2) program managers communicate with small groups of researchers from a handful of 
universities when they serve on review panels. Reports from researchers and NSF program staff characterize messages and practice with regard to BI as highly variable across NSF directorates and even within directorates (Risien \& Falk, 2013; National Science Board, 2011). Figure 1 illustrates the low overall primary flow of information mediated by individual discipline oriented researchers and program managers who penetrate and are informed by the institutions and the agency in a limited way. While other forms of communication do exist - such as formal NSF program announcements - the system lacked comprehensive and consistent flow of information about what it takes to meet the criterion and how proposals will be judged against the Grant Proposal Guidelines (National Science Board, 2011).

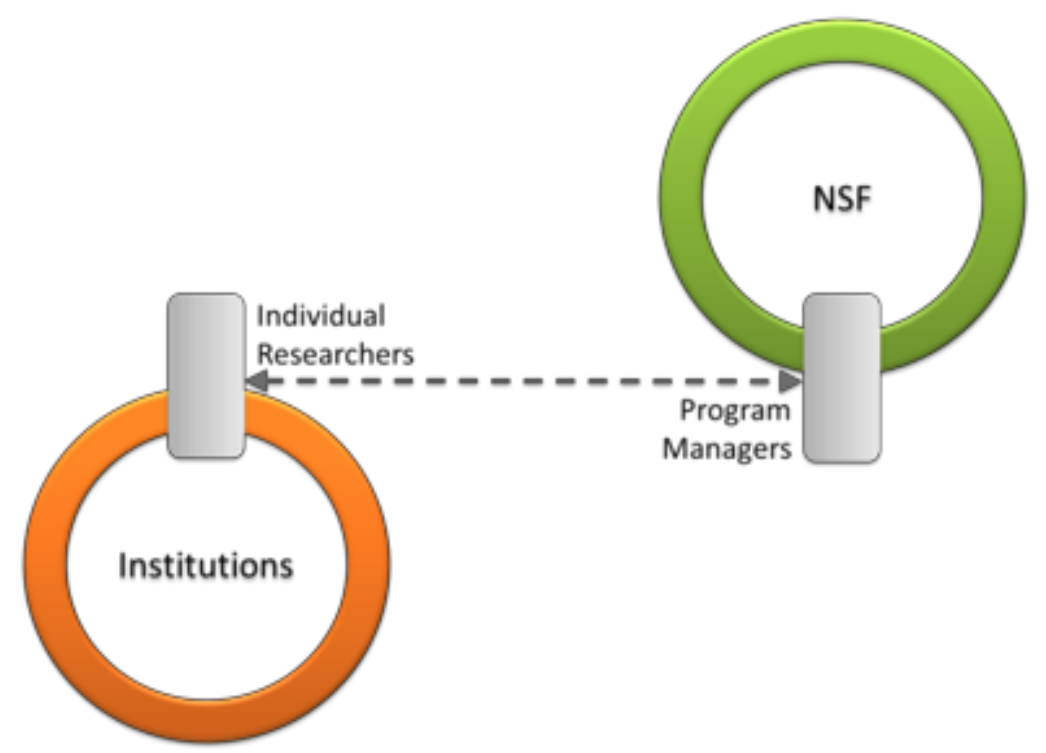

Figure 1. Flow of BI information between NSF and Institutions. 


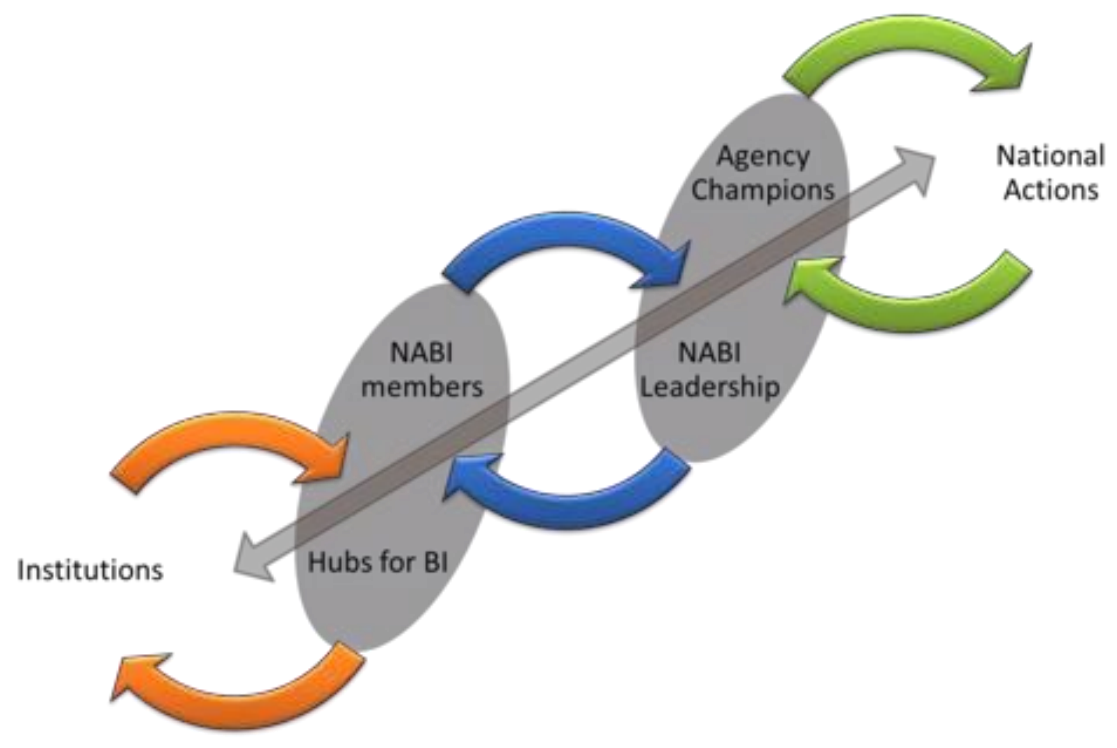

Figure 2. Dynamic flow of information and action facilitated by the network.

Figure 2 illustrates the mediating role implemented by NABI; between institutions on the lower left and the agencies (primarily NSF) on the upper right. NABI is designed to facilitate a dynamic flow of information, innovations and adaptations. Institutional types vary as does the nature of each "Hub for BI" or BI office. These BI hubs are boundary organizations within universities often serving in capacities akin to brokerage roles (Bouwma-Gearhart, Perry, \& Presley, 2012) mediating and translating information among researchers, BI programs, and funding agencies ${ }^{5}$. They may be a single independent BI office or unit housed under a provost, chancellor, or research office, a coordinated group of representatives across a campus, an outreach office that sits in one college serving specific disciplines, a K-12 or STEM program office or in some cases a self-appointed individual.

The coordinating individuals in these hubs, BI professionals, are the target membership the network seeks to support by building a community of practice. These NABI members tend to have created their own positions within a university or are hired to fulfill a hub role established by university leadership. In both instances they are generally charged with maintaining connection with both researchers and administrators as they support BI aspects of proposal development and, in some cases, delivery of BI programs. In addition to

${ }^{5}$ Some "BI hubs" are also STEM education centers. Bouwma-Gearhart, Perry, and Presley (2012) characterize STEM Centers and their literacy brokerage roles. 
connecting members to each other, NABI serves to connect the community of members, through its leadership, to NSF to create learning opportunities about national policy and practice. The NABI leadership also leverages the knowledge and experience of the community in attempts to assist the agency to innovate new approaches to implementing and evaluating the BI criterion ${ }^{6}$.

BI professionals drive the flow of information about BI at their institutions. Since many BI professionals do not have direct communication with agency staff they expand their landscapes of practice and field of knowledgeability ${ }^{7}$ by identifying as members of NABI. The network provides direct access to agency staff through NABI events, but also access to the flow of information filtered and synthesized within the network structure. Information is a key resource of the network and is expected to support members as they work to transform practices at their respective institutions. The NABI Principal Investigator, in coordination with a steering committee and advisory board, drives the flow of information in the network and leverages communications with BI champions within NSF. Although it is not clear at this early stage of study, it is possible that champions within NSF may be reciprocally assisted in their own professional practice by the presence of NABI and, as a result, may be more successful in attempts to make strides with regard to practices and policies of the agency in support of BI.

Because NABI exists in space with multiple boundaries where there was previously a void and little synthetic processing of information and connection among practitioners, the network is positioned to facilitate coherent understandings of both the current NSF practices for institutions and broadbased understanding of institutional realities and barriers to achieving the BI criterion for NSF and other federal agencies (represented by the diagonal bidirectional arrow connecting the three entities in Figure 2.). NABI is also poised to innovate at multiple scales by supporting individual members in their innovations, fostering co-construction of new approaches at the network scale, and creating new resources that can be taken up at the national scale. The communication paths described in Figure 1 are still prominent and network members reports that messages through this well-used mechanism remain

\footnotetext{
${ }^{6}$ NABI recently released Broader Impacts Guiding Principles and Questions for National Science Foundation Proposals http://broaderimpacts.net/wp-content/uploads/2015/12/nabi_guiding_principles-1.pdf.

7 Wenger-Trayner, E. and Wenger-Trayner, B. (2015) discuss knowledgeability - distinct from knowledge or competence which is socially or politically constructed and maintained in a single community of practice - as the embodied state of a living person gained by the way they traverse their landscape of practice, the communities within and boundaries between.
} 
highly variable at times lacking consistency with information mediated through NABI ${ }^{8}$.

Three activities dominate network engagement. The most prominent is the annual BI Summit that has steadily grown from a 2013 pre-network gathering of 80 community members to a Summit with about 115 participants in 2014, and most recently, to the third annual Summit in 2015 with 118 community members. The NABI listserv ( 450 members as of April 2015) is well-used and network leadership has been satisfied with the amount and usefulness of listserv participation. Members use the listserv to pose questions or ask for model tools and advice with spurts of conversations and sharing occurring approximately monthly and announcements occurring every few days. At times, listserv communication reveals the variable and fragmented nature of the NSF as members compare information they have received from different entities within the agency. The third form of engagement occurs through action-focused working groups and is a path with high potential for collective action as recently demonstrated by the release of the Broader Impacts Guiding Principles and Questions for National Science Foundation Proposals 9.

The NABI network communication plan was initiated with the email listserv and a quarterly newsletter, but long term plans are to use a new online platform being developed by the American Association for the Advancement of Science (AAAS) - as the major source of social connection, communication, collaboration and archiving network activity and innovations ${ }^{10}$.

\section{NETWORK HISTORY}

The brief history herein touches on critical points and activities including initial conception, procurement of funding, building the steering committee leadership, establishment of an external advisory board, hosting annual summits and recent change oriented actions of the network.

8 NSF Assistant Director for the Directorate of Engineering gave a keynote at the April 2015 BI Summit during which he impressed upon the NABI community that NSF is a large organization with over 2000 employees and the agency is discontinuous with regard to BI. He emphasized that the agency is still working to understand how to integrate relatively new BI policy into practice and called on NABI to be patient and help by generating solutions.

9 This document can be downloaded from the NABI website http://broaderimpacts.net/wpcontent/uploads/2016/05/nabi_guiding_principles.pdf.

10 The AAAS platform https://www.trelliscience.com seeks to enhance communication and collaboration in the scientific community. NABI is an early adopter of the platform. AAAS employees are active in NABI and one representative serves on the NABI advisory board. 


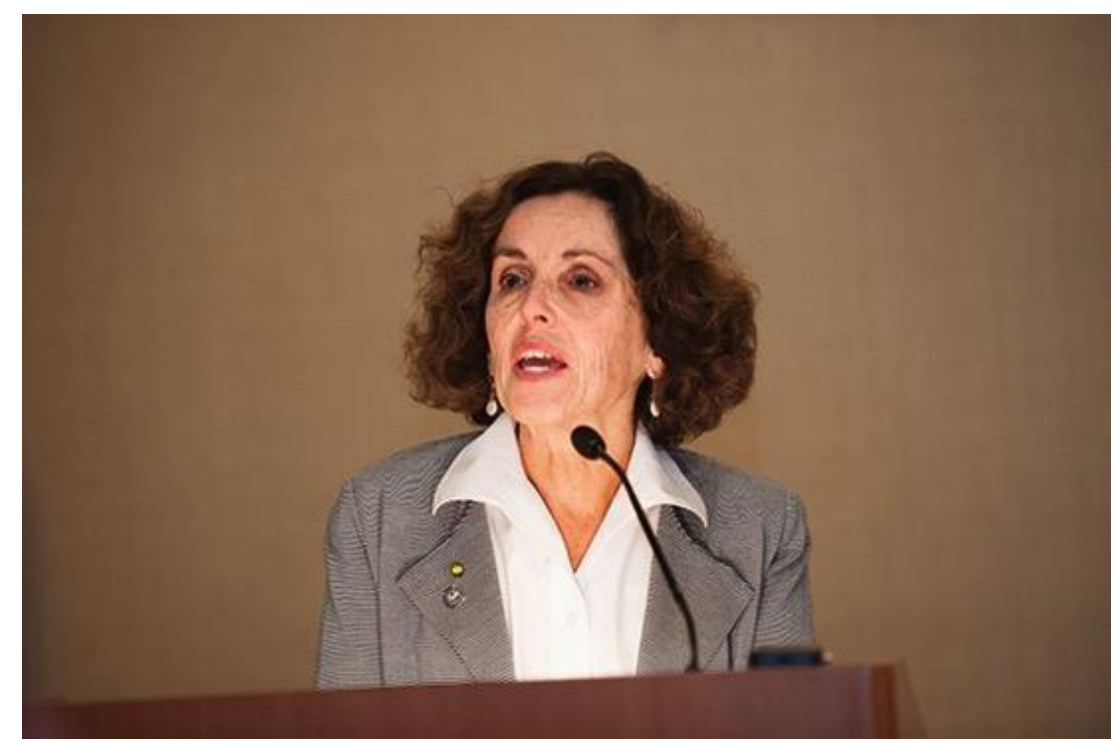

Figure 3. Dr. France Cordova in her first public appearance as the Director of NSF during the 2014 NABI Summit. Image courtesy of www.InPhotograph.com.

NABI was conceived during a conference style summit in 2013 when approximately 80 university based professionals and academics came together in anticipation of the need to develop enhanced capacities and coordinate BI activities at the campus scale in light of the soon to be updated NSF Grant Proposal Guidelines. A team emerged and submitted a proposal to NSF to begin the network as a Research Coordination Network (RCN). News that the five-year $\mathrm{RCN}$ would be funded arrived just in time to be announced at the second annual Summit in Arlington, VA in 2014. The event was a critical launch for NABI which - due to the strategic co-location with NSF offices - included seven high ranking NSF officials as speakers and was host to newly minted NSF Director Dr. France Cordova's first public appearance in the role during which she made this statement.

As a federal agency, we need to stay relevant with those who entrust us with taxpayer funds. We need to reach out to Congress and other stakeholders and be proactive in explaining what NSF is about and why we are vital to the nation's future... Not enough of our fellow citizens understand how relevant the research... is to their daily lives... In both formal and informal venues, we need to engage the public in order to help improve understanding of the value of basic research and why our projects are worthy of investment. 
The event included substantial involvement of AAAS including a keynote by the outgoing Director, Dr. Alan Leshner. Leshner also served as co-chair of the National Science Board Task Force on Merit Review (National Science Board, 2011) that played a critical role in enhancing the agency's commitment to BI.

The funded RCN that now financially supports NABI is summarized below in this excerpt from the submitted RCN proposal.

The goal of the Broader Impacts and Outreach Network for Institutional Collaboration (BIONIC) [now NABI] is to create a community of practice that fosters the development of sustainable and scalable institutional capacity and engagement in broader impacts (BI) activity. This goal will be accomplished through the achievement of the following four objectives:

1) Identify and curate promising models, practices and evaluation methods for the BI community;

2) Expand engagement in and support the development of high-quality BI activities by educating current and future faculty and researchers on effective BI practices;

3) Develop the human resources necessary for sustained growth and increased diversity of the BI community; and

4) Promote cross-institutional collaboration on and dissemination of $\mathrm{BI}$ programs, practices, models, materials and resources.

The name change from BIONIC to NABI itself - which occurred prior to receipt of the RCN grant - was a significant process indicative of the search for an enduring network identity. The initial focus on outreach explicit in the BIONIC name excluded notions of BI as more than outreach and educational programs, but as encompassing tech transfer, public safety and health, mentoring the next generation of scientists and engineers, equity in education and many other approaches including those yet to be innovated. This drove conversation about the future of the network as a source of innovation and channeled energy into sustainability planning from the start. The expansive nature of BI continues to be an active theme of discussion in the network as they strive to create collective identity and to understand how to best serve the membership and the overall goals of improving BI. 


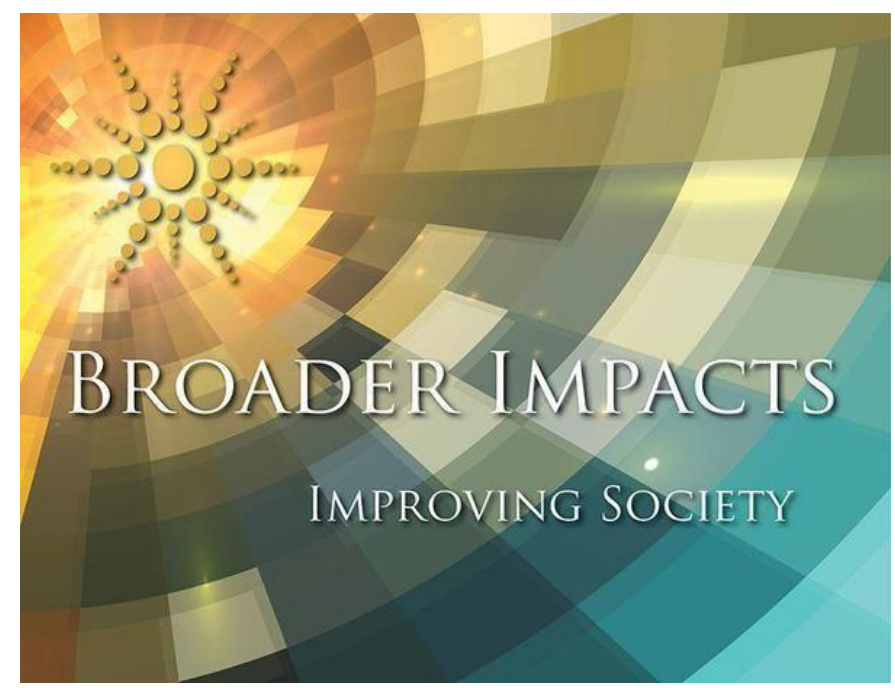

Figure 4. Imagery used by NSF Office of Integrated Affairs in Perspectives on Broader Impacts Report published just after award of the RCN to NABI and the 2014 Summit. Image courtesy of the NSF.

Participation increased to 118 registered participants for the 2015 Summit in Madison, WI, which saw continued commitment by NSF BI champions, professional organizations (AAAS, AAU, American Society for Biochemistry and Molecular Biology (ASBMB), and others). The event also signaled the beginning of international alliances between NABI and the European BI community.

Shortly after the Madison Summit, two NABI leaders and a NABI advisory board member from the AAU spoke on American approaches to BI at the international "Science Works: Impacts of Science" conference. The Madison Summit was critical in building community among active BI professional members - quite different from the Arlington event that launched the network with strong shows of support from leadership at NSF and the Washington, D.C., research community. In Madison, the Summit kicked off with a six-person panel from the University of Alaska, Fairbanks, focused on their experiences working to support $\mathrm{BI}$ at their institution and beginning to find ways to coordinate and collaborate. Activity throughout the Summit concentrated on sharing member experiences at their home campuses and development of a collective identity. During the Summit, a working group was initiated in direct response to a speech given by the Director of NSF International and Integrative Activities office to establish a guidance document to evaluate BI aspects of proposals. It was during the Madison Summit that NABI was observed to hit its stride in terms of serving the members and honoring the value of the collective practical experience in influencing movement and solutions at NSF. 
Since the Madison Summit, the network steering committee has voiced focus on three things:

1) continuing to serve the needs of the members through direct capacity and community building, communication, supporting the action of working groups and hosting Summits,

2) raising the profile of the network and the sophistication of the discussion around BI on the national and international scale through speaking engagements, response to agency requests for information, production and distribution of compelling BI stories and proliferation of innovations to support BI, and,

3) creating a long-term sustainable business model for the network.

\section{Leadership and Management}

The network is primarily managed by the Principal Investigator in close connection with the steering committee and a part-time Assistant Director who works directly with the Principal Investigator and functionally serves as a nonvoting member of the steering committee. While the network was conceived and designed to serve BI professionals, it includes members from several professional societies such as AAAS and ASBMB, and seeks alignment between these communities and the NABI community (Figure 5).

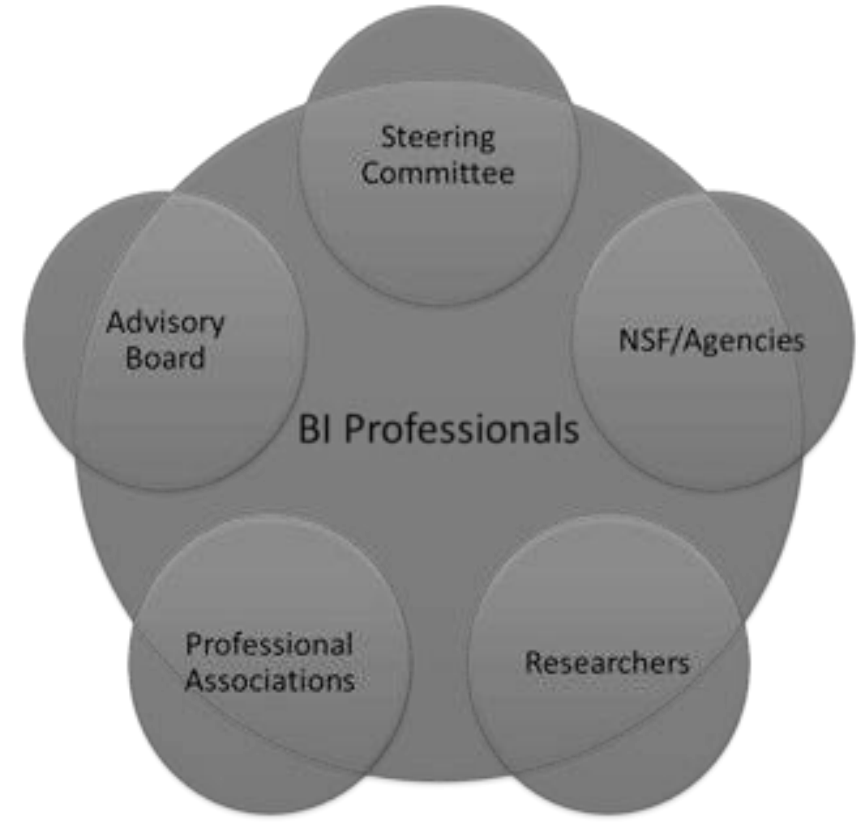

Figure 5. The sub-communities of the NABI community of practice.

The Principal Investigator, the primary netweaver in NABI, described the rationale for selecting the steering committee members and how they are 
envisioned as representative of, and embedded in, the community demonstrating the value placed on transparency and serving the needs of the community.

I tried to include people from across the country from different types of institutions and people who worked well together and worked for the greater good. We wanted people who were about transparency and asking [hard] questions... we try to be transparent in decision making, to think about all the different parts of the community that need things from NABI and try to meet those need as best we can.

The steering committee is an egalitarian and voting group of nine people who drive the strategic direction of the network, but also shepherds ideas of the membership by engaging members in communication and action through the Summits, the listserv, and working groups.

My hope is that when the grant is over someone else will become the [leader] of NABI, and I will be a voting member [of the steering committee]. My vision for the group is that it morphs into a selfsustaining entity that is self-governed and has different ideas through it, because I don't have all the ideas.

With an intentional eye on both succession and better representation of the variety of institution types, additional "at large" applications were accepted through an open process during September 2014 from which two new members were selected based on the same criteria in the quote above ${ }^{11}$. Demonstrating the embeddedness and representativeness of the leadership the network lead states, "We [the steering committee] are NABI and NABI is us, because we are just as affected and served by what NABI does as everyone else" (Interview, October 2015). The steering committee meets twice a year in person and maintains a monthly conference call for sustained engagement in management decisions and planning. The group has built strong social and professional collaborative connections and communicates consistently over email.

11 Julie Risien, author of this case chapter, sits on the steering committee as an at large member and conducts participant observations and action research in partnership with the NABI Principal and steering committee. 
The advisory board is comprised of national leaders in BI related fields and was established to "provide counsel to the principal investigator and grant team about the needs of various constituencies in the BI community" they are also called upon to facilitate broad awareness and dissemination of resources through their own networks and organizations. Their role is not to govern directly but to bring "diverse perspectives and strategic thinking into the governance" of $\mathrm{NABI}^{12}$. Board members meet in-person annually co-located with the Summit.

\section{Network Learning and Capacity Building}

The annual NABI Summit, serving as the central asset of the network, along with communication on the listserv makes up the bulk of interaction within NABI. The Summit is intentionally designed with an emphasis on open sharing, community building, learning and stimulating collective action with substantial unstructured social time. The culture of sharing is modeled by the steering committee and especially the network lead. Summit and listserv content is centered around three broad categories:

1) information sharing and showcasing the variety of approaches, successes and challenges at member institutions,

2) enhancing relevance and credibility by connecting the community to national scale developments in BI and building the potential for collective action, and

3) community building and formation of collective identity.

Information sharing, knowledge building and social learning in the community of practice focuses on models for institutional BI hubs and professional practices, tools for supporting proposal development, methods for providing training and professional development to the research community, advances in evaluation and opportunities for partnerships. These are pragmatic aspects of practice related to transformation based on the supposition that success in BI practice can begin to stimulate changes necessary for universities to meet contemporary challenges. For example, an early career researcher who engages with a NABI member to successfully propose and deliver a recognized broader impact may be primed to shift their thinking about the role of $\mathrm{BI}$ in her institution's promotion and tenure process.

12 This language quoted from a draft invitation to advisory board members to serve (February 2015) provided byNABI. 


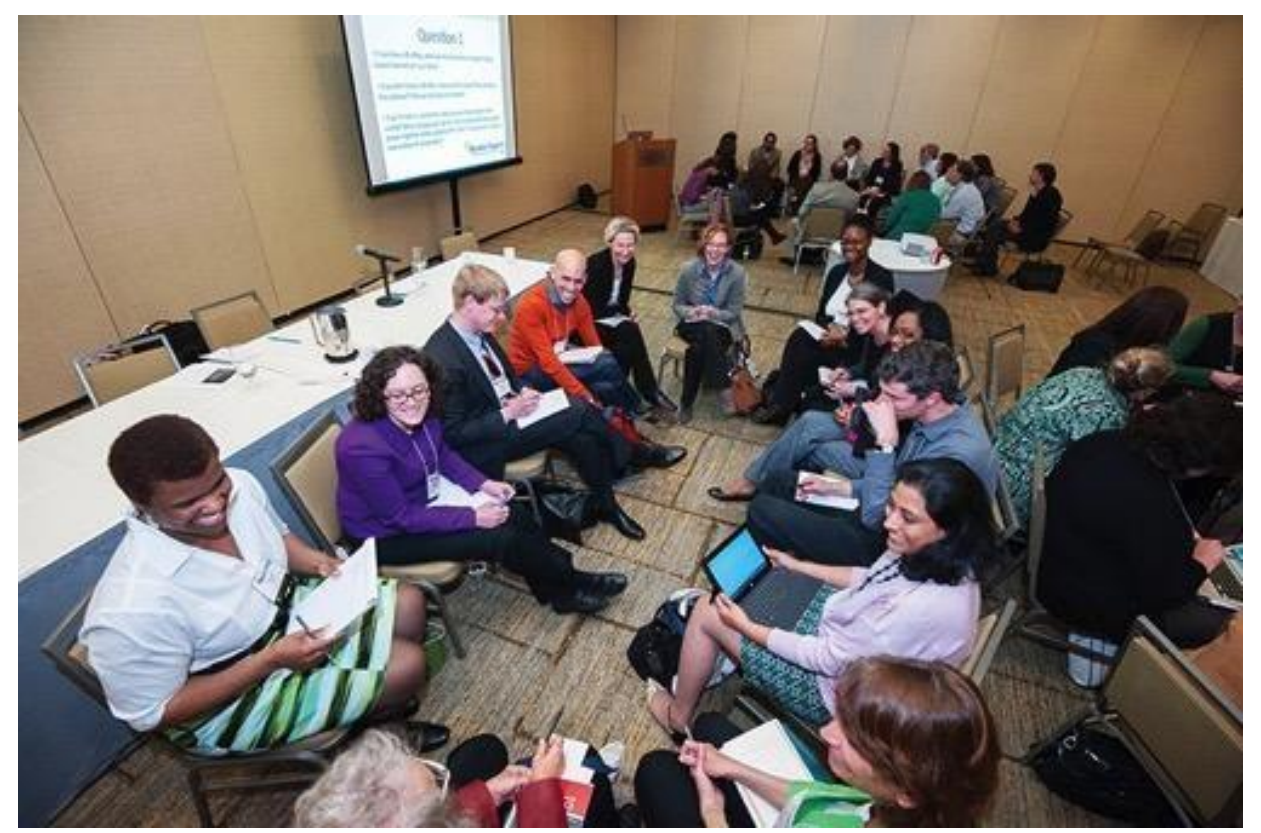

Figure 6. The 2014 Broader Impacts Summit Included Participants From Universities, Federal Agencies, Local Organizations And Professional Societies. Image courtesy of www.InPhotograph.com.

Enhanced relevance of network activity is sometimes stimulated by speeches delivered by high- ranking officials who work for or are strongly connected to NSF. The value of national scale Summit sessions are expanded by network leadership and advisory board synthesis and translation of session content into direct actions that the network could take to collectively respond to national needs. Finally, effort towards building community and collective identity is expressed through intentional support of emerging identity transcending a more incidental or accidental identity development commonly observed in interorganizational networks (Keast \& Mandell, 2013). This is demonstrated by open discussion on the use of language and its connection to network identity, which occurred, and was cultivated by network leadership, during the 2015 Summit. When time ran out to continue the conversation, the Principal Investigator wrapped up the session by clearly stating that this would be an ongoing discussion indicating space within network activities for future efforts to evolve identity and language within the network. The attention to language and identity show NABI as an emerging complex network that works to build community and create identity for members who occupy a professional boundary space and shepherd actors across boundaries in the intricate university landscape towards transformation (Keast \& Mandell, 2013; Raab \& Kenis, 2009; Wenger-Trayner, E. \& Wenger-Trayner, B., 2015). Boundaries will be discussed in more detail in Part 2. 
Capacity building in the community space may be scaffolded by NABIs intentional support of connections between members who share the experience of crossing the boundaries at their institutions and occupy a new and developing professional boundary space within their institutional setting. Building of community and collective identity within the network comes from two directions. The members appear to crave the experience of being understood by each other and many are observed openly discussing their shared experiences and challenges. In response, the network leadership is intentional about building a profession of BI, filling a void and developing shared language.

Preliminary analysis of interview transcripts and field notes provide insights around information sharing, enhanced relevance and community building. Social learning aspirations and early examples of information sharing were dominant in preliminary interviews. One member addressed network value this way, "Learning about struggles and successes that others have...I think NABI is really helpful in that regard" (Interview, May 2015) identifying learning specifically and NABI as the facilitator of learning interactions. Another informant shared enthusiasm for the network with this statement:

One thing I'm excited about is to have a direct link to continuously learn, to know more about what's going on out there and not get locked in, that this is the only way to do something, with the opportunity to constantly interact with folks you do open yourself up for learning...that's my targeted desire for wanting NABI to continue because I see such value in the learning (Interview, May 2015).

This aspirational statement implicated the simple act of gathering people and providing a "direct link" for interactions as closely tied with learning which the member connects to innovation with her reference to overcoming being "locked in to" one way of doing something. Both members put the network in the facilitative role and implicitly suggest such interactions support learning because of NABI. In addition to the Summit and listserv, learning is happening one on one; network members connect at the conference or over the listserv and report consulting with each other out of the conference setting. The network leader also conducts a lot of consultation which she describes here, "There are a lot of people who want advice on starting a BI office and I do that ... that oneon-one time is not just with me; there are other people who meet at the Summit and talk [later]" (Interview, October 2015). 
Informants also addressed NABI's role in enhancing the relevance of the work of $\mathrm{BI}$ professionals to national developments and the credibility associated with a national network supported by the NSF. One informant said, "I think it's great that you guys [NABI] have connections with NSF" (Interview, May 2015), pointing out that the network has a voice with NSF, but at the same time distinguishing this member as separate from the network or at least the aspects of the network with the power of a voice with the federal agencies. Another interviewee discussed leveraging the network to support work on the members' home campuses by saying, "I will point to this national network and say, you know there is this national network that supports this... and I think that will be helpful" (Interview, May 2015). The same member provided two other statements highlighting the potential for collective voice that could lead to collective action in defense of research spending with this assertion:

... quite candidly when science funding is being challenged, by having all of us focused on broader impacts [we can make] a solid argument about why we are [researching]... I can see NABI eventually growing into a role...to take people to the capital and bring key people in about to talk about how we [the research community] are really making a difference (Interview, May 2015).

The later comment followed some examples of how the member has participated in another community with such political actions and with this comment you can see the member's expectations that NABI can accomplish that at the national level.

Community building also emerged from preliminary data as a strong theme of importance to members of NABI. Shortly after the 2015 Summit in Madison one interviewee proclaimed, "I've been here [\# of] years now trying to find my affinity group and I've finally found it...these are my people!" (Interview, May 2015). The interviewee's statement is similar to several others expressed during both the 2014 and 2015 Summits. These overt expressions demonstrate a sense of shared practice indicative of communities of practice and a camaraderie that may link to personal motivations to participate. It is also apparent that NABI is filling a niche by building community neither network members nor steering committee members had experienced previously in this boundary space. Another member described NABI as "a place where you can find other people doing the same kind of [unusual] work" (Interview, May 2015) further supporting that the network is filling a void. 
The second part of this case study presents intertwined ideas that together help in examining the differences between a functional collaborative network and a prospectively transformative network, the latter with the potential to transform members in terms of practice in the BI domain, values and practices of the researchers they support, and systems that govern those practices. Below, a transformative lens is used to consider network characteristics and practices. In doing so it becomes clear that characteristics are more fluid and interwoven than can be adequately illustrated within the confines of a written case study. Part 2 attempts to tease out and differentiate between concepts of cross-scalar integration, transformative capacity, organizational learning and netweaving. In reality, these concepts are intricately tied together. For example, early analysis of participant observation and interview data from the NABI network shows member ideas related to cross-scalar integration are tightly coupled with concepts of transformative capacity. One can also observe that the practices associated with organizational learning (learning as a whole network) are prominently supported by the practice of netweaving.

\section{Cross-Scalar Integration}

Cross-scalar integration can be observed in NABI in terms of 1) building connections across boundaries (horizontally, vertically and diagonally - see Figure 2) and 2) working across different models of institutional BI support and infrastructure. It is helpful to continually remember the complexity of organizations such as Universities and the professionals who navigate them in sometimes undefined roles and positions. Further complexity is introduced in the building a national network of BI professionals that must simultaneously serve as a collective to build a profession where one did not necessarily exist and, at the same time, work across institutional differences. Wenger-Trayner, E. and Wenger-Trayner, B.(2015) describe a landscape of practice framework that provides an excellent metaphor for the complex set of practices and boundaries that organizations and people in the BI domain must navigate. In the case of NABI, integration across these dimensions can be characterized - although it is an oversimplification to do so - as primarily and intentionally horizontal as they build a community of practice in a professional boundary space. The boundary space - where this new domain of BI professionals is emerging - lies between science and society, and institutions of higher education and federal agencies. There are also boundaries between the practices and cultures of tenure-tracked research faculty and university professional faculty and staff along with the many other boundaries discussed in Part I. NABI works to build competence for 
this relatively new domain in a previously unoccupied space of the research landscape of practice.

As the network facilitates connections horizontally between peers working to build BI support and infrastructure at universities, those members also connect diagonally to the NABI sub-communities (see Figure 5). "Not all of us have a direct line to NSF, some people do, so there's opportunity to... share that information" (Interview, October 2015) was the way the network leader eluded to the diagonal integration of the network. Members also report positive effects of leveraging NABI and the connections they have created with the subcommunities to make progress on vertical integration efforts on their own campuses, "I was able to say [to leadership], 'NSF supports NABI so BI is important!"'. Another member, referring to efforts on to coordinate BI activities on campus said it this way, "I think it brings legitimacy, to know that we are part of a national network of institutions doing similar things, that this is a real thing (Interviews, May 2015)," allowing this member to legitimize BI to university leadership.

Leadership reported having the expectation, when NABI emerged, that the network could simply propagate a particular successful and novel model for creating an institutional BI office. However, the steering committee realized early on that the network would be working across difference in terms of university structure and culture and in terms of the skills, personalities and degree of autonomy individual members had at each institution. Two primary categories of members have emerged since NABIs conception: 1) BI professionals working on emergent structures and systems to build BI infrastructure and support on across campuses or within a large unit such as a college of science, and 2) centralized BI professionals hired by the institution in administration leadership efforts to build BI infrastructure. These two groups whether top-down or bottomup ultimately share the time consuming work of using capacity building and brokerage methods to catalyze change in BI practice and each category includes within it a variety of institutional situations. A member of the steering committee said about the two types of BI professionals in the network:

"This centralized versus decentralized thing isn't really the issue, the issue is the fact that each institution is unique and special, BI has a set of functions and where it sits in a [the particular] university is important" (Participant Observation, April 2015).

Network leadership has embraced the complex set of tasks supporting professional and community development horizontally across different models 
of building BI institutional support and systems. The leadership values the creativity necessary to build functional BI support for each context and avoid prescriptive models for success or assumptions about individual institutions. One informant speaks to NABI's role connecting members from the same institutions with each other:

I didn't realize how many groups on our own campus are pursing this from different angles. Just to see all the people from [my institution at the NABI Summit] there with their own ideas on what an office like this should look like..." (Interview, May 2015).

While members may identify with NABI as a community that supports and helps to build the competence in the BI domain, members must continually modulate their identification with other competing or complementing communities of practice with which they engage - communities such as their academic discipline or that of their parent unit on campus - further complicating the landscape and enhancing the diversity of the group ${ }^{13}$. It is this diversity of experience in practice that may yield high potential for NABI to provide value to NSF and other agencies as the NABI membership possesses the best collective understanding of the myriad issues around BI practice and policy. One steering committee member pointed to the network's asset of collective experience at the closing session of the April 2015 Summit by reminding members that the researchers whom network members support may work on one grant proposal or less each year, yet NABI members may work on 15 or more proposals a year. This affirmation was well received and was an important acknowledgement of the members' individual and collective experience and value.

\section{Transformative Capacity}

Transformative capacity is a growing idea in the study of transformational learning networks. Examination of networks with the transformational lens seeks change beyond simply learning new skills and creating new ties; it requires a deeper look to uncover network characteristics that contribute capacity for long-term change in perceptions, practices, systems and society. A system with transformative capacity can adapt structurally, socially, and culturally to changing conditions. Early analysis of the NABI network points to evidence that network structure and practices are supporting change and transformative potential at three scales: 1) the individual members, 2) institution, and 3) influence on national scale policy and practice through

\footnotetext{
${ }^{13}$ For deeper discussion on modulating identification between communities of practice see Wenger-Trayner, E. and Wenger-Trayner, B.., 2015.
} 
collective actions. A fourth path to supporting change is that of the whole network and domain of $\mathrm{BI}$, discussed in the section below on organizational learning. In NABI transformative capacity appears to be tightly tied to crossscalar integration; that is to say that the network function of moving information and building connection across several types of boundaries is an important part of transformative capacity.

\section{Individual and Institutional Change}

In terms of individual BI professionals, transformative capacity characteristics center on forming bonds with peers in the new and still forming domain of BI. Related agentic capacity, an individual's capacity to take action, appears subtly with comments that may seem simply like sharing information, but actually demonstrate forethought and intention (Bandura, 2006; 2012), "One of my [NABI] colleagues... uses some information as part of her orientations and I am going to incorporate that into mine", and another anticipates action, "I really liked the pointers and talking points one of my colleagues presented [at the Summit] and I am going to use that". Both informants indicated learning something new, but also an assessment of their own intention to apply it. Other times the connections are less operational and more indicative of shared experience, "We were all just talking about... how to be good advocates for our positions and our services, and the value of research (Interviews, May 2015)".

Another goal of the network is to build agency of BI professionals to affect change at their institutions by leveraging the existence of the network its connection with NSF and sub- communities (Figure 2) and innovations that emerge from peer interactions. Working with university administrators requires netweaving and brokerage skills (Whitchurch, 2008; 2009), but is also supported through what Bandura $(2006$; 2012) calls proxy agency, or the ability and will - when one lacks positional authority or resources - to influence those with the authority to act, essentially on a member's behalf, with intention toward improved BI throughout the institution. One member explains after many attempts to affect change, "We presented [our BI ideas for the institution] to our administration...it seems they are pretty excited about it and are starting to buy in" (Interview, May 2015).

Another interviewee provided an unsolicited example of action she has taken as a result of interactions at the 2015 Summit in this comment, "Since my return [from the Summit] I talked to my research office of sponsored programs and they have created a whole new page on their website about broader impacts" (Interview, May 2015). These statements are beyond preliminary indicators of 
agentic capacity; they explicitly discuss tangible outcomes of agency and proxy agency affecting perceptions and practice at institutions.

Over the long-term one could assess how structure, practices, learning and identity of the network may enhance agency and proxy agency and how these behaviors are triggered and sustained by members. Another interesting phenomenon to consider in future research is if agentic capacities built (in part) within the NABI context are employed to help to affect change in other domains. In other words, does the transformative capacity built through one network extend to other domains in an actor's life or institutional practice?

\section{National Change Through Collective Action}

Network members seem to generally have integrated into their professional practice a role of advocating for society within the research community. During the 2015 Summit discussions demonstrate that the reverse may also be true, that the network is taking on the role of advocating for science within society. A steering committee member used this statement to call NABI members to action, "It's clear that we cannot take the money we [universities] get [for research] for granted, broadly speaking we need to advocate with the mission of creating a society that values science" (Participant Observation April 2015). A few days later during the 2015 Summit two comments echoed the sentiment, "We need to be paying attention to politics," and with regard to the impact of capitol hill on research funding, "I'm not saying we need to all become lobbyist, but...that's the power of us all in one network, we are distributed all over the place... we need to engage our politicians...show them the good things that are happening in their districts" (Participant Observation). In a later interview, a member describes how she makes her BI information available for use by her institution in garnering political support, "Whenever our president is meeting with state leaders or senators...he always looks across campus and wants to know what we [my BI program] do in that district” (Interview, May 2015).

Ideas about collective action in the network exist beyond political action or the tangible outcomes associated with BI activities. There is also attention to a moral obligation to produce less tangible value oriented outcomes. The network leader reveals how she feels the network supports these aspirations.

When we get away from serving us [network members] to BI serving our community and us, then big things change... all of the sudden it's not just for a research grant... a means to an end... but 
also for changing my community and making things better for my kids and impacting my institution, all of the sudden my institution is known for being part of the community and giving back...that's where we go from here (Interview, October 2015).

The personal sense of value centered on science serving society seems to be a motivating factor for the steering committee. Their work, at the core of the network, is only indirectly linked to specific BI outcomes. In other words, the steering committee manages the network which helps variety of BI professionals do a better job providing support for researchers, who may develop more competitive proposals and therefore have an increased potential to serve society. The steering committee members, despite being arms-length from direct impacts in their network leadership roles, stay focused on the big picture and value their broader role in bridging science and society.

\section{Organizational Learning}

The recent interorganizational network literature emphasizes the need to study whole networks and terms of learning (Provan et al., 2007, Kenis \& Provan, 2008; Raab \& Kenis, 2009; Knight, 2002; Knight \& Pye, 2005). In a model of network learning, Knight (2002) defines whole network learning as "learning by groups of organizations as a group" where the interorganizational network itself learns (Knight \& Pye, 2005). There is little research to understand how whole networks learn (Provan et al., 2007). Instead, much of the research focuses on how an individual learns as a result of their interactions with and participation in a network (Knight, 2002). Using the idea of conceptual learning episodes (Knight \& Pye, 2005) ${ }^{14}$ preliminary examination of NABI data exposes two broad conceptual 'episodes' of the whole network learning: developmental adaptation and collective identity.

\section{Developmental Adaptation}

Borrowing from the practice and study of developmental evaluation (Patton, 2011), developmental adaptation refers to a set of intentional practices in the development of a complex system that allow it to adapt to emergent and dynamic realities. This is a timely and iterative reflexive process is centered on learning and appropriately and quickly adapting to complex conditions with a keen eye

\footnotetext{
${ }^{14}$ Learning episodes are conceptually distinct from temporally bounded learning events which occur at a specific time such as a workshop. An episode can be unplanned and emergent occurring around one concept over time.
} 
of desired large scale, often social, outcomes. In the case of interorganizational networks one can understand developmental adaptation in terms of both intention and capability to adapt practice, systems and human dynamics ${ }^{15}$ in response to direct or indirect feedback. Developmental adaptation can be used as an organizing principle to understand - in terms of whole network learning how the network leadership works to keep the network systems functioning, the content relevant and human dynamics enriching in order to sustain and grow the network to best meet the needs of a diverse membership towards the outcome of improved BI. In other words, how does the leadership recognize, reflect on and adapt practice in a timely manner as a result of their successes and shortcomings? Such adaptation may be indicated by a change to the scope, structure, personal engagement practices or even the mission or definition of success of the network. It's worth noting also that self-imposed exposure to vulnerability may be a precondition of adaptability.

There are several examples of emphasis by the NABI steering committee to learn from the membership and adjust quickly, for example within the course of a Summit, based on feedback. There is a sense the network will shift to a sustainable, yet to be determined, membership model by 2018 when the NSF RCN funding begins to sunset. The anticipated shift seems to add momentum to leadership's drive to provide targeted and maximum value to members and continually adapt to their needs. In late 2014, NABI deployed a comprehensive survey of BI offices. The survey was intended to gather information about the landscape of BI work at the various institutions and expose shared challenges and needs of the membership. Another purpose of the survey was to intentionally model collecting the type of information the steering committee believed that network members should be considering collecting on their own campuses. The steering committee also received directed feedback about the NABI events through a formal evaluation process. Even with these formal feedback structures in place, it appears that the open discussions by the steering committee with each other and informal interaction with members which often include directly asking how can NABI better serve - are equally if not more influential in decision making. When asked to summarize typical oneto-one conversations with members the network leader shared her habit of asking, "Are you being helped, is NABI giving you what you need...if not, then what do you need...if you're good then how do you want to get involved to make this even better?" (Interview, October 2015), demonstrating desire to adapt in a

\footnotetext{
15 Keast and Mandell (2013) discuss the human dynamic (sense of agency and identity) of whole networks as the source of complexity in complex networks and reject that structural complexity accounts for challenges in interorganizational networks.
} 
timely way making members' needs a priority and attempts to integrate members more deeply into the network by making a contribution. The results of such conversations make their way into steering committee meetings and spur discussions on exactly what actions should be taken to be sure specific needs are met.

During an October 2015 meeting, the steering committee also spent significant time revisiting their mission and vision. They straightforwardly confronted the fact that the vision and mission in the RCN proposal was no longer adequate acknowledging, "it's time to think outside the grant and develop a fresh mission" given what the steering committee now knows about the membership and their potential role in policy and practice. The effort to reflect and revise the vision and mission as the network develops shows a strong commitment to adaptive practice and a willingness to take risks in terms of working beyond fulfillment of the promises in the RCN proposal to best serve the grander public good mission of $\mathrm{BI}$ and the members who are seen as key facilitators in connecting science to society.

\section{Collective Identity}

Collective identity ${ }^{16}$ is closely tied with, and possibly a precursor to collective action. The concept has to do with both self-identification with a group and the external objective identification of a collective. In other words, collective identity enables individuals to differentiate themselves by identifying with criteria established within a community and a shared sense of belonging with a group. To fully emerge as collective identity such internal group identification must be known by non-members (Lamont \& Molar, 2002). In terms of whole network learning we can examine collective identity in two ways. First, as an intentional internal process to create a shared identity and language that serves the human dynamic within the network by providing opportunities for learning and to build member agency. Second, as consistency builds around identity established within the network, collective identity provides a coherent sense of the network's role and capabilities to outsiders. This second aspect of building collective identity may pave the way for collective actions. During the early stages of NABI, emphasis is first on the internal processes of identification (e.g., "Who do we

\footnotetext{
${ }^{16}$ Keast and Mandell (2013) discuss the collective identity aspect of network human dynamics in some detail as a property that emerges when individuals begin to identify with the network, sometimes over the organizations which they represent, and so began adjusting actions to support network goals.
} 
think we are?") and energy is just beginning to build with regard to external recognition of a network identity.

A compelling indicator of network learning in NABI is the open acknowledgement that the language members use to discuss BI is inconsistent and the subsequent call to action for the network to intentionally and collaboratively build a language that allows the network to lead BI discourse on their campuses and at a national scale asking, "What is it we are talking about when we talk about BI? Is it outreach, engagement, engaged scholarship?" (Participant Observation, April 2015). These open ended questions spawned thoughtful discussion about the meaning of terms within the network and outside the network, the role of the network defining terms and their meaning in the BI domain and the potential for a shared language to help define the boundaries of the network and its scope.

NABI also works to create a sense of belonging in a community of other BI professionals that helps to build collective identity as the members learn together. One of characteristics of the network leadership style that helps to build that sense of belonging is the leadership's public expressions of their own trials in developing solutions to BI challenges and their open invitation to members to learn together enhancing opportunities for members to connect based on similarities. At the April 2015 Summit, during a brief steering committee check in, some expressed concern that members may have a misperception that those in NABI with established BI offices have secure and fully functioning structures and practices. In quick action, the network leader integrated a discussion into the final reflective session at the Summit to highlight that even, "Those of us with BI offices don't have it all figured out," intentionally exposing vulnerabilities of those in leadership positions again offering opportunity for identification built on similarities. Other aspects of that conversation emphasized that network members are all learning how to do this together, there is no map, it is the network's role to bring a variety of experiences to innovate and create solutions that can be used by the membership to improve BI process on their home campuses. This discourse and many of the key practices described above are part of what distinguish NABI as a learning network as opposed to a training program. Competence in the BI domain is being created and defined and produced by the network as a whole, rather simply provided by network leadership.

\section{Netweaving}

Netweavers, transformational leadership, collaborative capacity builders (Weber $\&$ Khademian, 2008), process catalysts (Mandell \& Keast, 2009) and systems 
conveners (Wenger-Trayner, E. \& Wenger-Trayner, B., 2015) are all labels used to describe leaders who enable systems in support of change from the middle whether or not they possess positional authority - using non-hierarchal means to knit together human dynamics and structural realities of a network. Netweavers aim to enhance communication, facilitate connection and bolster collaboration in support of learning and development of network members and the network as a whole. In NABI, netweaving is orchestrated by the network leader who sees it as her job, "to build a team...to evaluate people and figure out who [are] the best people to build a network [as part of a steering committee],". She works to keep the network egalitarian, "I think that is what makes this network work, what makes it interesting is that everyone is equal." The netweaver is known to make explicit connection and introductions between members and partners with shared interests or complementary capacities and supports and encourages the steering committee and members to do the same. Indeed, such connections were a motivator for the network leader in establishing the network, "it is easier when you can leverage someone else's experience and miss some of the pitfalls" (Interview, October 2015). The netweaver facilitates learning from the experiences of others during the Summits by encouraging members to share their experiences with NSF in terms of interactions with program managers and learning from review panel responses to researchers with whom members work. This weaving practice recognizes the distributed expertise and the status of the network as a learning organization building a collective repository of knowledge for use by the entire network.

Weaving the net that ties together the network has a reciprocal nature in that the leadership structure of the network is referred to in relation to the members as opposed to separate from of driving the direction of the network. "NABI is us and we are NABI (Interview, October 2015). And asking, what can NABI do for you and what can you do for NABI?" (Participant Observation, April 2014) both provide examples of the integrated nature of the leadership. The netweaver also lays the individual threads that create stability in a web. She expressed her Summit goal of being able to, "meet each and every person... because that's where you meet people and really find out what they are doing and what they are struggling with" (Interview, October 2015). Steering committee members frequently report on members' challenges gleaned from one-on-one conversation as another path for the steering committee to stay connected to the member experience and better serve the network.

Within the steering committee the network leader seeks to maintain "the spirit of camaraderie and the 'round table' (Interview, October 2015)" as she actively distributes the role of netweaving among the steering committee asking them to 
"personally invite, welcome and check in with every single individual" (Participant Observation, April 2015) at the Summits to see if NABI is meeting their needs. In a later interview (October 2015), she shared her service-oriented approach to leadership proclaiming, "the minute you get away from what people need, you lose the ability to help."

The network is often referred to by the leader and members as "fluid" which aptly describes several characteristics on which the network leadership places high importance in their practice of netweaving. These include inclusivity and equality, back channel communication, being responsive to feedback, transparency in decision-making, individual communication and attentiveness, and acknowledging and leveraging member expertise by soliciting targeted participation in collective actions. Aligned with those priority characteristics the network leader rejects that competition has or should have a dominant role in the network and describes her view with this assertion:

Theoretically we all go back to our jobs and we are competing against each other because the researchers we help are competing against each other [for research grants], but when you look at NABI there is no competition, people share readily and are willing to help each other out and that's unique, one thing I hope when it transitions, whatever happens, that stays (Interview, October 2015).

The network leader's language signals aspirations to membership, contributes to shaping a shared narrative about NABI and provides a characteristic to be taken up by the network as part of a growing collective identity.

While the primary responsibility of netweaving sits with the network leader, she distributes the task of maintaining positive human dynamics associated with priority network characteristics which seem to be emerging as emblematic of the organization. Netweaving in the NABI context can be conceptualized as permeable concentric circles with the network leader at the hub, the steering committee extending connection to the members and the members extending to the researchers they support. Additional complexity is added by activities to integrate subcommunities (see Figure 5).

The ethic embedded in the network characteristics is described by the network leader in the below telling comment: 
People are doing this [BI work] without being part of our network, at the same time I think those in the network are finding the work rewarding and that it is easier to get their work done; so I think there are various paths to get there, I just prefer the one where we work together (Interview, October 2015).

\section{CONCLUSION}

The study of networks is evolving beyond the engagement models grown from social ecological systems theory and the practical training and systems improvement of interorganizational network theory. Embracing complexity and applying the lens that the human dynamic is a primary source of that complexity supports continued growth in this relatively new area of network study. NABI offers an interesting research opportunity in this emerging direction of network scholarship with the potential to make a contribution to our understanding of the human dynamics of interorganizational networks and how such networks can best serve as mechanisms for transformation.

The NABI approach is focused on supporting BI professionals through facilitating learning and innovation as a path to improved BI practice and outcomes, but also may have the potential to stimulate transformation. The BI professionals are central actors that play brokerage and boundary spanning roles. Researchers in higher education (Bouwma-Gearhart, Perry, \& Presley, 2012; Kezar, 2014; Whitchurch, 2009) are beginning to recognize such roles, that emerge from the middle, as instrumental in transformation and growing in importance relative to top down mechanisms which may be highly dependent on actors' identification with their institution over other domains in their complex landscapes of practice.

It appears that boundaries may be a barrier to transformation and the capacity to navigate across boundaries is tied to individual and group identities and identification. Research is needed to understand the importance of boundary navigation and modulation of identification to understand how increasing capacities in these areas may support transformation and what such improvements in these areas may mean for existing communities of practice and organizational structures. NABI provides a rich case to understand a network's role in transformation with regard to navigating boundaries. The network appears to leverage difference, explicitly meeting the needs of, and holding high regard for a heterogeneous membership in order to make strides in connecting science to society. Research could help in understanding if, and if so how, such 
learning centered and adaptive approaches relate to institutional transformation.

\section{REFERENCES}

Bandura, A. (2012). On the Functional Properties of Perceived Self-Efficacy Revisited. Journal of Management, 38(1), 9-44.

Bandura, A. (2006). Toward a psychology of human agency. Perspectives on Psychological Science. 1(2), 164-180.

Bouwma-Gearhart, J., Perry, K., \& Presley, J. B. (2012). Improving postsecondary STEM education: Strategies for successful collaboration and brokering across disciplinary paradigms. Association of Public and Land-grant Universities (APLU) Science and Math Teacher Imperative Series no. 4 APLU. Washington D.C. Retrieved from:

http:/ / www.aplu.org/document.doc?id=4100.

Clarke, M., Hyde, A., \& Drennan, J. (2013). Professional identity in higher education. In B. Kehm, \& U. Teichler, (Eds.), The Academic Profession in Europe: New Tasks and New Challenges (pp. 7-22). New York, NY: Springer.

Innes, J. E. and Booher, D. E. (2010). Planning with complexity: An introduction to collaborative rationality for public policy. New York, NY: Routledge.

Keast R. and Mandell M.P. (2013). Network performance: a complex interplay of form and action. International Review of Public Administration, 18(2), 2745.

Knight, L. (2002). Network learning: Exploring learning by interorganizational networks. Human Relations. 55(4). 427-454.

Knight, L. and Pye, A. (2005) Network learning: An empirically derived model of learning by groups of organizations. Human Relations, 58(3), 369-392.

Lamont, M. and Molnár, V. (2002). The study of boundaries in the social sciences. Annual Review of Sociology, 167-195.

Mandell MP and Keast R. (2009). A new look at leadership in collaborative networks: Process catalysts. In (eds.) J.A. Raffle, P. Leisink, A.E. Middlebrook (Eds.) Public Sector Leadership: International challenges and perspectives (pp.163-178). North Hampton, MA. Edward Elgar Publishing Inc.

National Science Board. (2011). National Science Foundation's Merit Review Criteria: Review and Revisions. Retrieved from: http://www.nsf.gov/nsb/publications/2011/meritreviewcriteria.pdf 
National Science Foundation. (Nov 2014a). Perspectives on Broader Impacts. Washington, D.C.: NSF. Retrieved from http://www.nsf.gov/od/iia/publications/Broader_Impacts.pdf.

National Science Foundation. (Nov 2014b). Grant Proposal Guide. Retrieved from http://www.nsf.gov/od/iia/publications/Broader_Impacts.pdf.

Olssen, M., and Peters, M. (2005). Neoliberalism, higher education and the knowledge economy: From the free market to knowledge capitalism. Journal of Education Policy, 20(3), 313-345.

Patton, M. Q. (2011) Developmental Evaluation. Applying Complexity Concepts to Enhance Innovation and Use. Guilford Press, New York.

Provan, K. G., Fish, A. and Sydow, J. (2007). Interorganizational Networks at the Network Level: A Review of the Empirical Literature on Whole Networks. Journal of Management, 33(3), 479- 516.Provan, K.G. and Kenis, P. (2008). Modes of network governance: Structure, management, and effectiveness. Journal of Public Administration Research And Theory, 18(2), pp.229-252.

Putnam, R. (2000). Bowling alone: The collapse and revival of American community. New York: Simon \&Schuster.

Raab, J. and Kenis, P. N. (2009). Heading toward a society of networks: Empirical developments and theoretical challenges. Journal of Management Inquiry, 18(3), 198-210

Risien, J. and Falk, J. H. (2013). CAISE convening November 19, 2013 Frontend Report: Understanding STEM Principal Investigators' Approach to Informal Education. Retrieved from: http://informalscience.org/images/research/CAISEBIISEFront

Sirianni, C. (2009). Investing in Democracy: Engaging Citizens in Collaborative Governance. Washington D.C.: Brookings Institution Press.

Skocpol, T. (2004). APSA Presidential Address: Voice and Inequality: The Transformation of American Civic Democracy. Perspectives on Politics, 2(1), 3-20.

Weber, E. P. and Khademian, A. M. (2008), Wicked Problems, Knowledge Challenges, and Collaborative Capacity Builders in Network Settings. Public Administration Review, 68: 334-349.

Wenger, E. (1998). Communities of Practice; Learning, Meaning and Identity. New York: Cambridge University Press.

Wenger-Trayner, E. and Wenger-Trayner, B. (2015). Learning in a landscape of practice: A framework in (eds.)Wenger-Trayner, E.; Fenton-O'Creevy, M.; Kubiak, C., Hutchinson, S., \& Wenger-Trayner, B.. Learning in Landscapes of Practice: Boundaries, identity, and knowledgeability in practice-based learning. Abingdon: Routledge. 
Whitchurch, C. (2008). Shifting identities and blurring boundaries: The emergence of third space professionals in UK higher education. Higher Education Quarterly, 62(4), 377-396.

Whitchurch, C. (2009). The rise of the blended professional in higher education: a comparison between the United Kingdom, Australia and the United States. Higher Education, 58(3), 407-418. 
PIONEERED BY THE ROCKEFELLER FOUNDATION

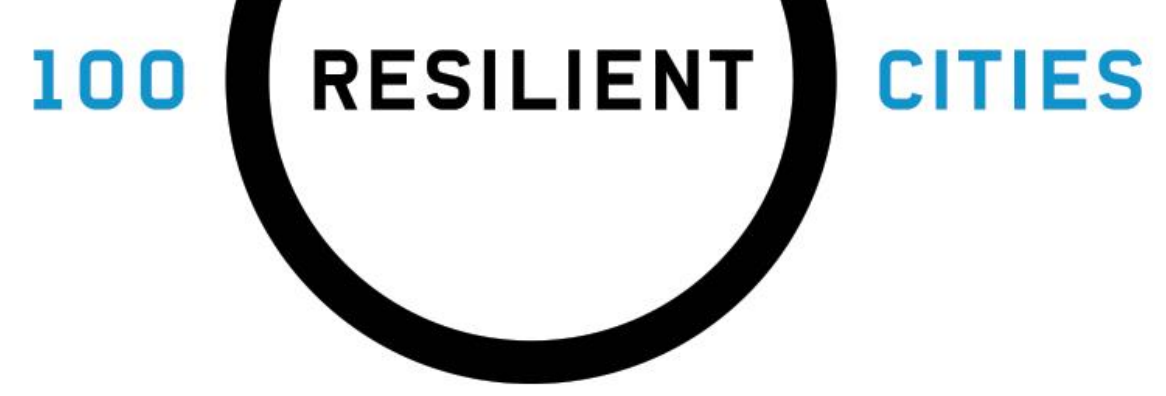

100 Resilient Cities

Claire S. Chase \& Lee Frankel-Goldwater,

University of Colorado Boulder

claire.chase@colorado.edu, lee.fg@colorado.edu 
CASE STUDY - 100 RESILIENT CITIES BY CLAIRE S. CHASE 8 LEE FRANKDL-GOLDWATER, UNIVERSITY OF COLORADO BOULDER

PART 1 - CASE INTRODUCTION AND PROFILE

100 Resilient Cities (100RC) is a network pioneered by the Rockefeller Foundation (Rockefeller) as part of their organizational mission to promote human wellbeing on a global scale. In the first part of the case study, we will describe 100RC as a response to the need to build greater resilience in cities before moving to a discussion about network design. Next, we will describe the history of the network since its inception in 2013. Finally, we will draw on the experiences of a first-round resilient city, Boulder, Colorado, to consider the network in terms of learning and capacity building.

A discussion of the 100RC network is dependent upon the definition of resilience used by key network actors. Rockefeller President Judith Rodin defines resilience as the "capacity of any entity - an individual, a community, an organism, or a natural system-to prepare for disruptions, to recover from shocks and stresses, and to adapt and grow from disruptive experience" (Rodin, 2014 , p. 3). This conception of resilience informs the characterization of 100RC network members as resilient cities. In this context, a resilient city is a network member chosen by Rockefeller. Resilient cities, as part of membership in the network, actively build preparedness capacity within city government via funding and access to the services and resources of Platform Partners, nonprofit and for-profit organizations providing resilience-building services to network cities.

\section{Network Origins}

Since 2008, the Rockefeller has funded seven resilience initiatives focused on action planning, design, and strategic partnerships (ACCCRN, 2013; Rockefeller Foundation, 2015). The 100RC network is one of Rockefeller's initiatives specifically focused on building resilience in city governments around the world. This section describes the 100RC network origins. First, we will describe the exigent conditions resulting in 100RC's emergence, and then move to how Rockefeller's 100RC functions as a response.

Rockefeller's resilience initiatives are centered around what the organization describes as "increasing dynamism and volatility" that makes people, communities, and systems vulnerable to natural and manmade catastrophic events (Rockefeller Foundation, 2015). According to Rodin (2014), a city, somewhere in the world, experiences a critical disruption every week. Extreme 
weather conditions, acts of violence, and issues of cyber security are examples of the types of events disrupting cities. These events have also revealed vulnerabilities of disrupted cities; the weaknesses, particularly in city government processes, that reveal a city's ill-preparedness to withstand and bounce back quickly from a major event. However, Rodin (2014) finds that cities don't have to experience crisis when potentially disruptive events occur. Rodin articulates Rockefeller's belief that if cities are actively building resilience than they will be better prepared for a potentially catastrophic event and will emerge from that event stronger than they were before. Furthermore, Rockefeller takes the position that how cities identify and process shocks and stresses impact a city's ability to build resilience. In other words, central to a city's ability to withstand, bounce back, and emerge stronger from a disruptive event is the process they enact to identify vulnerabilities and respond to those vulnerabilities. Accordingly, Rockefeller identified city governments as the entities tasked with identifying and responding to a city's threats.

In an effort to build resilience through city government processes to identify and respond to shocks and stresses, Rockefeller pinpointed two issues needing resolution within city governments. According to Bryna Lipper, 100RC Vice President for Relationships, the two issues standing in the way of a city government's ability to act resiliently include siloed and segmented city departments and a lack of resources and available solutions designed for implementation at the city scale (Lipper, 2015). In response, 100RC takes a systems approach, understanding a city's pressing issues as linked and positioning the city as a socio-ecological ecosystem. 100RC finds the siloed nature of cities as problematic because a siloed approach to solving problems inhibits a city's ability to address growing socio-ecological challenges. 100RC takes the position that city problem solving structures are fundamentally flawed because city departments were set up to address challenges programmatically through departments that focus on specific services across the city's physical and social infrastructure (e.g., water utility, public health, transportation). An example of a departmental approach to city governance can be found in the City of Chicago which has over 30 departments listed on their website, some with 10 different offices within them. In Boulder, Colorado, although each department has a master plan directly connected to a regional comprehensive plan, staff largely works on department-specific issues.

100RC's argument against siloed departments working on issues separate from other departments is evident when a city comes under crisis. An unexpected crisis like an environmental disaster provides an example of how issues facing cities are interrelated. A flood, fire, or earthquake may wipe out core 
transportation routes and utilities, which cause ripple impacts in homes and businesses. Loss of utilities may displace residents from their homes and cause businesses to close. Residents require space for sheltering but may also need social support, including health services. Businesses not physically impacted may still experience a depression in the local economy due to the closure of main transportation routes. A single department could not comprehensively address these issues, and, yet, a single phenomenon could cause cascading effects across a city's built and social infrastructures. For example, departments implicated include emergency management, transportation, health and human services, utilities, and potentially parks and recreation, if emergency sheltering takes place in community recreation spaces.

100RC also addresses the siloed nature of city government beyond crisis situations. Departments, by design, react to problems they encounter within the scope of their work. 100RC believes this is a problematic approach to solving problems. First, it is reactive rather than proactive about issues facing a city. Second, 100RC suggests that problems solved by single departments only address the issue from that singular perspective. For example, rapidly increasing commuter traffic into a city may result in the need for more repairs on roads, an issue that a department of transportation is tasked to address. 100RC's approach asks city governments to consider how singular issues may actually be symptoms of a larger problem facing the city. In the case of roads needing repair, transportation departments respond to these types of issues as part of their work, however, 100RC suggests that city governments should consider what broader issue is at play when commuter traffic increases rapidly (e.g., asking 'What is the underlying cause for an increase in commuter traffic?'). If underlying problems aren't addressed, the city will never build enough capacity to fully prepare for future problems. 100RC's guidelines for member cities fosters proactive identification of potential shocks and stresses and action planning to address shocks and stressors holistically in order to address the underlying problems.

The 100RC organization addresses the problems of siloed departments and the need for scaled solutions by funding CROs in 100 cities and providing a marketplace of services called Platform Partners designed to mitigate the issues city governments face. The Platform Partner marketplace is made up of 100RCvetted organizations and research institutions that provide a limited number of pro-bono services to assist 100RC member cities in local resilience initiatives. In the next section, we will discuss the role of the 100RC network design in addressing the critical state of the world's cities. 


\section{Network Design}

100RC is an international initiative pioneered and funded by Rockefeller. The project's premise is to incorporate a resilience-thinking framework-city planning that accounts for sudden shocks and long term stresses-into local governance structures through the funding and support of local Chief Resilience Officers (CRO) in 100 selected cities. 100RC supports cities and CROs in the development of a local resilience strategy as well as provides a network of resources and tools to help cities achieve resilience-oriented goals. The 100RC initiative is three-fold: select cities that have shown relative success in planning and enacting resilient thinking approaches, engage CROs to locally manage and lead resilience thinking efforts in each city, and create a marketplace of services for cities to utilize for future resilient efforts. The resulting knowledge building around resilience thinking in local governance then can serve to catalyze local and regional resilience thinking across the world (100RC, 2015b). The following section describes the 100RC network design, specifically membership related to the peer-to-peer CRO network, Platform Partner constituents, and 100RC organizational staff.

\section{RC Network Model Diagram}
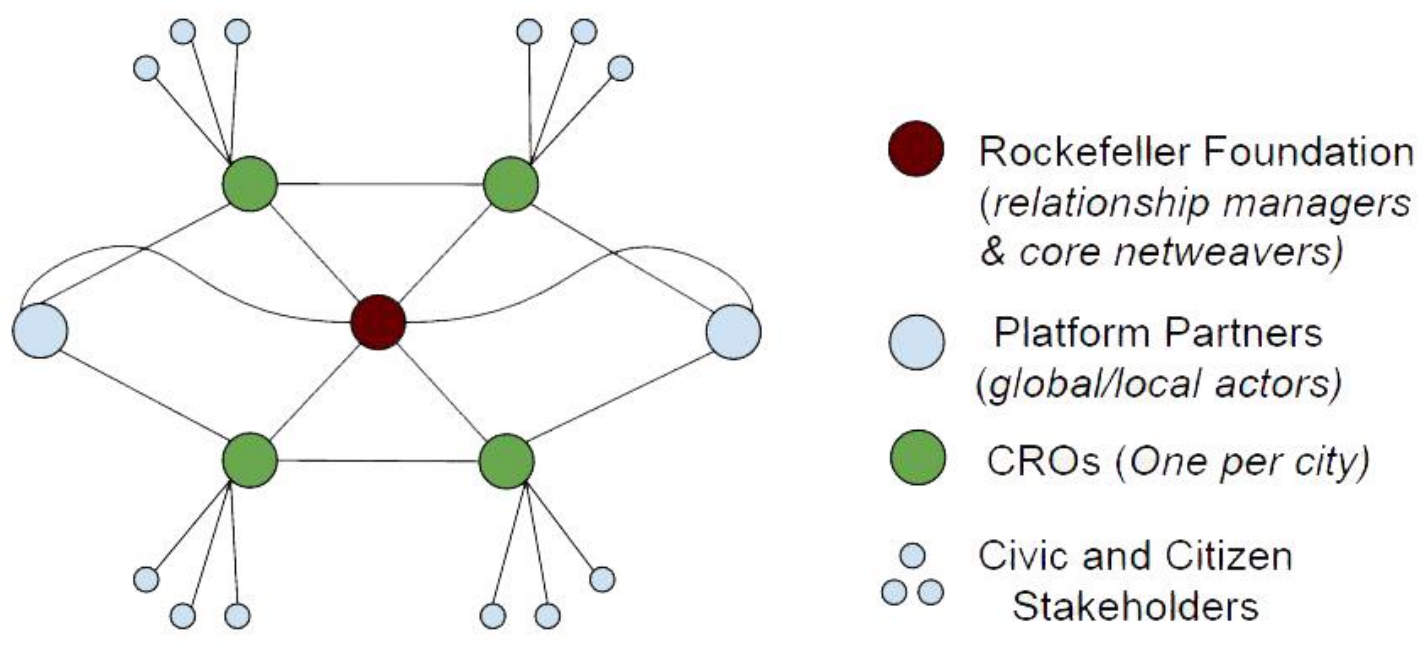

Figure 1. 100RC Network Model Diagram.

Member cities, selected by the 100RC organization, participate in the network through CROs. To be selected, city governments complete an application detailing their existing resilience efforts and commitment to building resilience 
in city governance (Berkowitz, 2014). 100RC selects cities in phases, with the first round of 33 cities announced in December 2013, the second round of 34 cities in December 2014, and the third group in 2016. 100RC President Michael Berkowitz advised that city applicants would be chosen based on demonstrated innovative and engaged leadership, a "recent catalyst for change," an ability to work with diverse stakeholder groups, and a willingness to develop and continue in partnership with the 100RC initiative (Berkowitz, 2014). The first 100RC group includes cities across North and South America, Asia, Europe, Africa, and Australia. According to Rockefeller President Judith Rodin, the cities "represent a diversity of urban resilience needs" with Berkowitz noting that the first round of cities "range from megacities to small regional hubs, coastal to land-locked, ancient to modern, yet are grappling with so many of the same challenges" (Berkowitz, 2014; Rodin, 2013).
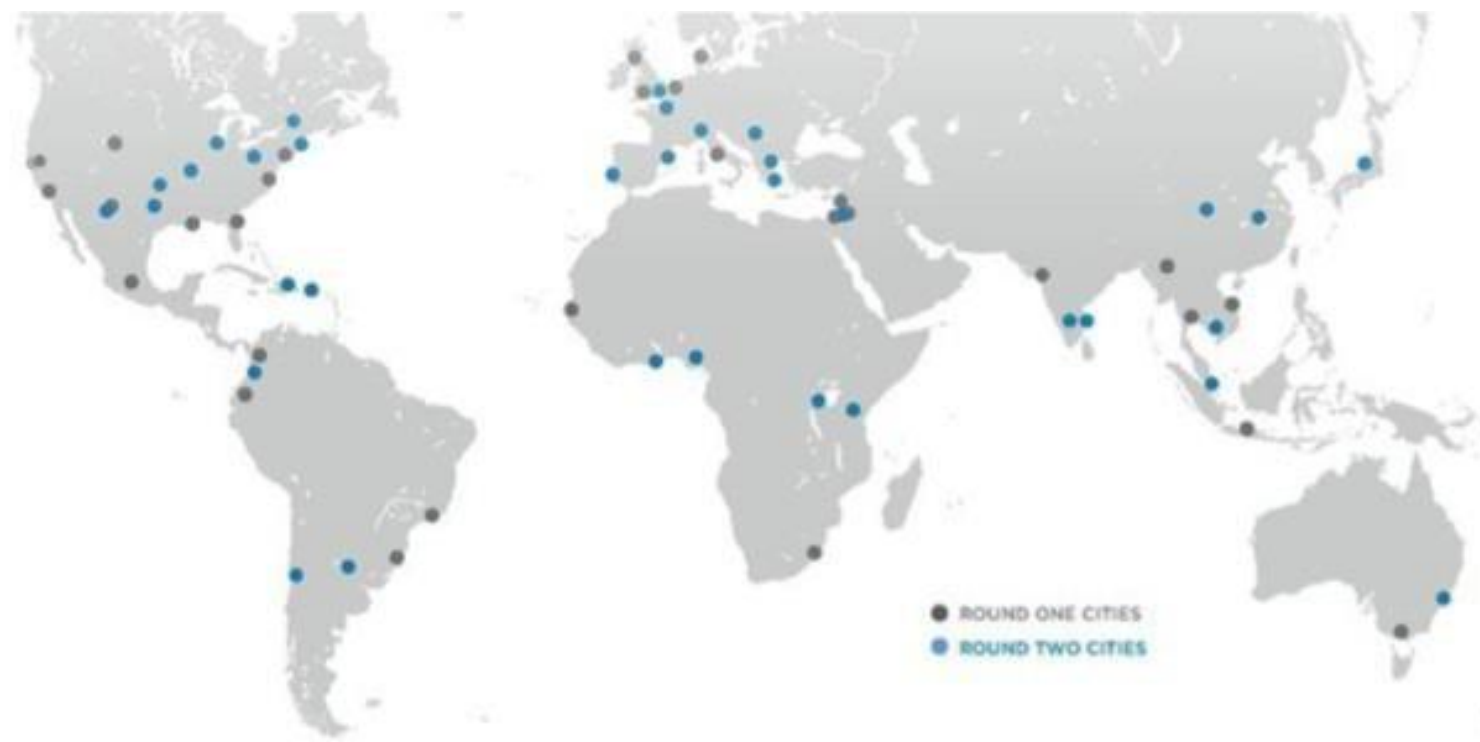

Figure 2. 100RC Rounds One and Two Selections. Retrieved from 100resilientcities.org.

Upon selection into 100RC, cities receive two years of funding for the hiring of a CRO. The role of the CRO is to lead resilience efforts at the local level. CROs are hired by cities (in collaboration with 100RC) to work across local city governments identifying current resilience projects as well as potential opportunities for engaging a resilience thinking perspective in crisis mitigation and long- term planning. Each $\mathrm{CRO}$ is paired with a 100RC relationship manager; this relationship serves as the contact point between city and the 100RC organization. The CRO facilitates resilience thinking at the local site, bringing together stakeholder and working groups to plan and implement a local resilience strategy. The first phase of the CRO's two-year work plan includes 
assessing a city's current activities and determining risk and opportunity within existing programs. The second and third phases include development and implementation of a city resilience strategy. These phases have the potential to vary widely across cities based on the local context of a city's shocks and stresses and civic engagement (Resilient Boulder Observation, 2014).

In addition to local development of resilience thinking within cities, the 100RC organization created a formal resource directory comprised of Platform Partners and a CRO peer network. The resource pool of Platform Partners includes private, public, academic, and non-profit entities, including organizations like ARUP, the U.S. Environmental Protection Agency, Palantir, Swiss Re, Sandia National Laboratories, and the Virginia Tech Advanced Research Institute. This group of Platform Partners provides services to cities in response to, or preparation for, critical needs. The aim behind Platform Partners is to provide cities with resources previously beyond their reach, bringing in innovative ideas, critical research, and potential solutions. In addition to Platform Partners, selected cities serve as resources for one another through the CRO network. The CRO learning network is organized by 100RC and includes channels for information flow and opportunities for best practices and collaboration. This structure provides an initial guide for visioning how the selected cities will provide support and mentorship for those outside of 100RC in years to come. The Rockefeller's 100RC initiative focuses initial support on cities as a way of catalyzing resilience frameworks in city planning worldwide.

In terms of formal modes of connectivity, the 100RC organization designed communication mechanisms, including newsletters, an email listserv, a document sharing site, and network events, that serve to structure interaction between members of the network (Resilient Boulder Observation, 2015). According to a CRO from a city selected in the first phase, mechanisms for connectivity are primarily used for sharing information related to the CRO position (CRO Interview, 2015). Formal communication channels like emails and newsletters are used to disseminate information to network members. 100RC shares information specifically to CROs regarding their work, including examples of reports produced by other member cities and opportunities for collaboration with Platform Partners. In addition, network members interact at a variety of 100RC sponsored events that serve as opportunities for CROs to learn about resources available to them through the 100RC organization and also informal opportunities to connect on common issues and challenges faced within their burgeoning positions in cities (100RC, 2015a). Such events include an annual weeklong CRO Summit held in one of the selected resilient cities. 


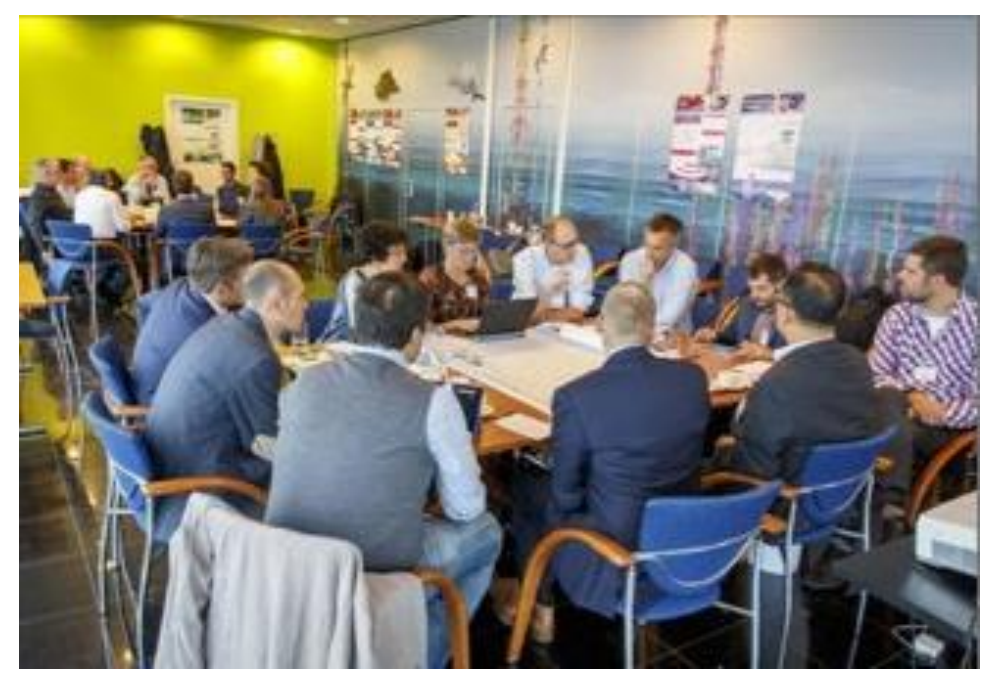

Figure 3. First Network Exchange Program in Rotterdam, Netherlands (100RC Network Newsletter, December 2015).

Another crucial component of the 100RC infrastructure are workshops centered on common shocks and stresses. 100RC hosted a series of sessions in which CROs from selected cities were invited to participate in discussions with other CROs from cities with similar environmental and social stresses (100RC, 2015a). For example, the Boulder CRO attended a meeting with CROs from Norfolk, New York City, and New Orleans regarding the implementation of resilience thinking frameworks into land use policies and city master plans in Spring 2015. More recently, a "Network Exchange Program" was created in October 2015 bringing together cities dealing with water management issues. The program featured an intensive workshop session and observations from the living lab of Rotterdam's water management solutions (100RC, 2015a). Informally, CROs also connect outside of the internal system through email and phone calls. In an instance among CROs in the Americas, members shared draft documents not officially submitted to the 100RC organization (Resilient Boulder Observation, 2015).

\section{Network History}

The 100RC network is a relatively young network, marked by the first CRO Summit in November 2014. In its first two years, the 100RC's planned growth resulted in a doubling of member cities and organization staff. Responding to the growth of the network, 100RC added relationship managers and other staff to support its new membership in early 2015. At the same time, the 100RC network is still in development, with 34 cities remaining to be selected in 2016 . 
The network structure has changed along with the growing number of cities and organizational staff. The network began with 33 cities in 2013 and added an additional 35 cities in 2014. After initial selection member cities must hire a CRO. The CRO hiring period results in a time of ambiguous membership because the lack of CRO means that the city lacks a distinct network member. Although the city is described as part of the network, in reality, the CRO is the network node representing the city. City selection of a CRO provides access to 100RC organizational resources as the CRO serves as both contact person and facilitator of Platform Partner resources in local city projects (Resilient Boulder Observation, 2015; CRO Interview, 2015). City and CRO additions have an impact not only on network membership, but also network capacity and organizational learning, discussed later in both Parts 1 and 2 .

\section{Learning and Capacity Building}

Although the 100RC takes a closed-door approach to sharing internal network strategies to build learning and network capacity among CROs, evidence from CRO interviews, observations, and publicly available 100RC materials point to opportunities for learning and capacity building among CROs and 100RC organizational staff. Additionally, it is important to consider the learning and capacity building potential within any network as an indicator of network health. According to Holley (2009), transformational networks can foster learning through reflection, processing, and shared knowledge building in order to drive future success. This section describes learning and capacity building in 100RC in two ways: through a consideration of 100RC as a community of practice, and, through the lens of Boulder, Colorado, a network member.

\section{Community of Practice and Netweaving}

First, considering 100RC as a community of practice stems from evidence that 100RC aims to become a community of practice in which members interact, share, and learn from one another. Wenger (1998) defines a community of practice using three characteristics: a shared domain, shared community, and shared practice. In addition, a core element to a community of practice is netweaving, the action of facilitating the health of the network through connecting network members and organizing projects (Holley, 2009). A network weaver, or netweaver, takes on the responsibility, intentionally or implicitly, for the health of the network and is sometimes enacts the role of the "Network Guardian" (Holley, p. 277). 
Based on the definition described by Wenger (1998), 100RC meets the baseline criteria of a community of practice. First, the domain of resilience thinking connects the network based on a shared realization that existing responses to city government aren't working effectively. Each resilient city network member applied to be a part of the network exemplifying a shared awareness and desire to engage in resilience thinking within city governance. Second, shared community is found in membership in the 100RC network as a resilient city. Cities are connected by the common experience of being selected to join 100RC and enacting the 100RC process within their city. By being a member of the 100RC community, cities adopt the collective identity associated with being "resilient" both through participation in network activities (e.g., 2015 City Leaders Summit on Resilience or $10 \%$ city resilience pledge) as well as through the shared practice of enacting 100RC's processes within their local city governments.

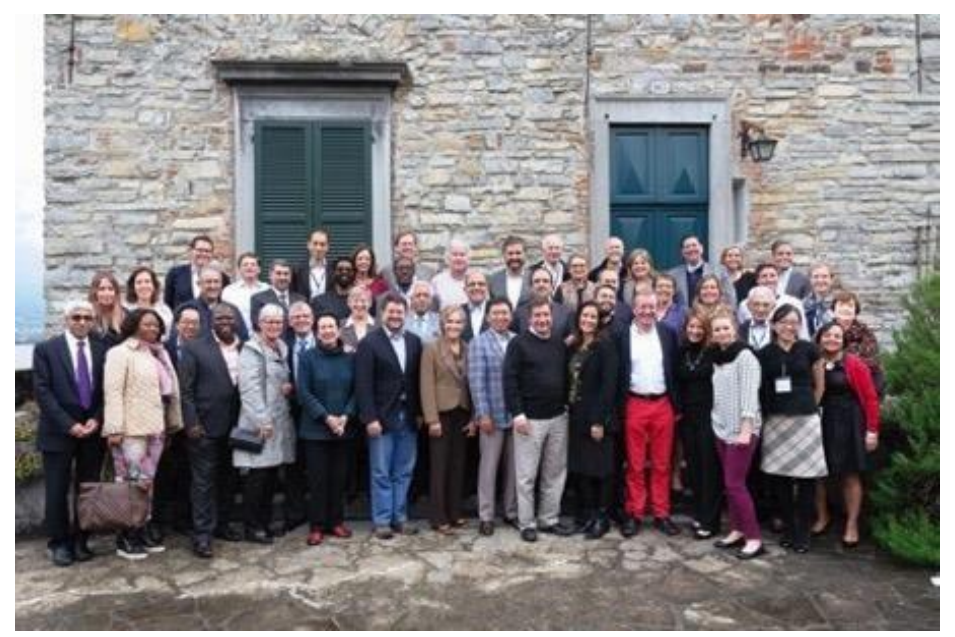

Figure 4. 100RC City Leaders Summit on Resilience in Bellagio, Italy. (100RC Network Newsletter, December 2015). 


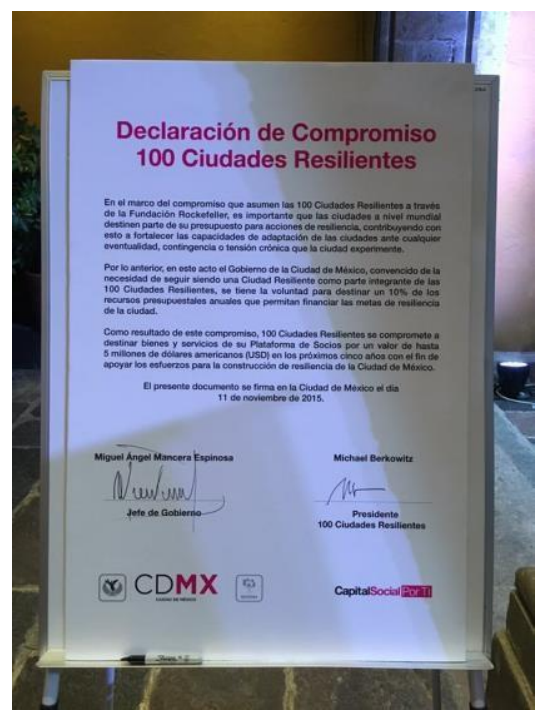

Figure 5. $10 \%$ city resilience pledge by Mexico City official at the 2015 CRO Summit. Image from twitter.com/maxwellcyoung (November 11, 2015).

CROs' shared identities are directly related to a common professional mission, to build resilience within city government, although the work of CROs may differ across cities. Each CRO engages in different practices within their local city government, however, 100RC mandates that all CROs create and implement a local resilience strategy. Additionally, CRO practices are guided by the 100RC Strategy Guidance Manual (100RC, 2015), which details required and recommended activities for CROs and local municipal staff assisting in resilience efforts. Despite guidelines provided by 100RC, the work of a CRO is largely emergent and responsive to the local environment. The emergent work of the $\mathrm{CRO}$ points to shared challenges found in pioneering a new way of thinking within city governments that have set ways of solving problems. The accumulation of challenges and successes across CROs embodies the idea in which communities of practice "develop a shared repertoire of resources: experiences, stories, tools, ways of addressing recurring problems" (Wenger, 2009 , p. 271). Although the extent to which CROs participate in shared learning or in the collective development of formal resources is uncertain due to the limited history of the network, a joint interview with San Francisco and Boulder 
CROs suggests that CROs feel a sense of camaraderie. Relationships developed based on shared practice, as in the case between San Francisco and Boulder, led to the development of informal resources characteristic of a community of practice, including the sharing of experiences, stories, and obstacles.

Due to the organizational influence on the 100RC network, netweaving occurs as the formal activity of the relationship manager assigned to selected cities. In the current stage of the 100RC network, relationship managers serve as organizational netweavers within the 100RC network. In the initial netweaving structure designed by 100RC, each relationship manager works with five cities, connecting CROs with other members based on common experiences and challenges. Relationship managers facilitate connections not only between cities, but also serve as key orchestrators of relationships between cities and Platform Partners offering relevant services (Resilient Boulder Observation, 2015). Relationship managers have systems in place to monitor and evaluate activities between cities. For example, relationship managers have weekly phone calls with CROs and often exchange emails throughout the week regarding topics associated with the CRO's partnerships with Platform Partners (Resilient Boulder Observation, 2015). The relationship manager works on behalf of the CRO to secure services with Platform Partners in the 100RC marketplace. Various reports are also requested from CROs detailing activities with Platform Partners, including requests for services, service updates and meetings, and final reporting. Platform Partners also keep relationship managers abreast of services provided to the city that serve as means for tracking connectivity between cities and service partners (Resilient Boulder Observation, 2015).

In that netweaving is a part of the relationship management position and funding is provided by Rockefeller, accountability is streamlined into organizational reporting. Relationship managers and the executive team meet regularly to discuss activities of each city. Relationship managers present to the executive team of high level administrators on the projects between cities and Platform Partners, updates on phase and documentation progress required by the organization, and challenges faced by CROs (Resilient Boulder Observation, 2015). This status updating session provides a layer of organizational oversight of the CRO members as well as an opportunity for gathering information useful for relationship managers in their roles.

Netweaving significantly impacts the formation and process of change in a network. The primary netweavers in the 100RC community of practice include Rockefeller staff and CROs playing essential project and knowledge development roles. It is evident from structured network weaving by 100RC Relationship 
Managers that opportunities exist for reflection, learning, and change, if needed. In the next section, the experiences of Boulder, Colorado, point to formal and informal mechanisms that have the ability to promote learning and capacity building. Although we do not intend to determine whether learning and capacity building occurs on the network level, the experiences of the Boulder CRO point to critical opportunities where reflection and synthesis could enhance long-term health of the network. The microcase of Boulder, as well as the discussions in Part 2 of this case (e.g., organizational learning, cross-scalar integration, and transformative capacity), are directly influenced by the conceptions of 100RC as a community of practice, and particularly 100RC's netweavers and netweaving activities.

\section{The case of Boulder, Colorado}

The 100RC peer-to-peer network is designed to enhance practitioner knowledge across CROs through formal and informal information sharing and knowledge building. Formally, CROs attend 100RC-sponsored workshops and forums addressing the issues most pressing to their cities. Informally, CRO members interact in ways that promote learning and capacity building that goes beyond formal ties to a common practice, and even beyond the scale of the peer network.

The following section focuses on the example of Boulder, Colorado, a first round member city. The case of Boulder, Colorado, highlights how critical points of tension and connection could move a network to enhanced learning and capacity building or stagnation. Boulder provides evidence that CROs must navigate between the normative guidelines set by the network and local needs of the cities they serve. An opportunity for learning and capacity building becomes evident in the critical conversations across scale that engage the extended network of local city governments, CROs, and the 100RC. In addition, similarities in the Boulder and Pittsburgh CROs' city political climates point to the possibility for peer-to-peer learning across the network. 


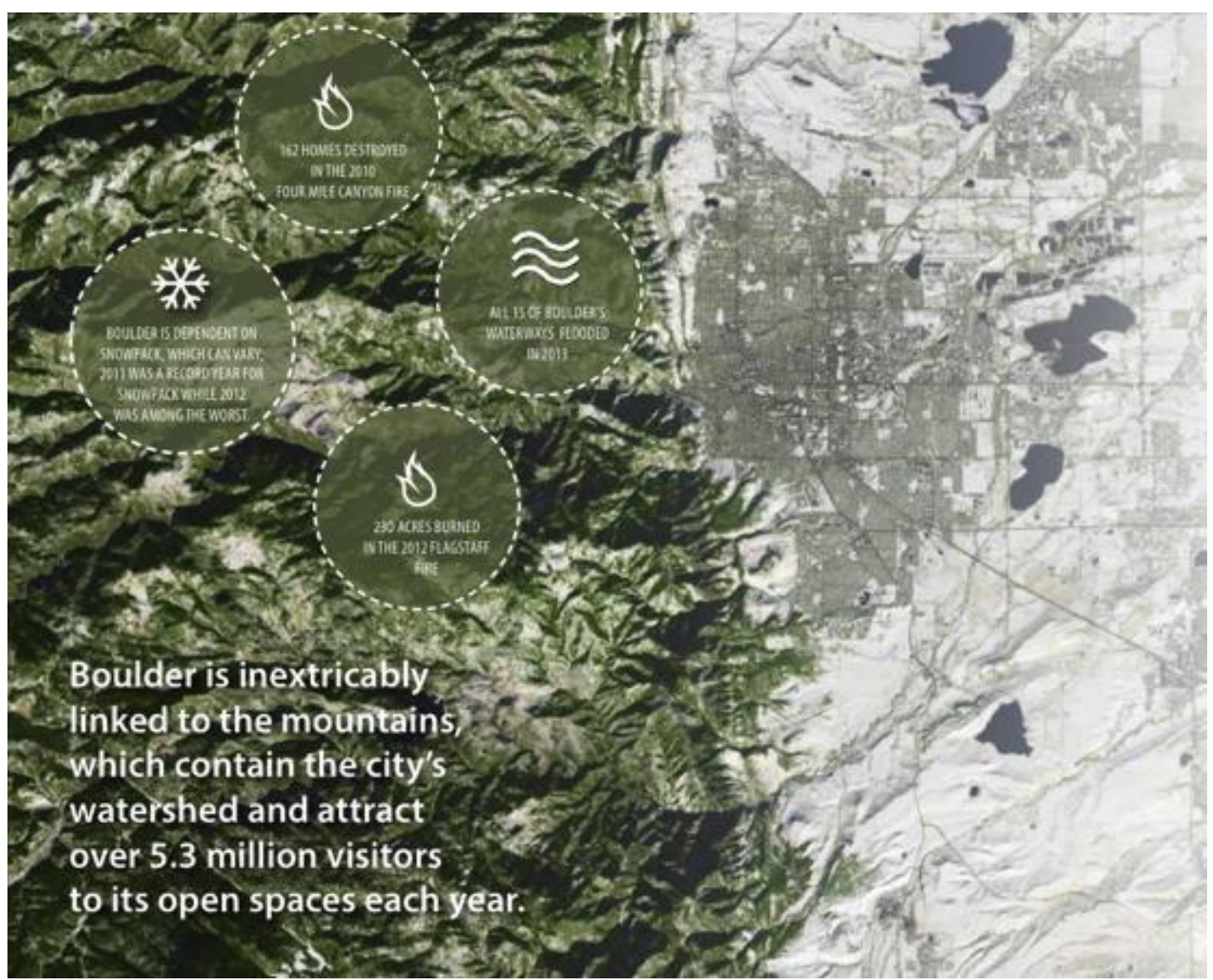

Figure 6. City of Boulder Resilience Strategy (bouldercolorado.gov/resilience, p. 14).

Resilient Boulder, the City of Boulder working team affiliated with 100RC, is self-described as the "problem child" of the 100RC network (Resilient Boulder Observation, 2015). This characteristic refers to the unique circumstances in Boulder that lead to changes in how the 100RC framework was enacted by the city. In addition, it reflects the complex conditions that the 100RC framework entered into when Boulder was selected as a resilient city in December 2013. Almost 10 months after the initial designation, the Boulder CRO launched Phase 1 of the 100RC framework in Boulder city government and was met almost immediately with substantial obstacles. First, the Boulder CRO faced the dual challenge of holding the inaugural CRO position in city government and entering into the position as an organizational outsider. According to a 100RC relationship manager, the Boulder $\mathrm{CRO}$ is one of few CROs hired from outside of city government and the only CRO with no financial or administrative support from their city (Resilient Boulder Observation, 2015). In other words, the Boulder CRO had not held a position in city government before accepting the CRO role. 
The contentious political environment in the City of Boulder at the time of the Boulder's Phase 1 launch also produced challenges to following the resilience strategy format as designed by 100RC. Issues surrounding housing affordability and related development divided Boulder citizens and produced heightened skepticism of the underlying intentions of city government (Burness, 2015). During the first phase, the Boulder CRO faced internal pressures to promote resilience work as the enhancement of existing efforts rather than as a new project. This was due largely to heightened criticisms from citizens regarding internal city government decisions and budget appropriations without City Council approval. To minimize the appearance of new programming, the Boulder CRO was asked to avoid politically divisive issues that might draw public attention (Resilient Boulder Observation, 2015).

In addition to navigating the political environment of Boulder, the CRO faced institutional obstacles associated with the work of building resilience in city government without a budget, resources, or institutional social capital. In an effort to make the 100RC resilience framework successful in the local context of Boulder, the CRO requested modifications to the 100RC designed framework to fit local needs. The back-and-forth negotiation that occurred between city government, CRO, and 100RC throughout Boulder's Phase 1 serves as a critical opportunity to assess how operationalization of the resilience framework functions under complex local conditions. The CRO's navigation of how the work would address both 100RC goals and local city government needs was not without tension and challenge from both sides. At the same time as the ongoing negotiation between local and network contexts, Boulder's 100RC Relationship Manager was replaced in early 2015 and the CRO position transitioned out of its original designation in the City of Boulder's Department of Planning and Sustainability to the City Manager's Office.

The challenges faced by Boulder are dependent upon the unique local context; however, no city selected by 100RC is immune to local challenges when adopting the network framework. In early 2016, a year after the second round of resilient cities were selected, a CRO noted that more cities were facing challenges in enacting the 100RC framework as originally designed. The critical framework negotiation that occurred between Boulder and 100RC provides an initial opportunity for organizational and network growth, however learning and capacity building will only occur if 100RC acknowledges, reflects upon, and develops strategies for collaboration when future issues arise. In particular, the Boulder example represents how the 100RC network is dimensional across three levels-100RC organizational staff, CROs, and local city governments- 
expanding beyond the 100RC organization and CRO connection. Further, in this scenario, the CRO becomes a second-level netweaver connecting the 100RC network to the city government in which they are simultaneously embedded. The local dimension of the broader 100RC network is important because city government staff play a role as extended network actors that wasn't fully realized in the 100RC design, yet ultimately determines the 100RC's success.

The case of Boulder challenges the initial 100RC network design, but also points to opportunities for peer learning. The progressive nature of selecting cities in phases resulted in a network of CROs with varying network experience. Members in the first round of cities quickly gained expertise experientially in their home cities and through their work with the 100RC organization. Once the second round of cities were chosen, the first CROs had already progressed through the initial steps of the 100RC framework. The incremental nature of adding new cities points to the potential for a mentor relationship between first and second phase cities in the second year of the 100RC network.

First round CROs, after a year of experience working in the position and within the network, have the opportunity to provide information and advice to second round CROs.

CRO-to-CRO sharing is another opportunity for learning and capacity building evident in from taking the perspective of a network member. Like other 100RC members, Boulder and Pittsburgh CROs share a common practice. However, the tie between them goes beyond practice to the potential challenges they face as a result of their cities' historical and political contexts. As previously discussed, Boulder's contentious political context resulted in local challenges to operationalizing the 100RC framework. For Pittsburgh, major shifts in local politics are occurring as a result of changing city demographics (O'Toole, 2014). As younger citizens settle into cities like Boulder and Pittsburgh, long-time political machines are being challenged by new voices. In Boulder, this shift resulted in criticisms that local city government sided with younger citizen views (Burness, 2015). In both Boulder and Pittsburgh, long established systems of strictly controlled development are challenged by a younger citizen demographic supporting growth and community development.

In the case of Boulder (first round) and Pittsburgh (second round), the CROs were introduced through a common 100RC relationship manager. Observing the similarities across city contexts, the relationship manager asked the Boulder CRO if she could share some of the lessons learned in the Boulder process (Resilient Boulder Observation, 2015). The initial information-request and 
sharing of experiences drawn from similar city contexts provides another critical network capacity building opportunity for the 100RC Network.

The experiences of the Boulder CRO were unique to the particular city politics at the time of the Boulder's 100RC launch, however overcoming challenges in the local context points to the possibility of network learning and capacitybuilding. According to Holley (2009) reflection of both successes and failures drives transformation in a network. The case of Boulder provides evidence that opportunities exist for 100RC network, and CRO practice, reflection and transformation. In the next part, analysis of 100RC points to additional insights about organizational learning, cross- scalar integration, and transformative capacity.

\section{PART 2 - EXAMINING THE CASE}

The second part of this case considers 100RC from the theoretical standpoints of organizational learning, cross-scalar integration, and transformative capacity by building on the information, descriptions, and structure presented in Part 1 . Briefly defined, organizational learning is the process of developing knowledge and capacity between stakeholders in a network, while cross-scalar integration is the integration of this knowledge and capacity across layers of difference in a network including geography, purpose, and socio-economic status. Transformative capacity represents the synergies that are supported by and nurtured within a network to produce results that transcend the capabilities of individual actors. Considered together, organizational learning, cross-scalar integration, and transformative capacity offer a valuable lens for understanding the subtleties, challenges, and potential in 100RC.

The following discussion is based primarily on interviews conducted with CROs during 2014-15, and while the interviews represent valuable primary data about 100RC, they also present two key limitations for understanding the network as a whole. The first is the CROs interviewed work in the first round of cities Rockefeller selected to participate in 100RC, which represents but half of active CROs. It is likely that this first group of CROs will have had experiences unique to their cohort as 100RC has adjusted some practices between the first and second rounds of cities, and CROs in later rounds will have had opportunities to learn and benefit from the challenges faced by first round CROs. The second limitation is that the CROs interviewed for this casework in Western and principally well-developed cities. As one CRO notes, colleagues in these circumstances have likely shared particular challenges and had profoundly 
different experiences when compared with CROs in less-developed areas (CRO Interview, 2014).

While these observations do perhaps limit broader generalizations about the progress of 100RC as a whole, the data does offer insight into a significant slice of 100RC and the CRO peer-to-peer learning network. CRO interview data is further supplemented by interviews with Rockefeller staff as well as through the authors' insights from attending 100RC events and analyzing available primary documentation. The resulting discussion on organizational learning, crossscalar integration, and transformative capacity sheds light on the current state of 100RC and points to opportunities for

growth and improvement to support the network's ongoing development.

\section{Organizational Learning}

Organizational learning can be defined as the way an organization develops, retains, and exchanges knowledge through an institutional memory. Institutional memory refers to knowledge that may be held in the practices and shared story of an organization, representing capacities that require the shared experiences of numerous individuals to maintain. Crossan, Lane, White, and White (2015) describe the role of shared stories in developing institutional memory noting that, "as stories evolve, richer understanding of the phenomenon is developed, and new integrated approaches to solving problems are created. Stories themselves become the repository of wisdom - part of the collective mind/memory" (p. 529). Organizational learning further considers how developing this shared story supports the ability of a network or organization to adapt to positive and negative stresses through the exchange of information between stakeholders. A discussion on organizational learning in 100RC therefore aims to identify the processes by which a shared conceptualization of knowledge and practice develops, and ultimately how these capacities can be improved and maintained over time.

Tosey, Visser, and Saunders (2011) note characterizations of organizational learning, some of which constitute a third order in which an organization gains the ability to challenge and redefine its own traditions from within. This third order, or third-loop, represents a system of feedback within an organization, one that creates opportunities for learning through self-reflection and analysis that can lead to fundamental changes in organizational behavior. Developing thirdloop learning is of principal interest to a discussion on networks as it supports the potential for achieving transformation, and represents a network's ability to redefine its core capacities from within its decentralized operating structure - a 
concept that is more deeply explored in the upcoming section on transformative capacity.

Applying the aforementioned concepts of organizational learning to a network offers a frame for understanding the interactions between a network's diverse stakeholders that support relationship building for the purpose of taking action. As in any organization, the nature and quality of relationships between stakeholders is fundamental to a network's day-to-day functionality, growth and development over time. This represents cohesion among the membership that is particularly important for networks, which often have rapidly changing organizational structures, and is vital for developing a shared network story that acts as a repository for organizational learning. As Lejano, Ingram \& Ingram (2015) note, the process of developing a shared story and institutional memory represents the core of the network's operating capacity and helps to facilitate learning between network stakeholders. It is this potential that is considered most closely in the following discussion on organizational learning in 100RC.

\section{Organizational Learning within 100RC}

The majority of interactions in 100RC are at three points, between CROs and the departments of the cities they serve, between CROs and relationship managers, and between Rockefeller staff within the various branches of the 100RC organization. The following discussion addresses these relationships in the context of organizational learning, pointing to opportunities for growth and transformation within the network. It is important to note that while there have been significant and fruitful interactions between CROs, these interactions appear to have had little effect on organizational learning capacity within 100RC 
as a whole, and are discussed more thoroughly in the latter section on crossscalar integration.

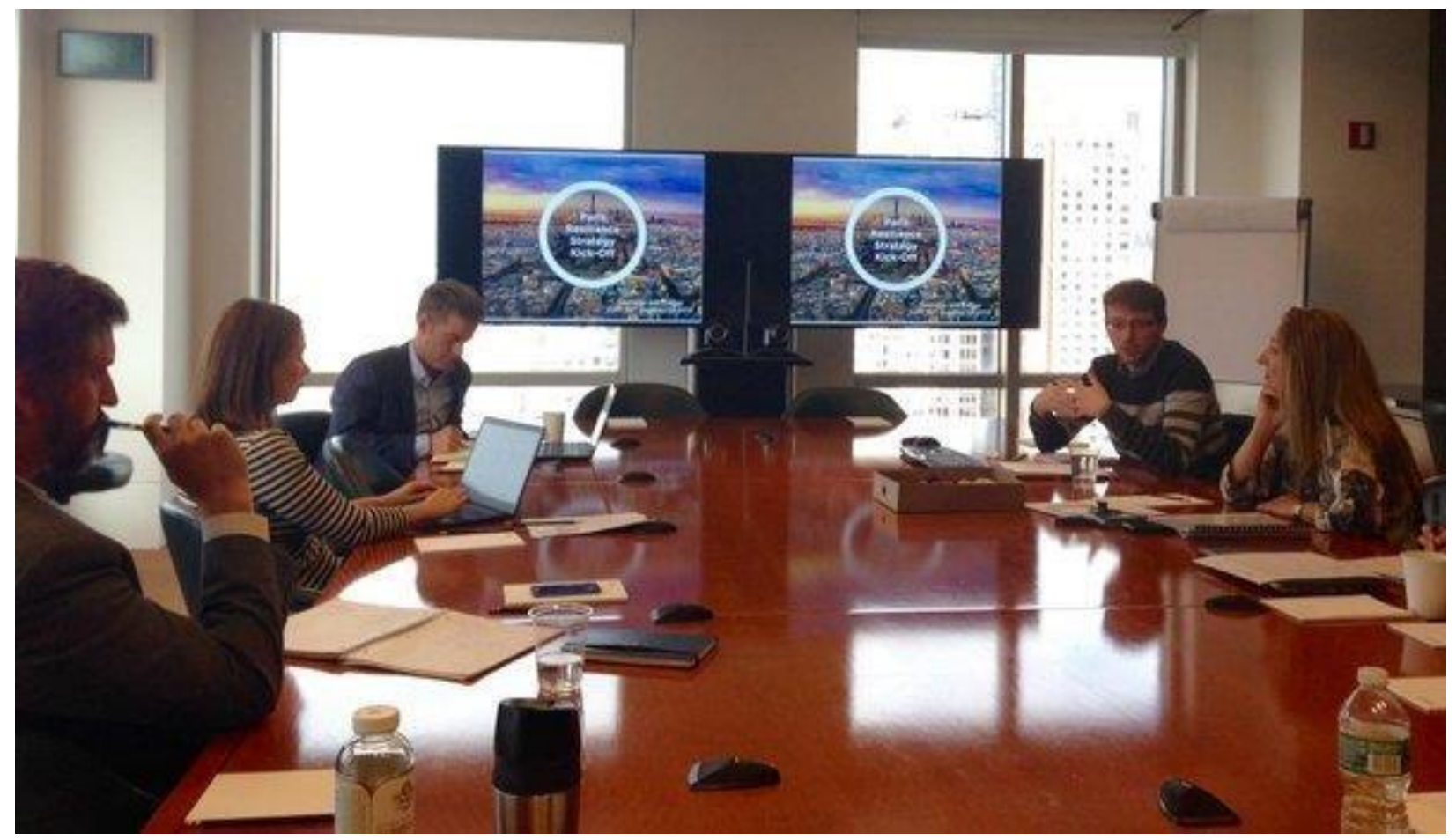

Figure 7. Paris, France, resilience team and 100RC organizational staff discussing climate and resilience strategy. Image from Olivia Stinson, 100RC relationship manager (twitter.com/Olivia_dawa, May 1, 2015).

The overall structure of communication in 100RC is described by a relationship manager in an interview conducted in New York City at the Rockefeller Foundation headquarters (CRO Interview, 2015). The discussion points to several examples of organizational learning within 100RC that focus on feedback and knowledge sharing between Rockefeller staff. For example, the relationship manager notes that she spends most of her time working with CROs and in meetings with Rockefeller staff, sharing her own insights, and learning about overall organizational objectives as determined by the Rockefeller 100RC administration. She also notes that there are substantial opportunities to connect with members from other departments, including the group that manages the Platform Partners. The relationship manager goes on to mention that feedback and information sharing between relationship managers is a regular part of her job. In the course of the interview she notes several contexts in which she has been able to provide useful input to various parts of the 100RC organization, particularly at departmental and whole-staff meetings, effectively impacting broader organizational practices. 
Based on this interview it appears that Rockefeller's 100RC staff and administration appreciate a culture of feedback. The lessons learned by an individual staff member can support processes of change in 100RC and thereby support organizational learning. It is difficult to conclude that this observation is true across the whole organization, as available data draws upon the one interview and may be limited to this individual's experiences, but the insights of this relationship manager do point to a promising potential for organizational learning in 100RC.

Building on this perspective from the CRO interviews, it appears that some degree of feedback does reach Rockefeller staff from the CROs in ways that contribute to organizational learning. As one CRO notes, communication with his relationship manager led to beneficial changes in knowledge sharing and communication (CRO Interview, 2015). This feedback, however, seems flow primarily from CROs to relationship manager and reflects back into the CRO experience only minimally. That said, there is indication that relationship managers coordinate and share lessons with each other, thereby supporting knowledge sharing that may influence the broader CRO experience (CRO Interview, 2015). Yet as noted earlier, the majority of a CRO's work focuses on the day-to-day challenges that arise within his or her city, most of which are unique to that city. This "downward gaze" appears to prevent feedback loops between CROs and Rockefeller staff that could support organizational learning and knowledge sharing capacities in 100RC and the CRO peer-to-peer network.

While this observation represents an impediment to organizational learning within 100RC, it does highlight a valuable component of the CRO's role at the city scale. Several CROs have noted opportunities they have had to introduce "systemic thinking" to the planning efforts between departments in their city's governments. While these city departments are not formally part of 100RC, they are within the scope of its intended impact as exemplified by the network's goals of bridging silos in city governance, and represent a kind of extended organizational learning. There is little indication that the relationship managers can aid CROs in this outcome, though several CROs mention that natural capacity building relationships between cities and CROs have developed around shared areas of need. This observation is explored further in a later section on cross-scalar integration, as its impacts on organizational learning in 100RC are as of yet minimal.

Based on the above discussion, there is an observable bottleneck between the CROs and the broader 100RC organization that impacts overall organizational 
learning and capacity building. Relationship managers broker feedback between CROs and Rockefeller staff in ways that limit direct feedback, and when considering a CRO's city centric workload, this may also disincentivize participation in the CRO peer-to-peer network. This layer of abstraction between CROs and Rockefeller staff may however be necessary to allow 100RC to function as an organization. There is often an intentional division of roles between those managing the network and those producing results through the network's capacities, as both tend to have actors working at different scales with different goals that help the network to function (Holley, 2012). 100RC has been facing and adjusting to the challenges of structuring these operating procedures since the early days of the network's development.

The CRO from Boulder, Colorado describes his experience as one of the first CROs in 100RC as being filled with communications challenges. Early in his term he recalls having to spend time fielding many calls from Rockefeller staff in different departments in 100RC. This is noted as inhibiting his ability to do his job and being a poor use of time resources. After several months he made a request to have one check-in point with Rockefeller, namely the Boulder city relationship manager, and to allow all communications to go through this checkin point. Rockefeller staff agreed to this request. As one of the first CROs, it is interesting to ponder whether this early course correction impacted the experiences of future CROs and the overall communication structure in 100RC. It also represents some degree of willingness within 100RC to adjust practices based on the needs of its membership thereby supporting organizational learning.

An additional point of challenge in 100RC is that cities, and therefore CROs, plug into the network at different starting points relative to addressing issues of resilience. Some cities, such as New York and San Francisco have been working on resilience issues such as flooding for some time, whereas other cities in the network have not. In combination with the communication bottlenecks mentioned earlier, this can impact organizational learning by limiting the ability for CROs to develop a shared story.

For example, several CROs have observed that the first year of CRO efforts, which focuses on a resilience assessment mandated by Rockefeller as part of 100RC, may be more useful for cities with fewer pre-existing evaluation and infrastructure capacities. The reasons noted point to the idea that time and resources could have been better spent on network building tasks, rather than coming to conclusions about a city's resilience that were already well understood and apparent (CRO Interview, 2014). A limitation of the data surveyed for this 
case is that the CROs interviewed are all from cities with these capacities already well developed. One CRO noted that it is possible that the resilience evaluations may be useful for less developed cities, a point that would be useful to research in the future. That said, there is clearly room for the redistribution of time resources in 100RC that could be refocused to support connectivity, trustbuilding, and improvement of capacity sharing within the network. As one CRO notes, "in organizations, the key is building trust and adding value..." this is how you participate and gain access to do your own work (CRO Interview, 2015), a point supported by several other CROs (CRO Interview, 2015).

One San Francisco Bay area stakeholder does however note that efforts to develop partnerships around pre-existing earthquake preparedness initiatives have integrated well with 100RC activities, and have supported CRO efforts across the San Francisco Bay area in valuable ways (CRO Interview, 2015). While this is an example of valuable opportunities that can support 100RC's efforts to build on existing capacities, it also highlights the variability of each city's circumstances that can impact an ability to develop a shared story. In the context of organizational learning this represents a challenge of scope and scale.

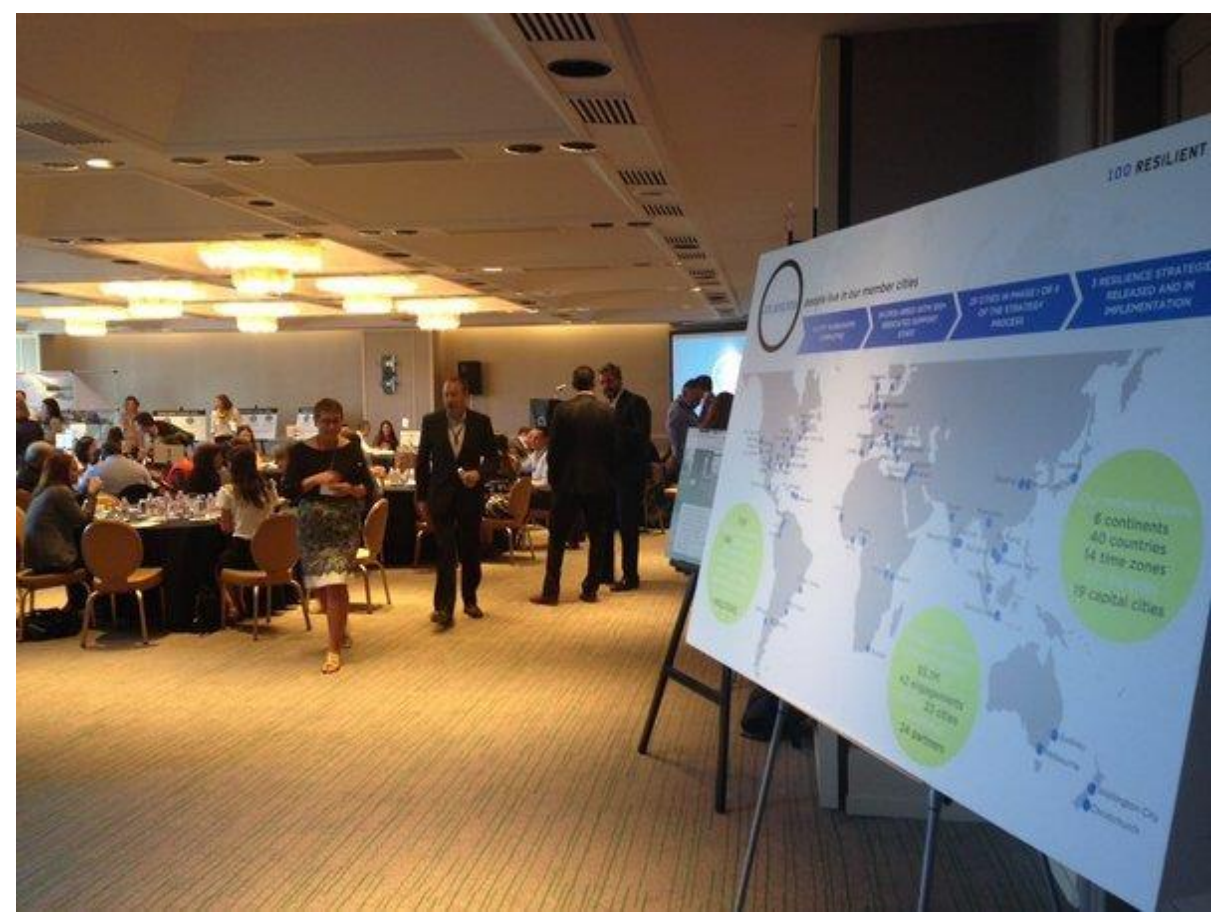

Figure 8. 2015 CRO Summit in Mexico City, Mexico. Image from Olivia Stinson

From one perspective it would be valuable to systematically integrate preexisting resilience efforts into network activities to build on the capacities they already present. This could however quickly lead to personnel resource overload and divert CRO attention further away from network activities. On the other 
hand, CROs could be encouraged to ignore preexisting efforts in favor of drawing on network partners and resources exclusively. In this case the network would lose out on opportunities to learn from these pre-existing programs, and miss opportunities to improve institutional memory and ultimately integrate the existing capacities of an individual city into the broader network knowledge base. A middle ground solution, perhaps on a case-by-case basis could be considered, however this may also be a time intensive option. How 100RC plans to address these areas of difference between cities is a valuable area for future study, as it will significantly influence an ability to develop a shared story and improve overall network capacities.

As an early stage network, 100RC has understandable limitations in its organizational learning capacity and development of a shared network story. There is certainly room for improvement based on several core observations concerning CRO interactions within the overall network. A promising potential for improving organizational learning lies in the Rockefeller administration's apparent willingness to incorporate feedback into decision-making that guides the overall structure and practices of the 100RC organization.

\section{Cross-Scalar Integration}

Cross-scalar integration considers the interactions between actors across and within the various layers of a network. Several common considerations when framing cross-scalar integration include geographic range, group size and constituency (including individuals), cultural roots, socio-economic status, and organizational function. Deciding how to slice and represent these scales differs depending on the conditions and context for analysis. One example of crossscalar integration in 100RC is when a CRO speaks with a relationship manager who collects information about that CRO's city, shares that information with the Rockefeller staff community, and then goes on to share lessons learned with CROs in other cities (CRO Interview, 2015). This example represents information flow between local and global scales, from CROs through relationship managers to the broader 100RC organization.

The following example considers organization type and structure as different scales within the network using the same actors, CROs and relationship managers, as context. CROs work for cities and communicate with government staff and community groups, while relationship managers are connectors between CROs and Rockefeller who work internationally for the Rockefeller Foundation, a private philanthropy. In this case, the city as an organization and a private philanthropy are thought of as different scales. One can also consider 
the information flowing across different geographic regions in the CRO peer-topeer network as a type of cross-scalar integration. A discussion on cross-scalar integration in networks therefore considers a landscape of interactions among stakeholders, where one stakeholder can contribute at multiple scales within the network. Each frame provides different insights and useful information about the network's health and functionality.

One way to consider a network's health is by examining the connectivity between its participants (Björk \& Magnusson, 2009). Network connectivity represents the amount and quality of connections between various actors in a network including communications, capacity, and information sharing. Cross-scalar integration is thus a useful tool for understanding networks as it represents a way to frame connectivity among different types of actors and points to opportunities for these actor's capacities to combine and overlap for action. As Taylor, Whatley, and Coffman (2015) note, the more access network actors have to each other, the less hierarchical the decision making structure, and the easier it is for skills, capacities, and resources to flow across the network.

These are important considerations as collaborative learning networks represent an alternative to the hierarchical decision making structure of top-down organizations by encouraging direct engagement, resource sharing, and action between the lowest tier stakeholders (Plastrik, Taylor, \& Cleveland, 2014). That said, in networks of a reasonable size, actors must have some degree of separation from each other to manage resources such as time and role responsibilities, practical considerations within any organization. The challenge is that networks must foster enough connectivity to support the flow of information and opportunities for creative collaboration, while maintaining enough distinction between scales to maintain functionality. A discussion of cross-scalar integration in 100RC is useful for exploring these lines of difference and connectivity within the network, and points to opportunities for growth, improvement, and future network study.

\section{Cross-scalar Integration in 100RC}

It is important to note that early stage networks, such as 100RC, may not yet present mature examples of cross-scalar integration, as connectivity in the network is still developing. There are however examples of developing connectivity and interactions across scales in 100RC that are worth considering, including a CRO's geographic proximity to other CROs, as well as several factors limiting cross-scalar integration, such as a lack of intercity knowledge sharing through the Platform Partners. The focus of this case study is the CRO peer-to- 
peer network and the following discussion aims to describe cross-scalar integration in 100RC from this lens. Two particular areas that are available for analysis with data collected are CRO interactions across geographic zone, and the international and local connectivity between Rockefeller staff, CROs, and the Platform Partners.

One of the most compelling observations across the CROs interviewed is a tendency to have natural synergies for cooperation and action when geographic zones of operation are shared. This is clear in discussions with CROs in the San Francisco Bay area as well as Rome and Rotterdam who make note of coordination and capacity building between neighboring CROs (CRO Interviews, 2015). One pressure leading to this may be that when cities share geographic proximity they are likely to share certain resilience pressures. For example, earthquakes are a primary resilience challenge for San Francisco, Berkeley, and Oakland all of which share proximity in the San Francisco Bay area. This can provide incentive for intercity cooperation around issues of resilience. One CRO noted this cooperation "in spite" of Rockefeller efforts, implying that these collaborations may be emergent within the network, as opposed to being orchestrated by Rockefeller staff. The CROs interviewed for this case therefore appear to be building trust relationships based upon some degree of shared experiences.

In the case of the CRO peer-to-peer network, this has deep implications for the way CROs communicate across the network and influence its growth. Connecting CRO-to-CRO based on resilience challenges and geographic proximity may be an important step for deepening connectivity within the network. While there is some indication that Rockefeller has fostered connections between cities based on resilience challenges (CRO Newsletter, 2015), these interactions do not appear to be focused on synergies between shared geography and resilience. This natural evolving cooperation between CROs forming around geography and resilience challenges makes this a valuable area for future study.

To further consider cross-scalar integration within the CRO peer-to-peer network it is important to examine the role of relationship managers in facilitating the connection between CROs, the activities of Rockefeller staff, and the capacities provided by Platform Partners. The relationship manager's primary responsibilities are to work with fellow Rockefeller staff in the various branches of the 100RC organization, make suggestions for CRO-to-CRO communications, and to serve as a bridge between CROs and broader network activities. As noted, CROs work on the city level and may have some influence 
on a wider regional scale, but it is the relationship manager that is the principal regional organizer. Additionally, when CROs wish to work with a Platform Partner, they first contact their relationship manager to begin the connection and confirm the appropriateness of the partnership. The relationship manager may then initiate the CRO and Partner connection. Relationship managers therefore serve key roles in maintaining communication structures within 100RC by facilitating its growth and development and supports cross-scalar integration through sharing observations, CRO feedback, and communication with Rockefeller staff (CRO Interview, 2015).

The CROs interviewed also appear to have positive working relationships with their relationship managers, and are appreciative of their work, even while presenting some skepticism about activities in the broader 100RC organization (CRO Interviews, 2015). The direct communication appears to have engendered trust relationships between these stakeholders, and represents an important point of social capital in the network. While this is supportive of connectivity in the network, the relationship manager also appears to play the only active role in engaging the CRO in broader network participation, as most of a CRO's efforts are focused exclusively on their city. Recently however, Rockefeller has initiated several programs to improve CRO partnerships, such as the 100RC Network Exchange Program that brought together CROs from the USA, Europe and Asia. While supportive of CRO to CRO collaboration, these programs have also come quite late in the terms of many participating CROs, leading one to consider how much impact they will have on long-term network activities should these CROs soon discontinue their participation in the network.

There is a dichotomy apparent in this observation. In his or her two-year term, the CRO must conduct a resilience assessment, develop a plan for resilience, and, if applicable, begin the implementation of that plan. Direct CRO-to-CRO interaction across the network comes off as a secondary priority, which is contrary to a core objective of $100 \mathrm{RC}$, the aim of fostering direct city- to-city partnerships through the CROs. The relationship manager provides the major opportunities for CROs to draw on network capacities to achieve project goals. At the present time and based on CRO interviews available, the relationship manager therefore represents a bottleneck in the CRO peer-to-peer network. At least one San Francisco Bay area stakeholder does however note the strength and value of the information available to them, through the CRO peer-to-peer network and capacities provided by Rockefeller staff, in support of their efforts (Chakras, July 2015). 
A key area of concern in developing cross-scalar integration within 100RC is the relationships between CROs and the Platform Partners (Partners). Of the CROs interviewed, most noted that the Partners provide important capacities for their work, but overall, come up as secondary to the CROs activities. The Partners tend to support particular focused and useful projects for the CROs and their cities, ranging from general consulting on resilience to specific community engagement and survey projects. Yet, when their projects are completed, the Partners appear to disengage from the CRO's work unless the city is willing to hire them for additional work. While this is to some extent in line with the goals Rockefeller set out for the Partners as a "marketplace of services," it also represents another uncertain participant within the broader 100RC network, and is therefore not a significant contributor to the underlying capacities of the CRO peer-to-peer network. While this may to some extent be by design, it represents a loss of "energy" or knowledge capital within the network.

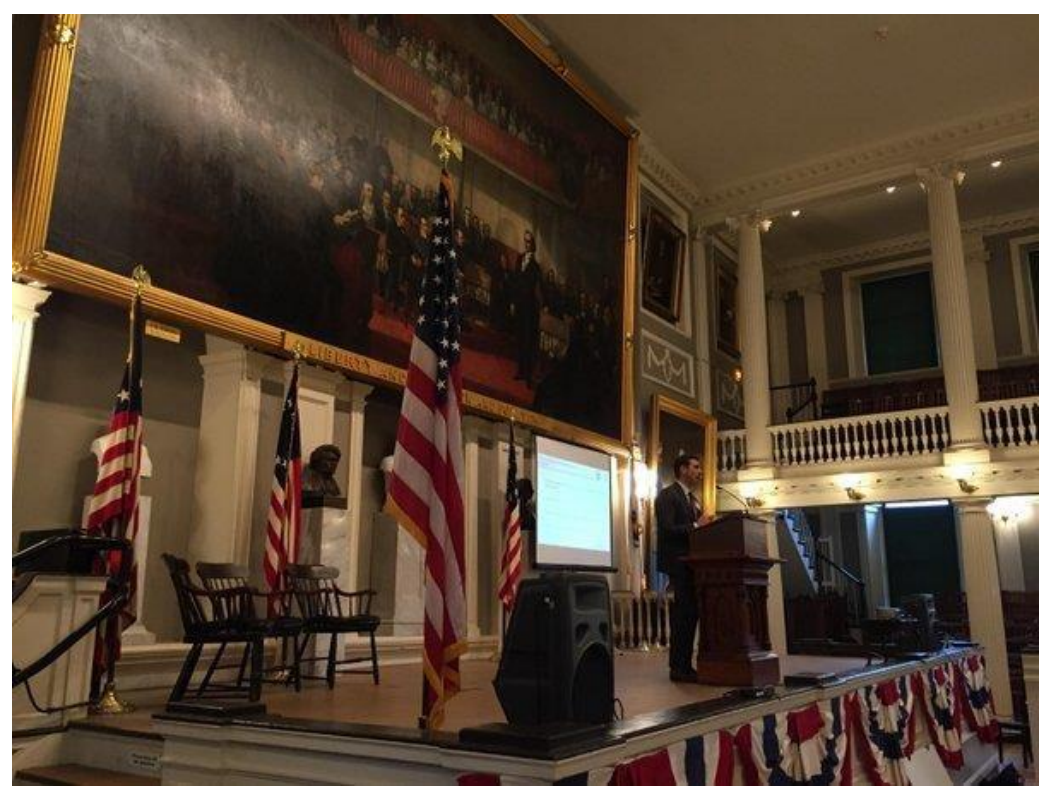

Figure 9. Jamie Torres Springer of HR\&A, a 100RC Platform Partner, presents at an agenda setting workshop for Boston's resilience strategy. Image from HR\&A Advisors (twitter.com/hraadvisors, May 19, 2015).

In the context of cross-scalar integration many of the Platform Partners operate at the global and local scales, work with communities within cities, as well as interact with CROs and the Rockefeller staff. In this way, the Partners link all segments of 100RC and yet are not truly integrated into the network's activities. This represents, at least up to this point in the network's development, a failure to take full advantage of the role Partners can serve in fostering connectivity between 100RC network actors. That said, there is at least one recent example 
of a Platform Partner supporting cross-scalar integration in the network. HR\&A, a Partner for New York City and Norfolk, also facilitated a land use planning workshop between NYC, Norfolk, New Orleans, and Boulder in Spring, 2015. This is one of the first examples of bringing 100RC cities together to discuss a common planning exercise for action across cities utilizing a resilience lens.

It is therefore at the CRO-to-relationship manager point of connection that the majority of communications between CROs and the broader 100RC organization takes place, and currently represents the most effective area of cross-scalar integration within 100RC in the context of the CRO peer-to-peer network. 100RC has additional capacities to draw from that can improve the ongoing development of cross-scalar integration, many of which have yet to be utilized, and is a valuable area for future evaluation and study.

\section{Transformative Capacity}

A primary consideration of this case study is to look for indications that 100RC has fostered a capacity for change that stretches beyond the individual and has empowered new opportunities for collective action. In addition, networks seek to create a community that positively impacts the lives of individuals and thereby influences the inner functioning of the organizations they serve - in essence inspiring transformation. Combined, this is one way to consider the notion of transformative capacity, that through engagement in the activities, projects, and dialog building of the network, members can add to and become part of a system of change that yields "more than the sum of the parts."

The transformative capacity of a network can be further elaborated on and discussed by considering three underlying aspects of the network. The first is connectedness, which considers how well members of a network can access each other for knowledge sharing and action. This includes interconnectedness, or the overlapping connectivity of a network's membership that removes bottlenecks to improve stakeholder to stakeholder communication. Transformative capacity also considers the relationships between network membership and the capacity for building trust and mutual understanding between stakeholders. This second component considers the quality of connections within the network, which are important for generating momentum for collective action and developing a shared network story - thereby supporting the development of institutional memory as discussed in an earlier section on organizational learning. A third quality of transformative capacity looks at a network's ability to influence stakeholders outside of the network's immediate fold, thereby becoming an instrument for social change as a whole. Broadly 
speaking these three components, connectedness, trust-building, and broader impacts, are one way to frame the potential for transformative capacity in a network.

While these components together represent a potential for developing transformative capacity, the ability to ultimately transform, they are not in themselves - transformation. Transformation in this context represents a network's innate ability to react to stresses from within and without in ways that allow it to continue to grow and adapt to changing circumstances thereby supporting the ongoing mission of the network and its stakeholders. This principle is the key difference between transformation and other theories of change such as adaptation or resilience. Adaptation or adaptive capacity is here defined as, "the ability to cope with surprises while retaining critical functions, structures and feedback mechanisms" (Yabes \& Goldstein, 2015). Transformation adds an organismic quality to this concept of adaptation, by considering the ways in which stakeholders collectively guide network decisionmaking, to retrain internal operating structures, and ultimately create impacts that extend beyond the network itself. It is this retraining that sets transformation apart, as it represents a shift in the underlying organizational system in response to pressures, and ultimately guides future decision-making as well as capacity for collective action. Transformative capacity in a network represents the potential for developing this organismic quality, and is why we explore the development of connectedness, trust-building, and the capacity for broader impacts in 100RC.

Seeking to understand this potential in a network is a challenging task as networks are flexible and ever evolving social and organizational structures. They are also usually decentralized, without fixed decision-making centers or command hierarchies, and aim to operate mostly through the connectedness and interconnectedness of its membership. This is not to say that networks should function without centralized operating elements such as steering committees and core leadership, they often do, especially at the early stages, however these operating elements best support a network when they serve to empower the connections and activities of the network membership.

As Plastrik, Taylor and Cleveland (2014) write, "the foundation of generative social-impact networks is the connectivity of its members to each other," (p. 83). These strengths make networks and transformation difficult to study as connectedness exists in a dynamic state, one that can shift easily overtime as network activities shift and change. 
This differs significantly from most top-down organizations that seek to enact decision making at the top through the capacities and activities of actors in lower tiers, and have a more observable command structure when compared to networks. Networks strive for the exact opposite, or at least a strong balance between centralized and broader member-driven decision making processes (Easterling, 2012). They often seek to evolve a structure such that the membership, the "lowest tier" of the organization, holds the reigns for decision making and can influence broader network behavior and action. When considering the transformative capacity of a network, it is this potential, this ability to tie the connectedness of a network to its capacity for action that must be most closely considered. With these challenges in mind, the potential for developing transformative capacity in 100RC can be brought to light through CRO interviews that hint at the state of connectedness and trajectory of the overall network.

\section{Transformative Capacity and 100RC}

In the case of 100RC and the CRO peer-to-peer learning network connectedness for action is quite nascent, a state that makes some sense given the age of the overall network. There is ample evidence, however, that fruitful connections have been made among CROs. While these connections have clearly not attained a "critical mass" that is necessary to sustain long-term network growth and transformative capacity, there is indication that learning and the capacity for deeper connectedness is present. In a joint interview conducted in December 2014 (CRO Interview, 2014), two CROs discuss solutions to administrative and resilience challenges they learned about through the actions of CROs from other cities. The San Francisco CRO notes a resource management initiative in Vancouver that provided insight for a similar solution in the Bay area. The learning opportunity is said to have been made possible because of the CRO network.

These CROs note that it is easier to communicate with fellow CROs that have "gone to war" together through the 100RC development process, than it is to communicate with the broader Rockefeller leadership. There are also strong examples of CROs collaborating in shared geographic zones with shared resilience challenges, as noted in the discussion on cross-scalar integration (CRO Interviews, 2015). These combine to imply that the process of participation in 100RC has helped to foster at least some degree of shared experience among the CROs, a feature that can be supportive of trust-building (Sawyer,

Ehrlichman, Kania, \& Kramer, 2016), connectedness, and ultimately of transformative capacity. 
The CROs interviewed also discuss some of the barriers to communication and connectedness among their peers, which fall into roughly three categories and can work against connectedness and trust-building. The first of these, and the one most commonly discussed, is the nature of a CRO's task and how the majority of professional time is spent focused on their own city, rather than the 100RC network which leads to a degree of isolation from network activities. A CRO's primary tasks include leading resilience initiatives on the ground in their city which includes an evaluation of current programs and potential opportunities, developing a plan for resilience, and interacting with members of their city's government to further and accomplish these aims. Among the CROs interviewed several point to a lack of incentive to participate in the network beyond the requirements stipulated by Rockefeller, mostly due to time constraints and uncertainty about the network's ongoing potential. Alternatively, they do note strong synergies and added value in shared geographic zones as noted in the earlier section on cross-scalar integration. Overall, however, this sense of isolation works against broader network communication and trust-building, and therefore limits the network's potential for developing transformative capacity.

The second category that limits CRO communication and connectedness is a lack of information- sharing capacity. Interviewees note that all CROs can reach out to each other via traditional methods (phone, email, etc.). The problem lies not in an ability to connect, but instead in what is discussed when CROs interact. CROs provide feedback and support directly to one another, at yearly CRO face-to-face gatherings for example, and through the city relationship manager but what appears to be missing are facilitated opportunities for CRO knowledge sharing and capacity development. Rockefeller will support CROs that wish to meet face to face, as one relationship manager states (CRO Interview, 2015), however the network's ability to support knowledge sharing is currently poorly developed, limiting the potential for transformative capacity through underdeveloped opportunities for collaboration - a point that is exacerbated by the CROs nearly exclusive in-city responsibilities.

The third category limiting transformative capacity in 100RC is what can be termed as network "buy in," or the desire to support and participate in the network over the long-term. This challenge stems from uncertainty among CROs around the fate of 100RC after the initial funding period is up, and the fact that many of them will need to fundraise to support the implementation of their resilience plans as well as, in some cases, the salary for their jobs as a CRO. This likely impacts buy-in because of an uncertainty in their own future 
participation in the network, which may last only two or three years, and is complicated by a potentially immense responsibility to self-support that participation. This issue likely compounds the aforementioned connectivity and knowledge sharing issues, impacting transformative capacity by limiting trust and collaborative potential in the overall network.

Transformative capacity of a network can also be considered in terms of broader impacts. This is not the case for all networks, as some are intentionally insulated from the outside and value transformation for its membership exclusively, but it is an important consideration for networks such as 100RC that aim to make broad impacts that extend beyond its fold (Taylor et al., 2015).

100RC and the CRO network are in an early stage of development, and it is common that early stage networks have a short track record of impact. There are however several examples that CROs have pointed to that suggest some degree of impact which extends beyond 100RC activities.

The most salient of these is the opportunity that CROs have to work with numerous branches of city government and regional stakeholders to inspire cross-departmental linkages. In Rome and Berkeley for example, CROs have noted this as a highlight of their positions (CRO Interviews, 2015). CROs state that the role afforded by their position in government has allowed them to link departments together in ways that otherwise would not have occurred, leading to positive outcomes for the city and its citizens. In one example, the CRO of Rotterdam discusses an open and collaborative planning process that he engaged in with colleagues around climate change resilience (CRO Interview, 2015). He notes that his colleagues like that he is bringing "a new lens" to the planning process on issues of resilience and systemic thinking. Several other CROs including those from Rome and the San Francisco Bay area mirror this perspective, and have found opportunities to draw on the knowledge and capacities of 100RC to support similar efforts. There is indication that a CRO's relationship manager supports these efforts through broader, regional partnership building and social networking (CRO Interview, 2015). 


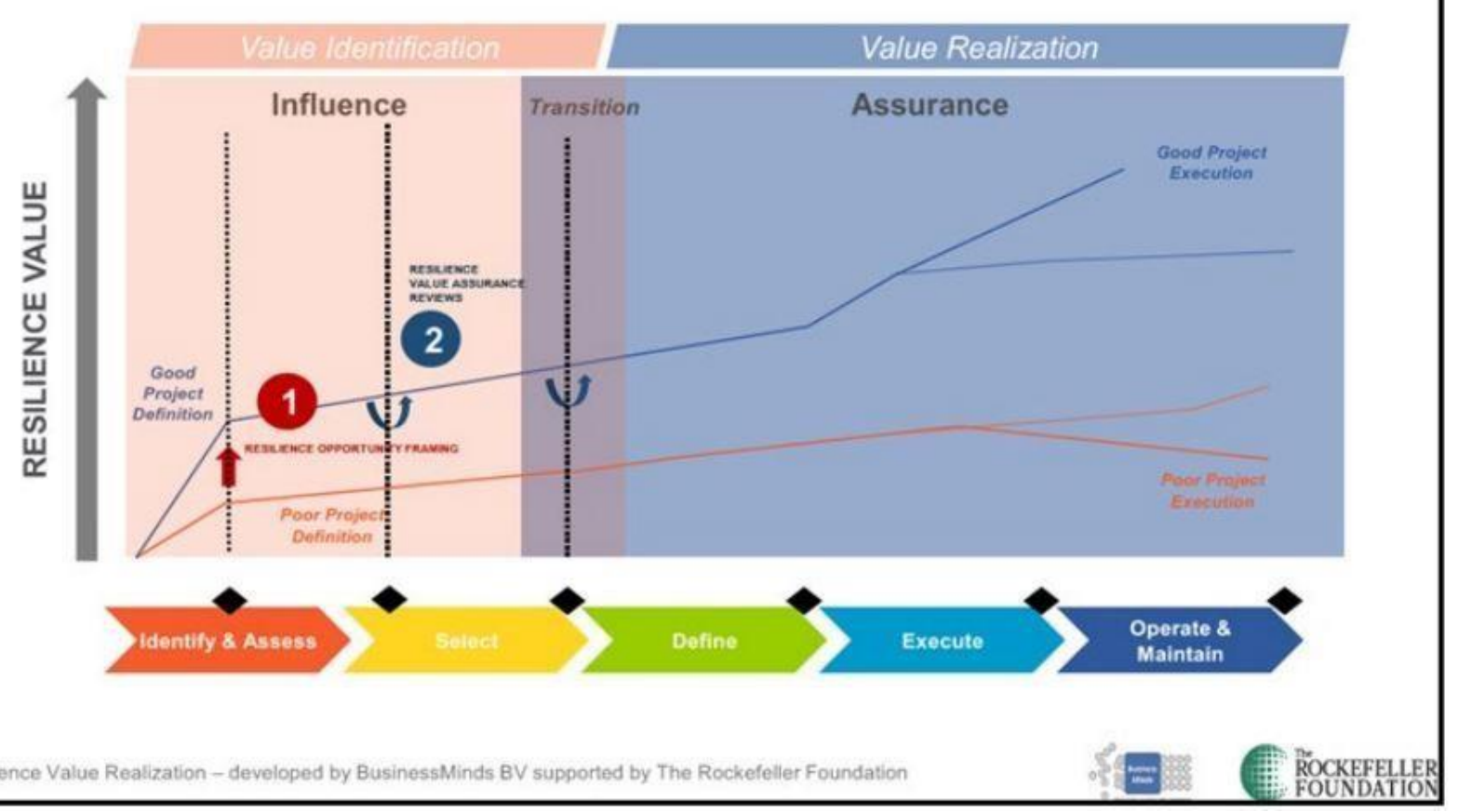

Figure 10. Resilience value mapped over time. Image from Resilience Opportunity Framing Workshop in Norfolk, Virginia (100RC Newsletter, March 2016).

While CROs and Rockefeller staff are fundamental to the CRO peer-to-peer network, a discussion of transformative capacity in 100RC would be incomplete without considering the roles of Platform Partners in network activities and building connectedness. Platform Partners are fundamental to the 100RC mission of providing a marketplace of services for CROs to draw on for their cities. The general reaction CROs interviewed have when asked about the Partners is a mixture of gratitude and dismissiveness. Many are unsure of the role and place of the Platform Partners in their efforts at times, however those interviewed do retell anecdotes from other CROs of very successful Platform Partner interactions. Two common issues come up across interviews: first, the matching of international consultants with local, community-oriented issues, and, second, the isolated nature of Partner's knowledge. Several CROs have suggested that this comes off as "inauthentic," as the consultants are often culturally unrelated to the communities they serve. A second issue is that the proprietary nature of many Partner's knowledge set makes it difficult to share these resources across the network. Though Rockefeller did not conceive 100RC with the intention that Partners would share knowledge across the network, CROs have noted this as a limitation of the Partner's overall role. If this assessment is accurate, as the scope may be limited due to the range of data available, it represents a kind of knowledge and skills bottleneck in 100RC that 
is possibly counterproductive to the network's development. CROs have noted however that the Platform Partners have been particularly valuable in the initial planning and data gathering phases of their terms. In this way the Partners may have boosted the network's potential for transformation, but appear to provide little ongoing momentum to this end.

From this discussion it is clear that 100RC is far from manifesting true transformative capacity, but the potential is there. As noted in the beginning of this section, transformative capacity can be considered from the standpoints of connectedness, trust-building, and broader impacts. In summary, networks aim to provide its membership with opportunities to grow together and influence change in ways that would be difficult for an individual or small group to accomplish alone (Yabes \& Goldstein, 2015), and 100RC is certainly accomplishing this. The greatest barriers to developing transformative capacity in 100RC however appear to come from uncertainty about the network's future and a lack of stakeholder trust or "buy in" within the overall network. With strong funding and institutional support, as well as a highly capable member base, 100RC certainly has the right underlying components and resources to achieve transformation. It is in how these pieces can be realigned and fit together, as well as how the membership is nurtured, that will ultimately determine if 100RC can achieve transformation and its long-term goal of achieving a networked solution to global issues of resilience.

\section{CONCLUSION}

This case study captures the first two years of the 100RC network, focusing on how the emerging network design has enabled and constrained learning, capacity-building, and cross-scalar integration, factors that impact a network's transformative potential. The case of 100RC serves as an example of a wellresourced international network with a diverse and dynamic membership. The study points to the critical emergence of informal infrastructures that promote connectivity and knowledge building that reach beyond the formally designed mechanisms created to connect the organization and its members. Part one has laid out the conceptual origins, early history, and design of the network, while part two has sought to build on these observations to consider organizational learning, cross- scalar integration, and transformative capacity from a netweaving standpoint to lend further insight into the challenges and promise for the future of the network. As a dynamic network, 100RC has changed over the time span in which this case study focused and will continue to change over time. For example, after this case was completed in Spring 2016, an additional 
interview with an 100RC staff member revealed the development of onboarding learning modules for CROs and updated protocols for selecting resilient city members. Additional study and interviews with key stakeholders and netweavers, as well as deeper access to internal documentation could lend further insight into the opportunities for growth and emergent capacities presented by 100RC.

\section{REFERENCES}

100 Resilient Cities (2015). Strategy guidance manual: Developing high impact resilience strategies (Version 1.3). New York, NY: Author.

100 Resilient Cities (2015a). CRO Newsletter (Vol. 5).

100 Resilient Cities (2015b). What is the 100 Resilient Cities Platform Partners? Retrieved from http://www.100resilientcities.org/blog/entry/what-is-the100-resilient-cities-platform-of- partners

Asian Cities Climate Change Resilience Network (ACCCRN) (2013). ACCCRN City Projects: Asian Cities Climate Change Resilience Network. Retrieved from: https://www.rockefeller foundation.org/app/uploads/8ff925b82254-4b71-a7fb-6082464b844e-acccrn-cities.pdf

Berkowitz, M. (2014). What makes a good 100RC application? 100 Resilient Cities Blog. Retrieved from: http://www.100resilientcities.org/blog/entry/what-makes-a-good-100rcapplication 1\#/-_Yz43NTM5MCdpPTEocz5j/

Björk, J., \& Magnusson, M. (2009). Where Do Good Innovation Ideas Come From? Exploring the Influence of Network Connectivity on Innovation Idea Quality. Journal of Product Innovation Management, 26(6), 662-670. http://doi.org/10.1111/j.1540-5885.2009.00691.x

Burness, A. (2015). City staffer 'assisted with and reviewed' consultant's profanity-laden speech. Daily Camera. Retrieved from http://www.dailycamera.com/news/boulder/ci_28217274/boulder-citystaffer-assisted-and-reviewed-consultants-profanity

Crossan, M. M., Lane, H. W., White, R. E., \& White, E. (1999). An Organizational Learning Framework: From Intuition To Framework. The Academy of Management Review, 24(3), 522-537.

Easterling, D. (2012). Building the Capacity of Networks to Achieve Systems Change. The Foundation Review, 4(2), 59-71. http://doi.org/10.4087/FOUNDATIONREVIEW-D-11-00023.1

Holley, J. (2010). Network Weaver Handbook: A Guide to Transformational Networks. Athens, OH: Network Weaver Publishing. 
Lejano, Raul P., Ingram, Helen M., Ingram, M. (2015). Introduction: The Stories Environmental Networks Tell Us. In The Power of Narratives in Environmental Networks (pp. 1-26). Lipper, B. (2015). 100 Resilient Cities. Natural Hazards Workshop. Broomfield, Colorado. O'Toole, J. (2014). The political makeover of a rust belt city. Politico Magazine. Retrieved from http://www.politico.com/magazine/story/2014/02/ pittsburgh-politicalmakeover-of-a-rust-belt-city-103040.

Plastrik, P., Taylor, M., \& Cleveland, J. (2014). Connecting to Change the World: Harnessing the Power of Networks for Social Impact. Island Press.

Retrieved from https://books.google.com/books?id=8BQBAAAQBAJ\&pgis $=1$

Rockefeller Foundation (2015). Resilience. Retrieved from: https://www.rockefellerfoundation.org/our-work/topics/resilience/ Rodin, J. (2013). 100 Resilient Cities. Rockefeller Foundation Blog. Retrieved from: http://www.rockefellerfoundation.org/blog/100-resilientcities

Rodin, J. (2014). The Resilience Dividend: Being Strong in a World Where Things Go Wrong. New York: Public Affairs.Sawyer, D., Ehrlichman, D., Kania, J., \& Kramer, M. (2016). The Tactics of Trust, 61-62. Taylor, M., Whatley, A., \& Coffman, J. (2015). Network Evaluation in Practice: Approaches and

Applications. The Foundation Review, 7(2). http://doi.org/10.9707/19445660.1247

Tosey, P., Visser, M., \& Saunders, M. N. (2011). The origins and conceptualizations of "triple-loop" learning: A critical review. Management Learning, 43(3), 291-307. http://doi.org/10.1177/1350507611426239

Wenger, E. (1998). Communities of Practice: Learning, Meaning, and Identity. Cambridge: Cambridge University Press.

Wenger, E. (2009). Communities of practice: A brief introduction. In J. Holley (Ed.) Network Weaver Handbook: A Guide to Transformational Networks (pp. 270-276). Athens, OH: Network Weaver Publishing.

Yabes, R., \& Goldstein, B. E. (2015). Collaborative Resilience to Episodic Shocks and Surprises: A Very Long-Term Case Study of Zanjera Irrigation in the Philippines 1979-2010. Social Sciences, 4(3), 469-498. http://doi.org/10.3390/socsci4030469 


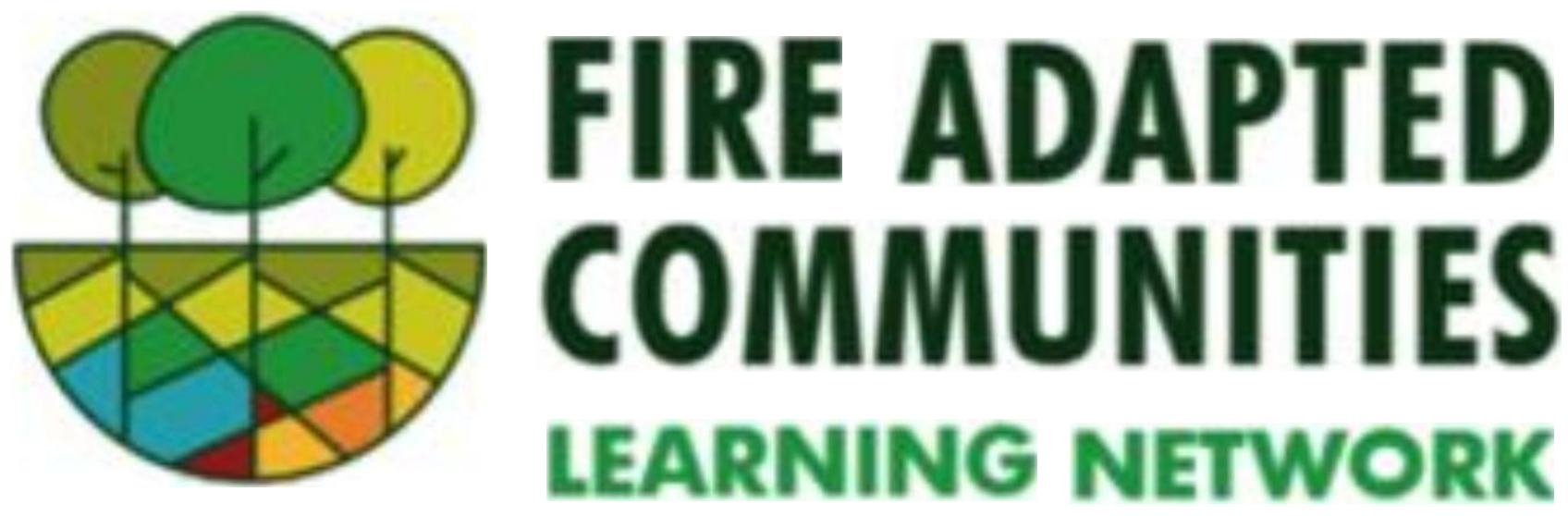

The Fire-Adapted Communities Learning Network

Jeremiah Osborne-Gowey, University of Colorado Boulder

jeremiah.osbornegowey@colorado.edu 
CASE STUDY - THE FIRE-ADAPTED COMMUNITIES LEARNING NETWORK BY JEREMIAH OSBORNE-GOWEY, UNIVERSITY OF COLORADO BOULDER PART 1 - CASE INTRODUCTION AND PROFILE

The Fire Adapted Communities Learning Network (FACLN) is a relatively young learning network (formed in 2013) whose mission is to connect and support people and communities who are striving to live more safely with wildfire. The network strives to spread best practices and innovations in fire-adapted concepts nationwide via collaborations and information exchanges to bring resiliency concepts to bear to help communities respond to and live safely with wildfire, before, during and after. This paper is a case study of the FACLN that examines the network's history, origins and design as well as a number of factors that appear to be important for successful networks (e.g., netweaving, cross-scalar integration, learning and capacity-building, organizational learning, etc.).

\section{Network Origins}

Over the last one hundred twenty-five years, natural resource management in the United States has gone through a number of shifts in thinking, focus and approaches. Today, natural resource management finds itself amidst another period of transition. Early resource management tended to focus on single species or relatively narrow portions of biotic communities. Later, as our understanding of the inherent complexity in natural systems grew, we began incorporating multi- species planning and ecosystem approaches to natural resource management as well as managing for ecological processes. The geospatial, temporal and social complexities of resource management, however, all-too-often overload our institutions and dated policies. Perhaps nowhere is this more apparent than in wildfire management in the United States. Despite calls some 40 years ago by fire, forestry, and biological scientists for agencies and resource managers to abandon blanket wildfire suppression policies and practices and incorporate the dynamics of natural fire regimes into ecosystem management (Pyne, 2004), the budgetary and policy mandate focus "continues to be dominated by fire-related initiatives," many of which are oriented around fire suppression and its related activities (Goldstein, Butler, and Hull, 2010).

In 2001-02, partially in an effort to 1) bring together natural resource managers in a collaborative environment that worked across political, organizational, administrative and ecological boundaries and 2) develop landscape-scale ecological restoration plans in fire-adapted ecosystems, The Nature Conservancy 
(TNC), the U.S. Department of Agriculture's Forest Service (USFS) and the natural resource management agencies of the U.S. Department of Interior (DOI) created the U.S. Fire Learning Network (FLN). The FLN is a collaborative network "designed to change fire management practices by engaging participants in collaborative learning at regional and national scales" (Goldstein and Butler, 2010) while hastening restoration of fire-adapted landscapes.

A new learning network formed in 2013 - the Fire-Adapted Communities Learning Network (FACLN) - partially in response to one of the goals of the National Cohesive Wildland Fire Management Strategy's (National Strategy) of creating fire-adapted communities (WFLC, 2011). Modeled after and integrated with the FLN, the FACLN is a joint effort between TNC, USFS, DOI and stewarded by the Watershed Research and Training Center. According to the FACLN, fireadapted communities are communities in wildfire prone areas that recognize and collaboratively work at multiple scales to build resilience toward wildfire ${ }^{17}$. The objectives of FACLN are 1) accelerating the adoption of fire adapted community (FAC) concepts across the United States using the learning network approach, 2) encouraging the development and sharing of innovation (and its diffusion) across multiple and multi-scalar networks, 3) integrating knowledge across institutions, disciplines, and boundaries to address complex socioecological resource management challenges and 4) providing "a meaningful and efficient feedback loop to the FAC Coalition and federal program leaders to more efficiently and effectively support fire adapted communities" (FACLN, 2013). Where FLN projects often focus on and work from the wildlands toward human communities, FACLN work focuses outward from social (and ecological) communities into the surrounding landscapes.

\footnotetext{
17 In this case, 'resilience' can be thought of as the ability of social and ecological communities to bounce back after wildfire
} 


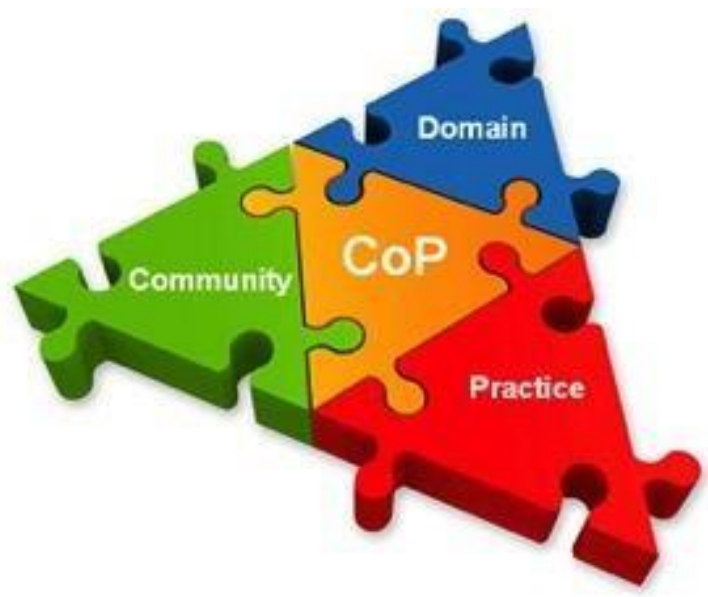

Figure 1. The three primary components of Communities of Practice (CoPs) by Wenger (1998).

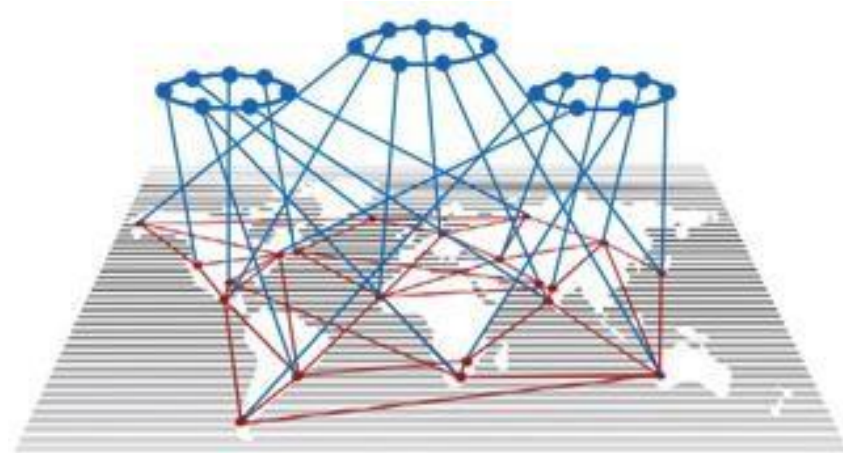

Figure 11. The three primary components of CoPs by Wheately and Frieze (2006).

FACLN, formed as a community of practice (CoP; Figure 1; Wenger 1998) dealing with the social, ecological and economic effects of wildfire while building adaptation and resilience to wildfire.

Similar to CoPs, learning networks often seek to find ways of sharing knowledge and innovation across disciplinary, institutional, administrative, social and geographic boundaries and tend to be self-organized. One of the characteristics of FACLN that distinguishes it from a CoP however, is the more formal structure of relationships, connections and member nodes whereas CoPs may be less formal in nature (see Wheatley \& Frieze, 2006 for an alternative viewpoint). Both the FACLN and CoPs, however, share a participatory action component (e.g., feedback loops), serve the needs of members and the larger community, advance the field of practice and share discoveries with a wider audience (Wheatley \& 
Frieze, 2006). FACLN attempts to accomplish this by a) recognizing the unique socio-ecological circumstances and capacities inherent in each community, b) recognizing the need for unique and variable responses to wildfire and c) encouraging the development and sharing of ideas, innovations and best practices (more on these, below). The FACLN does these to create adaptable and resilient fire-adapted communities while attempting to overcome the challenges, barriers and complexities inherent in fire and resource management.

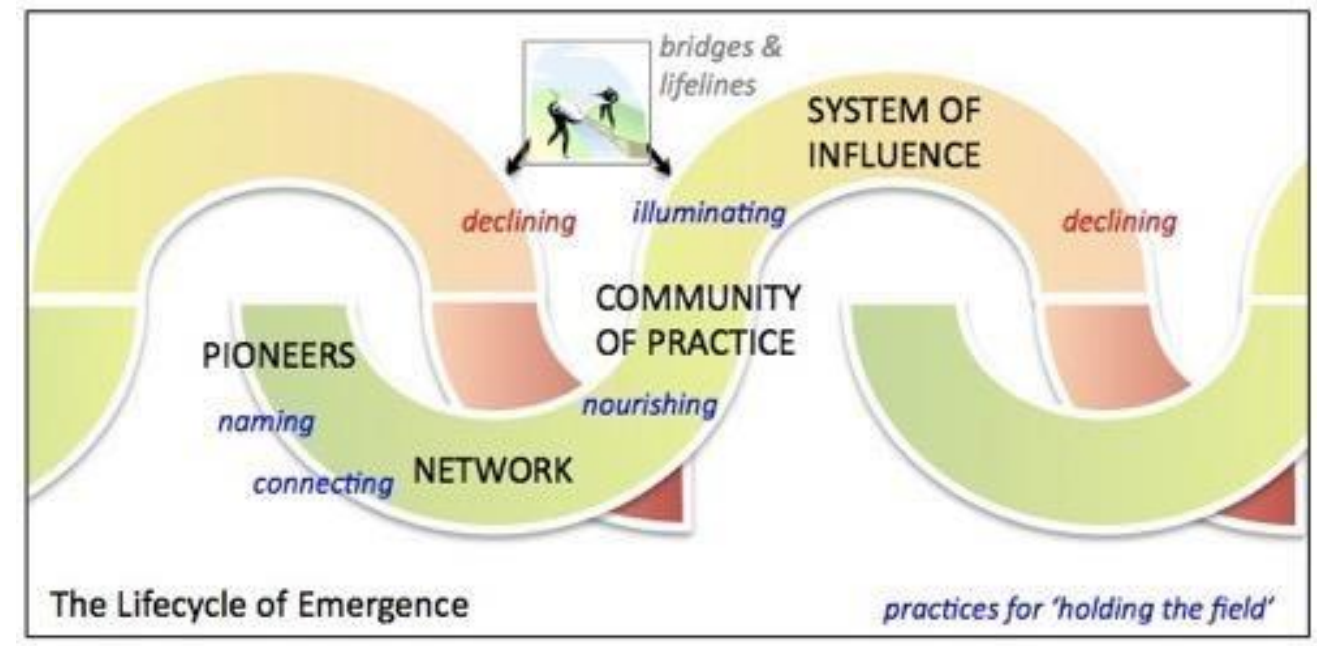

Figure 12. The lifecycle of emergence. Image courtesy of http://www.berkana.org.

The political, budgetary and managerial realities of federal resource management agencies coupled with national laws and policies governing wildfire response, however, can create tensions in local communities struggling for autonomy and agency. This, in turn, can lead to a decoupling of national policies from local responses to wildfires or create tensions in how local conditions (e.g., ecological, social, economic) are addressed during a fire response carried out under the aegis of a federal agency - that is to say, blanket policies and procedures may not be appropriate to or address local conditions and/or needs. The FACLN structure and goals were partially aimed at addressing the need to balance local conditions, autonomy, agency and influence with the broad scale realities of federal resource management agencies as a way to facilitate adoption of FAC principles/concepts.

Each of the partner organizations involved with the initiation of the FACLN recognized opportunities to advance their mission and objectives while partnering with other wildfire-oriented organizations and projects to better raise 
the public's general awareness of the role of wildfire on the landscape while helping communities become better prepared to deal with the effects of wildfire.

The USFS and DOI operate under 'multiple use' mandates and policies and are some of the nation's largest land resource managers. With well over a century of active wildfire suppression and inflated wildfire suppression costs, these agencies are gradually moving away from blanket wildfire suppression policies and tactics, incorporating wildfire into landscape restoration efforts as part of their suite of resource management tools. The Nature Conservancy's mission is to conserve the lands and waters that support human life. They realize their mission by embracing integrity and respect for people, communities and cultures and by working collaboratively on landscape restoration projects. The focus of WRTC efforts are on promoting healthy forests and human communities, achieved via landscape restoration projects. Thus, each of the partner FACLN organizations either has a focus on broad-scale landscape restoration or promoting healthy communities. Because wildfire cuts across each - e.g., restoration and extractive industries, communities, political and geographic boundaries, agencies, local-to-federal budgets, etc. - and the societal and political will is becoming more accepting of the role of wildfire on the landscape, the climate is conducive for the creation of a collaborative learning network that addresses federal policies but gives local communities agency in how those policies and directives are accomplished.

\section{Network Design}

The ecological, social, and political realities of attempting to adopt policies and procedures for managing natural resources and wildfire at the national scale are enormously complex. The FACLN came about as a result of one of the directives of the National Cohesive Wildland Fire Management Strategy (hereafter, Strategy), the U.S. intergovernmental response to the Federal Wildland Fire Management Policy ${ }^{18}$ of 1995 . The Strategy focused on three key areas of wildfire management: restoring and maintaining landscapes, building Fire Adapted Communities, and responding to wildfire ${ }^{19}$. The FACLN is an organized network of self-selected individuals and groups ${ }^{20}$ dedicated to collective action for solving

\footnotetext{
18 The 1995 Federal Wildland Fire Management Policy was reviewed and updated in 2001 and again 2009. For additional information, see:

http://www.fs.fed.us/fire/management/policy.html

19 See the National Cohesive Wildland Fire Management Strategy website for additional information. https://www.forestsandrangelands.gov/strategy/

20 Any individual, group, or community that identifies as and demonstrates "fire-adapted" actions can apply to join the network. More about membership, below.
} 
complex social problems that require considerable time and adaptive capacity to address - a "generative social-impact network" (Plastrik, Taylor, \& Cleveland, 2014).

The FACLN was originally conceived as a network of pilot hub communities in the U.S. interacting together (i.e., collaborative) to share ideas and innovations in a timely and transparent manner to foster innovation and continued learning about fire adaptation. The network was designed to share information (e.g., novel approaches to fire management, what's working in different locales, social capital, etc.) at multiple scales, bridging local, regional and national extents. For FACLN, local refers to a municipality (or unincorporated areas) and its surrounding community or a collection of a few adjoining counties. The FACLN understanding of region loosely refers to the Western, Southeastern, and Northeastern state jurisdictions (see Figure 4). For practical purposes, however, FACLN regions have included collections of counties or adjoining states.

The original network consisted of eight (8) pilot (hub) communities in 201321, "each committed to implementing, assessing and sharing the work they are doing to increase their communities' resilience to wildfire" (see 2015 Evolution Strategies doc). An additional ten (10) communities were added to the network in $2014^{22}$, bringing the total hub organization community membership to eighteen (18; see Figure 4), although Summit County, Colorado was subsequently identified as an affiliate (rather than core) community ${ }^{23}$. Potential network members submit an application to the FACLN to become members. Applications for membership, both the original communities and more recent members, are considered by FACLN leaders based on fire adapted activities each community is undertaking, strength of connections to other fire adapted programs and projects, and commitment "to implementing, assessing and sharing the work they are doing to increase their communities' resilience to wildfire."

\footnotetext{
${ }^{21}$ The initial eight pilot hub communities of the FACLN were Santa Fe, NM, the Lake Tahoe area of California and Nevada, Towns County, GA, the Mid-Klamath region of northern California, Leavenworth, WA, the Rogue Basin in southern Oregon and northern California, Ely, MN, and Woodland Park, CO.

22 The additional ten communities added to the FACLN in 2014 included Deschutes County, OR, Barnegat Township, NJ, Flagstaff, AZ, Southern California, Baker County, FL, Ada County, ID, La Plata, Montezuma and Archuleta Counties, CO, Summit County, CO, Travis County, TX and Island Park, ID and West Yellowstone, MT. http://fireadaptednetwork.org/fac-networkwelcomes-10-new-hub-organizations/

${ }^{23}$ See additional membership discussions below.
} 


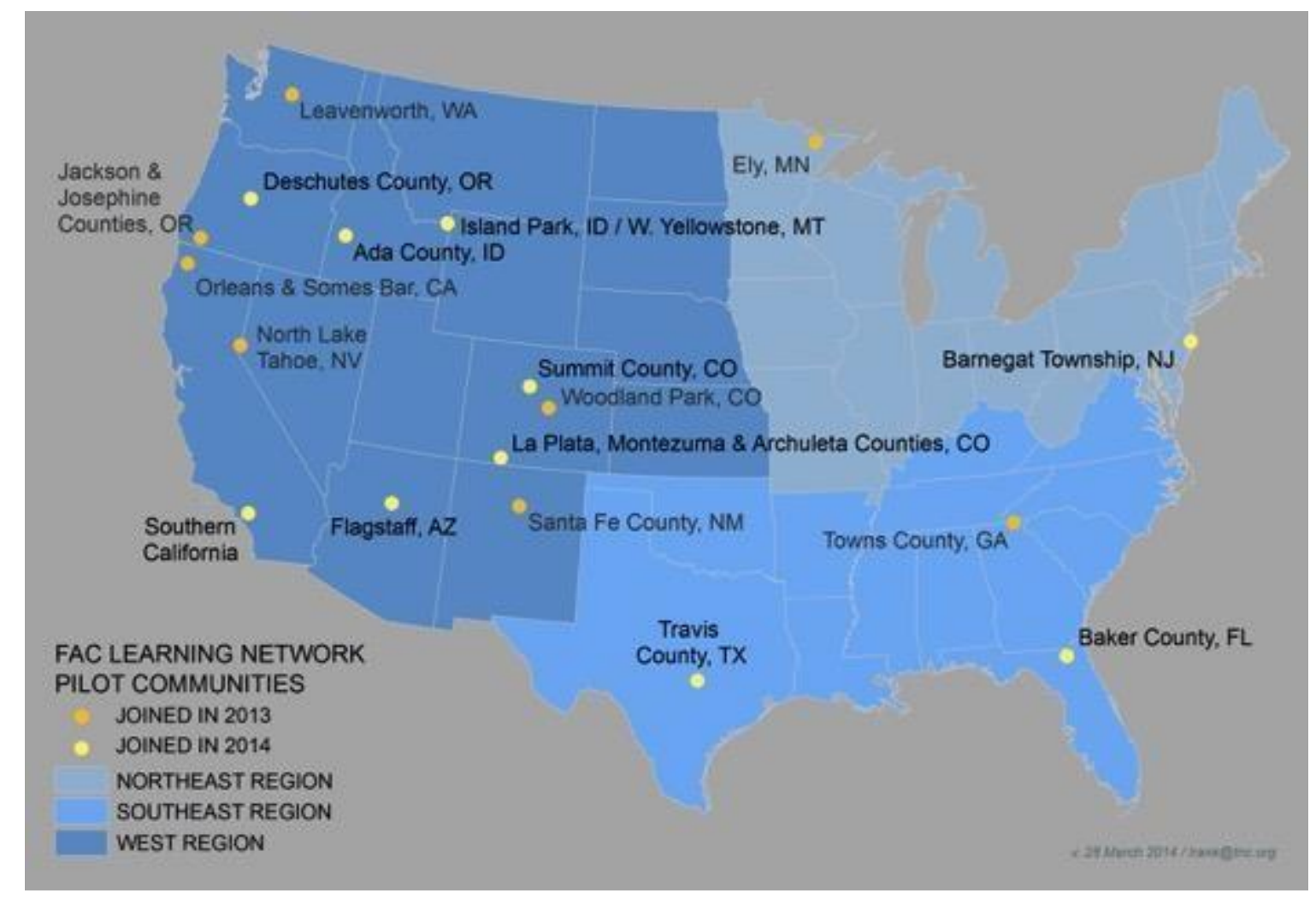

Figure 4. Regions and pilot communities (joined in 2013) in the Fire-Adapted Communities Learning Network (FACLN). Image by Liz Rank, The Nature Conservancy.

Member network communities, comprised of individuals and organizations committed to the goals and principles of the network, are typically identified as counties but can also include cities and municipalities (e.g., Leavenworth, WA and Ely, MN) or other geographic regions (e.g., Klamath Mountains and Lake Tahoe area). Network membership is expanded (i.e., recruitment) by either a) an individual or organization reaching out to the FACLN, self-identifying as 'fireadapted' and demonstrating commitment to sharing their experiences or b) existing FACLN members identifying existing leaders in the field and practice of fire adaptation and resilience, then recruiting them. FACLN membership was originally the same for all members. After two years of operation, and "in conjunction with continued learning from other networks," and realizing some of the hub communities were not launching formal learning networks nor had interest or capacity for expanding their FAC work beyond their original geographic scope, the FACLN leadership (see description, below) adopted two levels of membership: core and affiliate. Core members - by invitation of the FACLN Coordinating Team - actively convene sub-networks, participate in CoPs and develop and share resources related to fire-adaptation and resilience. Affiliate members are practitioners in fire adapted communities, feature their 
work in national forums, and connect with other people working on fire adaptation but may not be building CoPs or expanding the network beyond their primary locale.

Initial funding to start the FACLN came from the Promoting Ecosystem Resilience and Fire Adapted Communities Together (PERFACT), a cooperative agreement between TNC, USFS and the agencies of the DOI ${ }^{24}$ (Figure 5). The network is administered by a Coordinating Team comprised of project managers working at the USFS, the Watershed Research and Training Center (WRTC) ${ }^{25}$ and the Fire Learning Network (FLN) ${ }^{26}$. The FACLN also includes advisers and researchers from other agencies, organizations, and universities that help inform the network about other fire adapted work and programs as well as the latest knowledge about learning network structure and function. Additionally, representatives of the FAC work with the WRTC and the FLN to steer FACLN project work, with members later having a larger role in the steering and direction of FACLN.
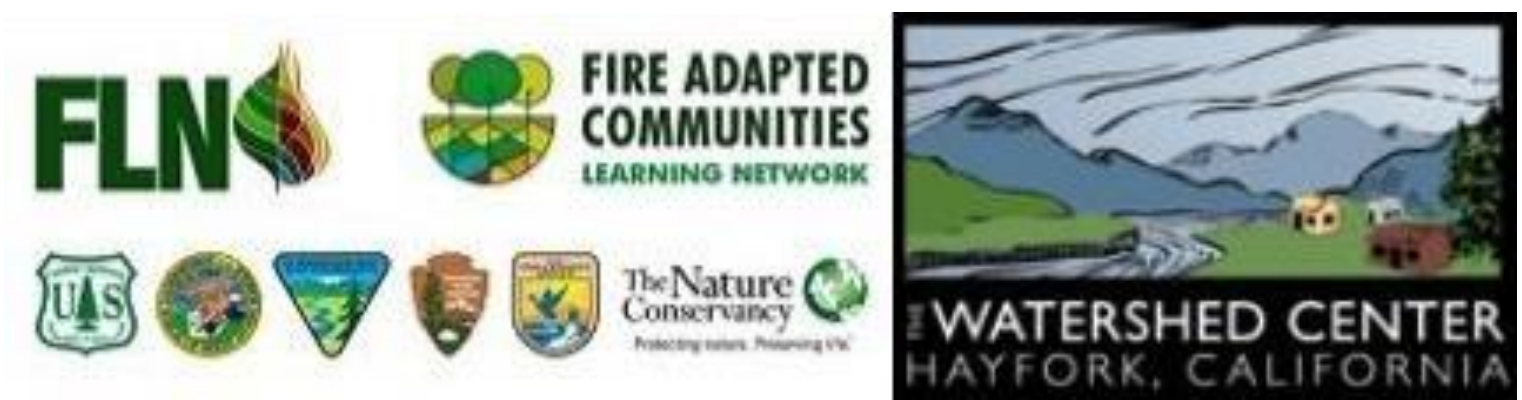

Figure 5. Partners of the PERFACT Cooperative Agreement.

\footnotetext{
24 The goal of the PERFACT cooperative agreement - partnership - is help to help people live with fire via fire adapted communities, resilient natural landscapes, and the social and operational capacity to meet the challenges of a changing fire environment https://www.conservationgateway.org/ConservationPractices/FireLandscapes / FireLearningNe twork/Documents/PE RFACT-LivingWithFire-Jan2015.pdf

25 The Watershed Research and Training Center is a community-based non-profit organization dedicated to promoting healthy forests and communities through research, education and training and based on an ethic of land stewardship and restoration. http: / / www.thewatershedcenter.com/

26 The Fire Learning Network (FLN) is a joint project of The Nature Conservancy, the USDA Forest Service and several agencies of the US Department of Interior and is focused on accelerating the restoration of landscapes that depend on fire to sustain native plant and animal communities as a means to restoring a balance between ecological, economic and social values -

https://www.conservationgateway.org/ConservationPractices/FireLandscapes/FireLearningNe twork/Pages/fire- learning-network.aspx
} 
The role of the Coordinating Team - comprised of the WRTC, FLN managers and FAC program leads - is to leverage existing wildfire resilience efforts outside the FACLN, provide technical guidance and support to sub-regional member leaders and communities, help with document curation and learning, and aid in subregional workshops. In some cases, FACLN communities that share a common geography coordinate efforts and learning at a sub-regional level. Sub-regional network hub leaders - not part of the Coordinating Team but integral to the network function - typically work within their geographic regions to facilitate and convene learning exchanges and workshops with other organizations, institutions and projects working on fire adaptation. Sub- regional network hub leaders also work closely with the Coordinating Team to pass along or incorporate new knowledge into the network (more on this, below).

One of the original goals of the FACLN was for member partners to facilitate the development of sub-regional peer learning networks to accelerate the adoption of wildfire resilience 'best practices.' Two years in, and at the behest of FACLN member requests, members of the FACLN Coordinating Team established several new Communities of Practice (CoPs) to help facilitate and "advance the innovation and sharing of best practices related to priority community wildfire resilience topics" (i.e., peer learning) ${ }^{27}$. Peer learning and information exchange within FACLN occurs primarily through regular convening and facilitation of sub-regional workshops and learning exchanges and, more recently, via the networking in the new CoPs. The FACLN project managers would participate in these sub-regional workshops and exchanges, aggregate best practices and learning, then share results with the larger FACLN community at annual meetings held throughout the country in various member network communities.

\footnotetext{
${ }^{27}$ For a list of the focal areas and communities of practice, see the FACLN webpage: http:// fireadaptednetwork.org/focus-areas/
} 


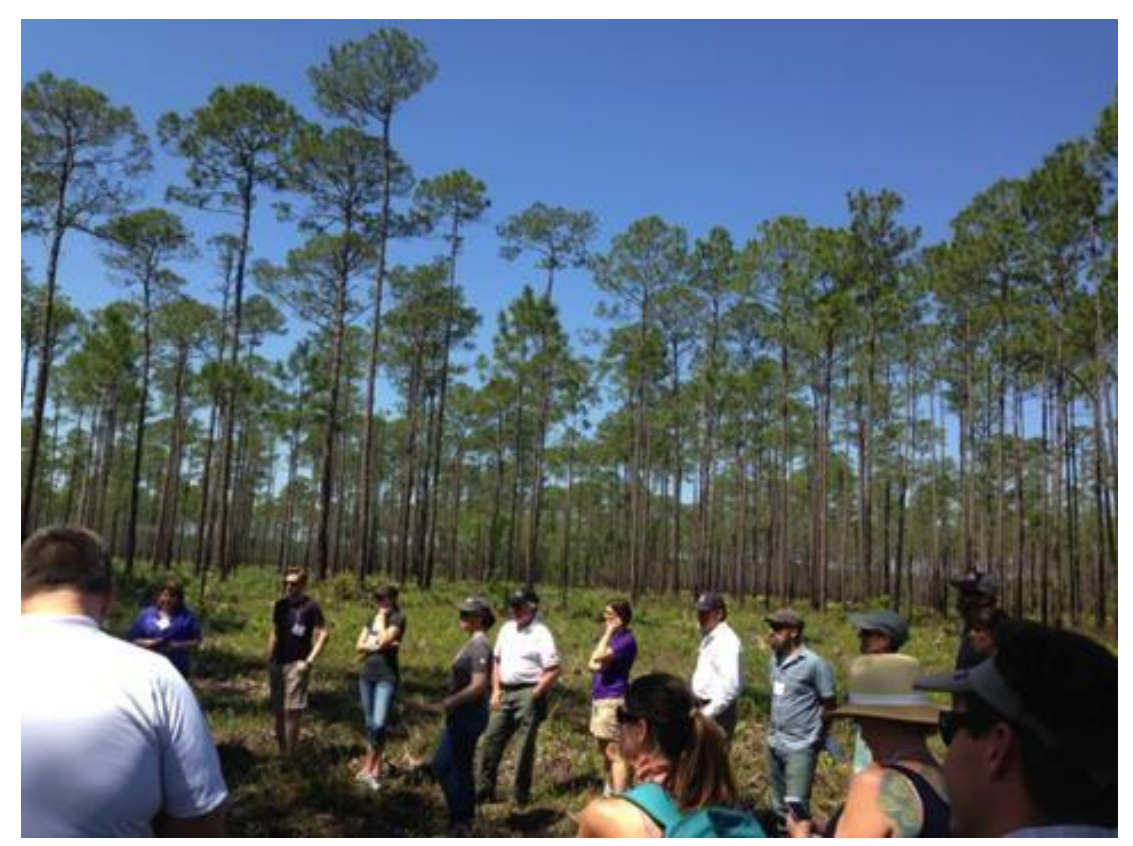

Figure 6. Fire-Adapted Community Learning Network members participating in a prescribed fire learning exchange in Baker County, Florida in 2016. Image from http://www.fireadaptedwashington.org/.

FACLN projects are primarily carried out at the sub-regional and local scales with members championing wildfire management projects relevant to the needs and realities of the area. Yet the administrative and management structure of the network - with direction and leadership from various agencies, organizations and from regions across the U.S. and the intentional focus on building communities of practice and sharing learned knowledge and experiences with members of the broader network - would seem to lend itself to more effective operation at differing temporal, organizational and jurisdictional scales. Additionally, having a funded team focused on document curation and learning, facilitating exchange of information with other members of the network, and facilitating partnerships of members with other wildfire adaptation and resilience projects/groups may be one of the keys to the success of the network realizing its objectives and working toward transforming wildfire management. 

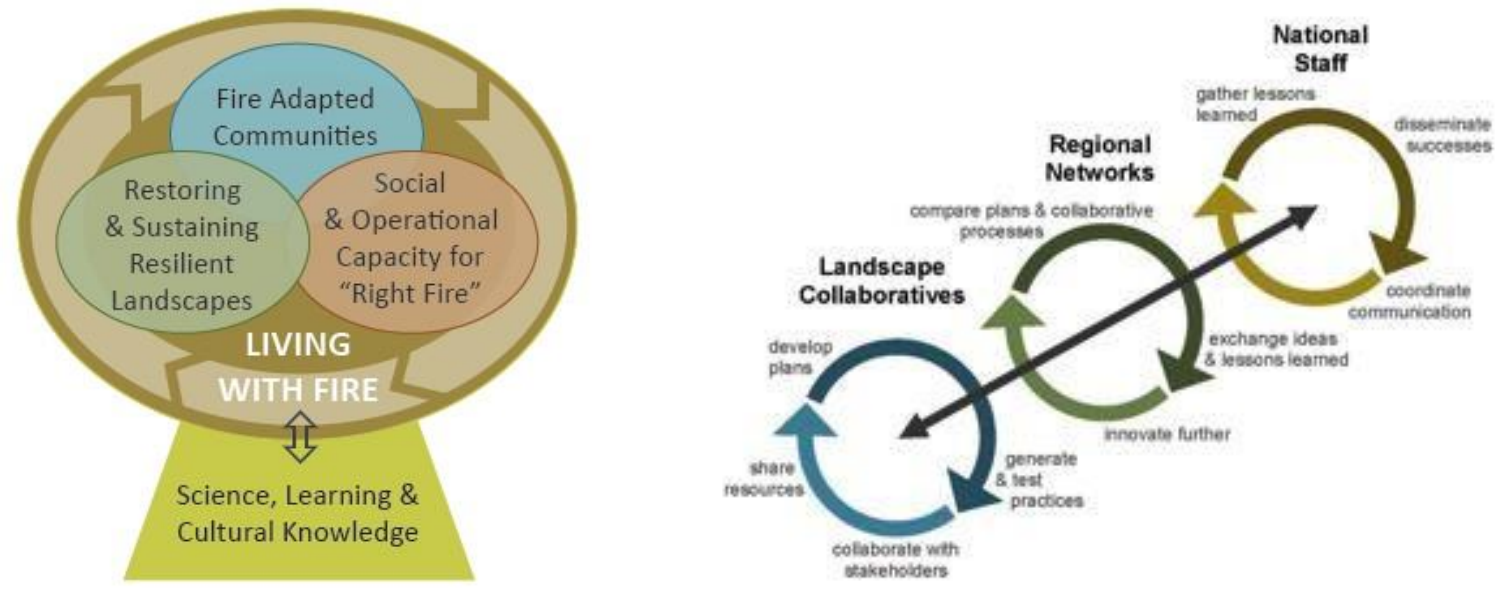

Figure 7. Typology and organizational structure of the Fire Adapted Communities Learning Network as outlined in the PERFACT Cooperative Agreement.

\section{Network History}

In late 2012 and early 2013, the FLN and WRTC worked with the FAC Program, USFS Cooperative Program leads, and the FAC Coalition lead (the National Fire Protection Association; NFPA) to develop the concepts of the FACLN, set preliminary goals, reach out to and select potential hub communities, and determine initial hub community disbursements. Officially launched at a cooperative, inter-organizational meeting at the Banner Bank Building in Boise, Idaho on April 10-11, 2013, the FACLN sought to accelerate the growth of fire adapted communities across the U.S. in much the same way the FLN used the interactive and in-person model to advance the restoration of fire adapted ecosystems across the U.S. Supported by the Promoting Ecosystem Resilience and Fire Adapted Communities Together (PERFACT) ${ }^{28}$ project - a cooperative

28 Rooted in collaborative efforts with emphasis on co-learning and adaptive management, the Promoting Ecosystem Resilience and Fire Adapted Communities Together (PERFACT) cooperative agreement strives to integrate industry best practices and the best available science and cultural knowledge to help people live with fire via "fire adapted communities, resilient natural landscapes, and the social and operational capacity to flourish in a challenging, changing, fire environment"

(https://www.conservationgateway.org/ConservationPractices/FireLandscapes/FireLearningN etwork/Documents/PE RFACT-LivingWithFire-Jan2015.pdf). For additional PERFACT information, see https://www.conservationgateway.org/ConservationPractices/FireLandscapes/FireLearningN etwork/Documents/PE RFACT_June2015.pdf. 
agreement between TNC, USFS and agencies of the DOI [with a sub-award to the WRTC] - the FACLN sought to adapt the FLN model and, in coordination with the FAC (of which it is a member network), the USFS, the WRTC and the NFPA, leverage and integrate with existing and ongoing fire adaptation efforts.

Originally consisting of eight (8) pilot hub communities at its inception with an additional ten (10) hub communities added in 2014, criteria for inclusion in the FACLN as a hub organization/community included:

Existing organizational capacity, a strong fit with the existing organizational portfolio and mission, existing pertinent staff capacity, proven experience convening outcome- and productoriented workshops, pay-it-forward culture, technical assistance capacity, a culture of innovation, an existing sub-regional network, and a culture of learning (FACLN internal document, 2014).

Thus, considerable emphasis for the FACLN was on leveraging and integrating with proven resources, organizations and networks to help communities embrace resiliency concepts about wildfire and induce action before, during and after wildfires.

In 2015, after nearly two years since its inception and as part of the FACLN's objectives of remaining a nimble organization, the FACLN solicited directed feedback from network members about their perceptions of network effectiveness and areas where the network could bolster or shift network resources. In response to this member feedback, the FACLN reoriented its membership structure, developed additional feedback mechanisms between members and the Coordinating Team, adopted a "collective value proposition" (we help society live safely with wildfire) ${ }^{29}$, and established seven (7) CoPs "to advance innovation and share best practices related to priority community wildfire resilience topics"30. The CoPs are core member-driven and may include experts from outside the network. These new CoPs include: community wildfire protection planning, engagement and communication, network building, (forest thinning and fuels) treatment economics, community of practice for using fire, watershed management, and working with landowners/homeowners. The CoPs

\footnotetext{
29 In June of 2015, the core members adopted a "core value proposition" to be accomplished by Network members. Additional information about how this is accomplished at http://fireadaptednetwork.org/about/network-members/.

30 Find more information about the seven FACLN focus areas at http://fireadaptednetwork.org/focus-areas/.
} 
are core member-driven and can also include experts from outside the network. Each of the CoPs has their own norms and ways of interacting with others yet each is dedicated to collaboration across member projects and sharing resources, ideas, needs and best practices.

Given the organization is still relatively young, there have been no major personnel changes - the administrative and managerial structure of the network remains essentially as it was at its inception in 2013. What has changed, however, is the way in which member organizations and communities help steer the direction of the network. Steering of the network was originally the work of the Coordinating Team along with advice from expert leaders of the founding organizations and programs. Results from the member-driven organizational assessment, however, indicated a desire among network members to have a say in direction of the network. This "self-evaluation" is essentially the third learning loop (learning about learning) in triple-loop learning (Tosey, Visser, \& Saunders, 2012) and illustrates the network's desire to be both nimble and to learn from its members (described in greater detail, below). In addition, this process illustrates the network's capacity for adaptation, making organizational change possible.

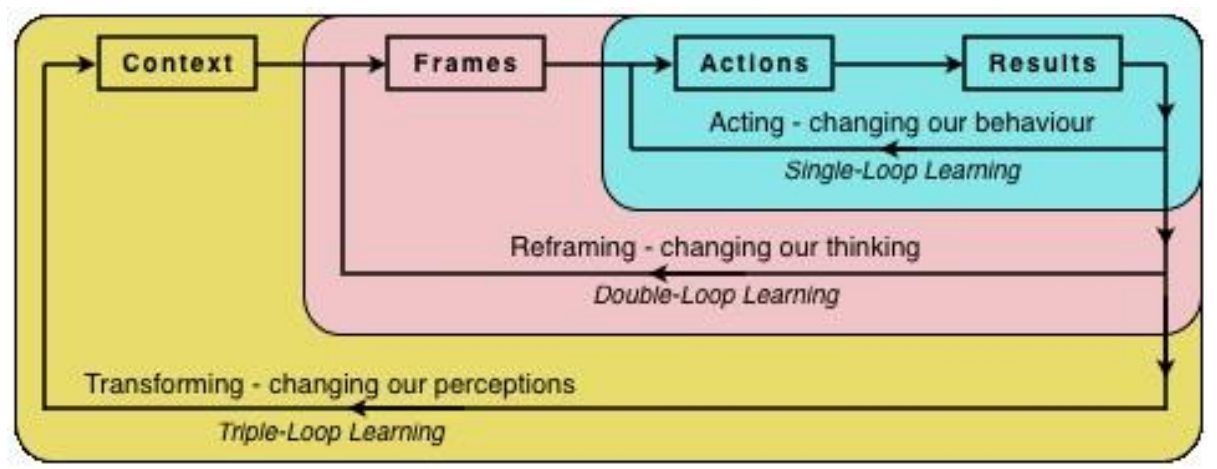

Figure 13. Illustration of triple-loop learning as it relates to transformation. Image courtesy of http://www.mentoringforchange.co.uk.

Growing and sustaining the network is approached primarily using two methods: network members recruit other members while the Coordinating Team actively recruits potential new members. Coordinating Team and the WRTC provide substantive technical expertise and support resources to member communities to help them accomplish the goals of the network and its members. FACLN members, by and large, already ascribe to many of the values/goals of the network before "buying in" to the network. Having resources provided by the network to carry forth the messages of fire adapted communities to others namely that it is possible to live with fire - essentially acts as a positive 
reinforcement for existing energy and enthusiasm of FAC principles. Conversely, members of the Coordinating Team, with input from their interactions with FACLN members and others outside the network, actively search for experts and leaders in the field and recruit them to join the network. Thus, membership is driven both at the local and network-wide scale.

While the FACLN is still a relatively young network and enjoys a fairly high level of enthusiasm and participation, the Coordinating Team recognized the need to prioritize resources to active network members. Thus, in 2015, the network developed two different member participation levels: core and affiliate. This relatively minor organizational change resulted in the ability to prioritize limited network resources toward members (and member projects) actively engaged in the network and seeking to expand it.

\section{Netweaving}

Primary funding for the FACLN comes from the USFS and Fire Adapted Communities Coalition (FAC) via the Promoting Ecosystem Resilience and Fire Adapted Communities Together (PERFACT) ${ }^{31}$ project - a cooperative agreement between TNC, USFS and agencies of the DOI (with a sub-award to the WRTC). The PERFACT funding runs through 2019 and comes primarily $\mathrm{n}$ two forms: paying staff and project awards. Financial awards from the network to member projects are selected by the Coordinating Team after review for alignment with network goals/objectives, effectiveness, and accountability. Additionally, considerable support for the network comes from participating members and member networks in the form of in-kind contributions (e.g., resources, time, equipment, etc.). This leveraging of additional resources by the network with network-funded projects also achieving objectives of other non-network projects and programs results in a network providing considerable value to its members while building support for adoption of fire adaptation and resilience.

While there is accountability to the funders and some of it appears to happen almost naturally - owing in part to PERFACT staff serving in administrative and leadership capacities for the network as well as serving in positions for other member networks and organizations (e.g., USFS, TNC, WRTC, etc.) - there have been some internal tensions about exactly what and how to remain accountable

\footnotetext{
31 The PERFACT project supports two learning networks, the FLN and the FACLN. For additional PERFACT information, see

https://www.conservationgateway.org/ConservationPractices/FireLandscapes/FireLearningNe twork/Documents/PE RFACT_June2015.pdf.
} 
to the funders. The multi-function staff roles, however, allow for semi-regular conversations between partners and staff who are intimately familiar with the FACLN and its projects and may serve as a "check-and-balance" for the FACLN and its funders. Additionally, TNC files regular and ongoing updates to the funder (USFS) as well as prepares semi-annual reports ${ }^{32}$.

Given the collaborative nature of the network and the emphasis on sharing experience, expertise, resources and knowledge, it comes as no surprise there are no shortage of netweavers within the FACLN. Network weavers, or netweavers, are individuals who are aware of and connected to the networks around them, identify mutual interests and challenges, strategically connect people to address interests and challenges, and generally work to make the networks more robust (Holley 2012). In many ways, a netweaver serves as a catalyst for self-organizing groups.

Not surprisingly, there are several members on the FACLN staff acting as netweavers. For example, the Program Manager for Networks and Development, Wendy Fulks, regularly connects with members and writes blog posts that summarize experiences and successes that connect members across the broader network. While not carrying out any of the awarded projects, the FAC Network Program Associate, Emily Triosi, works to keep members connected with each other and with outcomes from the various projects and member communities by providing multiple venues for group work. Triosi also organizes and shares key organizational documents, curates important network documents and files ${ }^{33}$ and helps facilitate monthly and quarterly network member conference calls. More broadly, the Director of the North American Fire Learning Network - Lynn Decker - is well connected to many fire-adapted and resilience networks, projects and people across the nation and actively works to connect members and projects across various networks (e.g., FLN, FACLN, FireWise, FAC, Ready-Set-Go!, etc.). Additionally, while also an employee of TNC, Decker serves in an advisory role to the FACLN Coordinating Team, amplifying the collaborative value of the partner network connections. Thus, while a netweaver is often thought of in terms of working at the over-arching or meta-

\footnotetext{
32 See a copy of one of the semi-annual reports to the USFS regarding PERFACT funding: https://www.conservationgateway.org/ConservationPractices/FireLandscapes/FireLearningNe twork/Documents/ PE RFACT-Report-Jan2015.pdf

33 The FACLN maintains an updated and responsive website (http://fireadaptednetwork.org/) as well as managing an active and robust, Podio site - an online cloud-based collaborative productivity tool for organizing teams and group work in a focused, clear and effective manner. More about Podio at https:// podio.com/.
} 
level, in many ways, netweaving is occurring at various levels within the network.

Evaluation of a network is important for understanding the structure, function, characteristics and relationships to assess whether network goals are being met and if not, why and how to make a course correction(s). Evaluation of the FACLN occurs on multiple fronts. The most common evaluation occurs almost informally and at small (e.g., sub-region) scales with FACLN administrators regularly checking in with members and member-awarded projects. These check-ins serve two primary purposes - accountability of the project to the network (e.g., sharing outcomes and knowledge) and ensuring the network is providing the resources needed to carry out the projects (e.g., collaborations, networking, knowledge sharing and learning, etc.). At the regional scale, informal network evaluation occurs when members host and/or participate in semi-annual workshops and training exchanges. These gatherings provide informal opportunities for members to discuss the network, evaluate its effectiveness and identify areas where the network might serve a broader purpose. At the network-wide scale, the annual meeting of FACLN members serves as a key waypoint for members from across the network to share experiences and expertise while allowing the Coordination Team the chance to hear how members view and participate in the network. More recently, in 2015, the Coordinating Team undertook an effort to survey members and member organizations about how they viewed the FACLN and areas where the FACLN could improve. This formal, network-wide evaluation process resulted in the Coordinating Team opening up the steering of the FACLN to members (steering of the network had previously just been done by the Coordinating Team) as well as the adoption of 14 new operating principles from core network members.

\section{Learning and Capacity Building}

There is some speculation about the ability (and capacity) of "local" communities to adequately and nimbly address complex resource management issues (Bradshaw 2003). Yet, a substantial body of literature indicates communities can respond to endogenous and exogenous variables and changing circumstances while fostering learning and building capacity for effective adaptive management of natural resources (Armitage 2005; Plummer and Armitage 2007; Foster-Fishman et al., 2001). In the absence of much literature on transformative capacity, however, I focus the discussions here on building collaborative capacity as a key component of learning and capacity building and (necessary?) pre-cursor to change and transformation. 
In a review of 80 articles, chapters and practitioners' guides, Foster-Fishman et al. (2001) found four "critical" levels of collaborative capacity: member capacity, relational capacity, organizational capacity, and programmatic capacity (see Table 1 in Foster-Fishman et al., 2001). Here I use these levels to analyze FACLN from the perspective of learning and capacity building.

Foster-Fishman and colleagues (2001) suggest member capacity is the extent to which members "have the capacity to perform needed tasks and work collaboratively together" and includes existing skills, knowledge and attitudes that "build, support and access this capacity." Relational capacity, as defined by Foster-Fishman and colleagues (2001), the ability of members to facilitate positive internal and external relationships. Organizational capacity, according to Foster-Fishman and colleagues (2001), is the ability to "engage members in needed work tasks to produce desired products" and requires 1) strong leadership with diverse skillsets, relationships and vision to "transform individual interests into a dynamic collective force that achieves targeted outcomes," 2) formalized processes and procedures, 3) "well-developed internal communication systems that promote information sharing and problem discussion and resolution," 4) "human and financial resources to perform collaborative work," and 5) "continuous learning orientation" that includes feedback and evaluation loops that adapt to changing conditions. FosterFishman and colleagues (2001) define programmatic capacity as "the capacity to guide the design and implementation of programs" that either initiate or catalyze changes that have meaningful impacts in relevant communities via promotion of culturally competent coalitions. FACLN displays a number of characteristics and capacities from each of these four "critical" collaborative capacity areas.

First, given one of the focuses of the network is to draw upon existing CoPs and not "reinvent the wheel," FACLN members largely already possess substantial core skills, knowledge and attitudes in at least one professional area related to wildfire (or have demonstrated commitment to build those skills and knowledge base). For example, many of the FACLN communities include active partnerships with local fire departments, elected city and county officials, local natural resource managers located in the area (e.g., USFS, BLM, State agencies, etc.), local fire safety councils and private forest/land management businesses, and existing programs in the area that routinely deal with fire (e.g., Firewise). Additionally, FACLN members largely possess similar attitudes or - at the very least - motivations about dealing with wildfire (e.g., reduce risk of property/life loss, enhance ecosystem function, etc.). These common attitudes serve as a sort of metaphorical glue for keeping 
the community together (and developing it) broadening the adoption of fireadapted principles. The local homeowners associations in the Island Park Sustainable Fire Community (one of the 17 FACLN communities nationwide) are primarily interested in participating in FACLN as a way to realize decreased risk of property loss from wildfires whereas the local USFS managers are primarily interested in decreasing loss of human life in the communities while allowing historic fire regimes help restore ecosystem function (Interview: Liz Davy, 2015).

Second, as a way to sustain, grow, adapt new strategies and partnerships to build increasing capacity over time ${ }^{34}$, effective FACLN managers are supposed to foster relationship building (i.e., relational capacity) between its members and members of other wildfire-related CoPs. Indeed, one of the primary roles of the network is in serving as a "netweaver" to "work directly with the network participants to foster connections among them" 35 . According to a FACLN brief ${ }^{36}$, one of the primary lessons learned during their short time as a network is that "funding a local coordinator is essential" to the success of that FACLN community. While this local coordinator may not serve all the functions of a fullscale netweaver, their role is essentially that of a netweaver at the local scale. Additional inter- and intra-relational capacity within the network is continuously being built cultivated formally by coordinators and netweavers actively reaching out the community and potential partners (inter-relational), and regularly bringing together regional and national FACLN members (intrarelational) for workshops, training sessions and annual conferences.

Additional relational capacity is built via the development and revisiting of a shared vision and key operating principles (as happened during the 2014-15 network internal review and feedback process) and valuation of individual and group differences. That is to say, FACLN recognizes and actively embraces that each community brings different knowledge, values and circumstances to the fire adaptation table and there is no single recipe for fire adaptation. Though many communities already have Community Wildfire Protection Plans in place, others are not yet at the point of creating wildfire plans or do not yet have the capacity. FACLN works to build relational capacity by connecting people working on wildfire adaptation and resilience in communities to each other and

34https://www.conservationgateway.org/ConservationPractices / FireLandscapes/fac/facnet/ Pages/default.aspx

35 For a more thorough treatment of what FACLN is, its roles, and members/partners, see the FACLN Field Guide: http://fireadaptednetwork.org/wp-content/uploads/2016/03/FACNetFieldGuide-Jan2016-01.pdf 36 http:/ / fireadaptednetwork.org/wp-content/uploads/2015/12/Brief_FACNet-Oct2015$1 . \mathrm{pdf}$ 
empowering and supporting the communities in developing plans to manage their preparation and response to wildfire.

Third in Foster-Fishman and colleagues' 2001 list of key components of collaborative capacity, the FACLN demonstrates organizational capacity. The steering of FACLN demonstrates effective leadership and communication at multiple levels throughout the network - from the coordinating team to the community leaders. Despite only being a network for about three years, FACLN membership has more than doubled since its inception. While some of the growing membership is likely due to excitement and shared vision of many throughout various fire-adaptation related CoPs, FACLN leaders have helped move the FACLN progress and learning within FACLN forward. This leadership and network learning was illustrated during a recent, internal, network evaluation effort.

In 2015, FACLN leadership - recognizing that members wanted to have more of a say in the steering of FACLN - put together a survey of members to assess what they felt was working, what was not working, and the future of the network. While not an evaluation of the network in the classical sense of the term, FACLN leaders - in an attempt to keep the network nimble and response to changing member conditions - recognized and responded to the needs of its members (i.e., leadership and learning epitomized). In another show of leadership and learning, the FACLN adopted an additional fourteen (14) core member-driven operating principles in 2015 (from the original founding five [5] principles) and consider the principles "a work in progress," informed largely by membership and addressed as changing conditions necessitate; illustrative of Foster-Fishman and colleagues' "continuous improvement orientation" and robust internal communication system with feedback mechanisms (2001).

Foster-Fishman and colleagues' (2001) fourth critical component of collaborative capacity - programmatic capacity - is also something FACLN routinely demonstrates. While their definition may be dry-sounding, programmatic capacity is important because if a network has no common vision or goals, nor resources or means of moving toward a network's stated objectives and goals, there is little capacity for the network to be effective, much less capable of bringing about change. Not only are the goals of the network clear, focused and realistic, but there is evidence the goals each FACLN community establish are tailored to their community's unique circumstances and needs and are carried out (sometimes) in innovative ways but generally intended to fill unmet community needs. For example, a sizeable majority of homeowners in the Island Park Sustainable Fire Community (one of the seventeen FACLN communities) 
are not from the area and are seasonal residents. This makes regular face-toface interactions - one of the primary ways in which FACLN accelerates the spread and adoption of concepts and actions that help communities become better fire-adapted - rather problematic (Interview: Liz Davy, 2015). To overcome this obstacle, the local FACLN members organized community workshops and carried out voluntary property assessments and wildfire risk mitigation efforts during seasonal periods of high-residency. Additionally, and prior to hosting the workshops and neighborhood work, they sent multiple effort mailings to absentee landowners, followed by door-to-door visits during peak residency season to raise awareness about their efforts and increase community participation, demonstrating the responsive manner in which FACLN handles the unique contexts of each community.

Peer-to-peer learning is one of the primary objectives of the FACLN. As such, the network attempts to build and foster avenues and capacities for learning. For example, the FACLN coordinating team hosts monthly calls with members to discuss new projects in each community, problems or successes they have experienced, idea sharing, event coordination and planning and other general topics. In this way, the network experiences both vertical (members-tocoordinating team) and horizontal (peer-to-peer) learning.

The FACLN also hosts quarterly webinars that serve to keep members updated on topics of particular interest to the network (e.g., CWPPs, network development projects, lessons learned from various communities, etc.). Each FACLN community also plans and hosts regular (usually annual) work training exercises that bring together fire practitioners from their region to share information and develop skillsets relevant to the needs of the community. Additionally, the network hosts an annual meeting bringing together members from across the network for knowledge sharing and skills training.

Learning and organizational capacity is also built and facilitated via number of other network resources including hosting regular learning/training exchanges (TREX program), project and task tracking and a searchable database of resources and docs (using the online networking platform Podio) and providing a searchable member directory that lists member skills, interests and projects. In short, the FACLN's activities seem to demonstrate programmatic capacity via building and facilitating the vertical and horizontal learning capacity of the network, in essence allowing members and managers to regularly ascertain and maintain the pulse of the broader network while sharing knowledge, skills, and lessons learned. 


\section{Cross-Scalar Integration}

The most effective networks, particularly those attempting to bring about transformation, often require the ability to integrate learning and newly-created best practices across multiple scales. It is important to note that transformations of social-ecological systems (SES) "are not scale independent and require an understanding of cross-scale interactions" (Olsson, Bodin, \& Folke, 2010) with small- and large changes sometimes triggering change at different scales, including changes that are multilevel, multiphase and sometimes abrupt. Thus, it is important to understand networks and their feedback loops at various scales and across and within them.

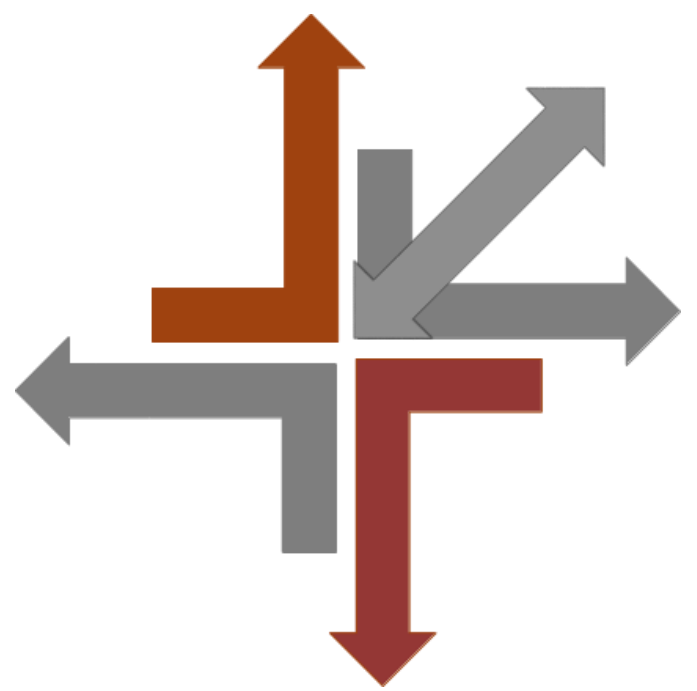

Figure 9. The three potential learning loops. Retrieved

Cross-scalar integration, however, can sometimes 1) cause friction in how the network functions especially if resulting changes push established norms and rigid procedural structures (e.g., communication in the chain-of-command), 2) trigger new collaboration initiatives that render the initial network less salient (or even mute), or 3) not recognize the tight coupling between social and ecological systems (Olsson \& Galaz, 2012a). Thus, integration of learning for the sake of transformation requires knowledge and skills that link SES dynamics across various scales within the network (Olsson, Bodin, \& Folke, 2010; Olsson \& Galaz, 2012b).

During the initial development of FACLN, leaders recognized that federal resource management policies created to address the needs of a generalized 
public (e.g., comprehensive, nationwide wildfire planning) were creating tensions for local communities whose social and ecological contexts were specific to a geography but may not have been addressed by the "blanket" federal policy. To help bring about more rapid adoption of fire-adapted principles while still addressing components of the National Cohesive Wildland Fire Management Strategy (referred to as "the Strategy"), FACLN leaders recognized local communities wanted greater autonomy and agency in managing the resources in their area. At the same time, national resource managers needed local actions that addressed the broader, national policy mandates. Given the network already had substantial capacity for cross-scalar learning and knowledge/skills sharing and its emphasis is - simply put - on helping communities become better fire-adapted, local and community activities that address the network's emphasis appear to be considered by FACLN leaders to add to the overall coherence of the network. Thus, it appears having been empowered by the network to solve wildfire issues as they see fit, each FACLN community's unique methods of addressing fire-adapted concepts seems to strengthen the network as a whole.

As a way to centralize information and its dissemination, learning curation and coordination is carried out primarily at the national level within the FACLN. While FACLN coordination team members are partly responsible for assessing and facilitating information flows from each community (local to national integration), learning also happens organically when various FACLN communities engage each other during routine interactions (e.g., monthly calls, annual workshops and skills trainings; local-to-local integration). What holds the network together despite heterogeneity between network communities is 1) the shared vision/goals and 2) the tight coordination at the network scale that includes regularly updated resources (e.g., Podio, funding, webinars, monthly call, annual reports, etc.). Additionally, because the network has an explicit recognition of the unique needs at each site, there seems to be little tension created within the network from community heterogeneity.

Another factor helping hold the network together is a common, shared identity. While each community may be addressing fire adaptation using different tactics and approaches, all network members are working toward embracing fireadapted concepts and each recognize the collective value in sharing experiences. Additionally, in part as a means of expanding the network but also focusing member participation into similar fire-adapted themed groups, FACLN members established seven CoPs in 2015 to advance innovation and share best 
practices ${ }^{37}$. This member- driven process may help solidify the roles of network members by giving members agency in how achievement of the network's goals are accomplished. Alternatively, it may also serve to differentiate homogenous sub-units that may explain why there appears to be little tension and relative lack of network stressors from community heterogeneity.

In short, the FACLN appears to have created an effective community of learning and sharing that empowers members to find unique, and ecologically and socially appropriate solutions to a common issue - community fire adaptation. While there have been some member tensions within the network (mainly revolving around member input into the steering of the network), and despite the different approaches members of the network employ to address fire adaptation, the vertical and horizontal communication channels and feedback loops built into the network appear to help solidify the value and effectiveness of the network.

\section{Transformative Capacity}

One of our primary interests in learning networks is in their ability to bring about changes to existing ways of doing things, whether gradual (but thorough) or rapid and dramatic - in other words, transformation. Transformation of social-ecological systems requires knowledge and skills that can link ecosystem and social system dynamics, development of strategies to overcome barriers, and the enabling of institutional changes that foster transformations (Per Olsson, Bodin, \& Folke 2010). Similarly, Wilson et al. (2013) suggest four primary SES characteristics are necessary for transformation (and that may be distinct from characteristics necessary for adaptive maintenance or resilience): identity, feedbacks, structure, and functions. Several criteria appear to be important for developing a framework for analyzing transformations and assessing transformative capacity in social-ecological systems: experimentation and innovation, agency and social networks, opportunity context, diversity, boundaries, collaboration and triple-loop learning ${ }^{38}$ (Per Olsson, Bodin, \& Folke,

37 See the seven "focus area" Communities of Practice (CoPs) at http:/ / fireadaptednetwork.org/focus-areas/.

3838 Single loop learning takes results from actions and feeds them back to the actions. Double-loop learning takes results from actions and feeds them back to the underlying assumptions that resulted in the actions being taken. Triple loop learning takes results from actions and feeds them back into the context that led to the assumptions and actions. Thus, triple loop learning employs feedback mechanisms from the network back into itself with the result that the network changes based on changing contexts and circumstances. See Tosey and colleagues (2012) for a critical review. 
2010). Wilson et al. (2013) further suggest purposeful, positive transformation is supported by vision, identifies with place and an unhappiness with the status quo, leverages high personal contribution to social capital, are often open social networks, and employ latent capital(s).

The FACLN did not explicitly set out to be a "transformative" network, nor is the word (or its derivatives) found in any of the network's documentation or in any of the interviews conducted with members of the network. Instead, the network origins are largely in attempting to change the way in which communities interact (i.e., live) with wildfire - though not radically. Nonetheless, the network displays many features and characteristics present in networks that have brought about transformations, transformative networks and during system transformations. For example, the network and its members have developed a strong social identity, recognizing a) the critical role wildfire plays in ecosystems, b) recognizing the need for human communities to be resilient before, during and after wildfires, and that effective SES change comes about only after addressing linkages and dynamics between ecological and social systems. Thus, all work being conducted within the FACLN addresses both ecological and social systems. It may be too early to tell, however, if the network itself is bringing about transformation and at what levels. It is important to note that not all networks set out to bring about transformation, let alone be transformative networks. Additionally, a network may support transformation at some scales, but not all. Further, what constitutes "transformation" at one scale may just be adaptation at another, while timing of transformations (or sub-transformations) is rarely discussed. These distinctions are unclear in the literature and bear further elucidation.

Nevertheless, it is conceivable - plausible, even - the FACLN's capacities allow for (facilitate?) transformations at smaller scales or geographic locales but not network-wide. If this were the case, however, we might expect some member communities to be ineffective at adopting fire adaptation concepts or to continue operating with the status quo. Instead, what appears to be happening in member communities is the emergence of novels ways of connecting people and resources to address fire adaptation. What is clear, however, is the unique needs and timing of actions/results differs among the FACLN communities. If learning in FACLN is indeed multi-scalar, we would expect the network to eventually reach a threshold where current fire adaptation - whether in definition, practice, approach or some combination of the three - is wholly different from the current status quo. The problem, at least for learning network researchers, lies in being able to forecast when those thresholds have been met rather than looking backward before recognizing transformation. 
Much of the work FACLN members do is geared toward overcoming barriers to adoption of FAC concepts. Because the conceptions of, enabling conditions, and barriers to adoption of FAC concepts vary by community, through time and involve complex system interactions, solutions must be responsive to changing conditions (adaptive), address the unique circumstances of and be adopted by each community, and be collaborative in nature. The feedback loops and responsiveness of the network to learning and course corrections - in effect, triple-loop learning - allows the network itself to change in response to feedback from outside and within the network (i.e., the network itself appears to be both responsive and adaptive to feedback). Because the network values and encourages communities to come up with their own solutions to the complex fire-related problems each face, the solutions communities develop are often innovative and collaborative in nature while addressing the needs of the community. Additionally, the vertical knowledge sharing and learning espoused by the network (e.g., TREX learning and training exchanges, regional and national workshops and meeting, etc.) appear to facilitate communities employing tactics that have been successfully demonstrated in other communities - essentially "experimentation" with different approaches to addressing the problem.

The FACLN internal network feedback efforts in 2014 (e.g., member survey) and 2015 (e.g., collective development and adoption of additional network guiding principles) demonstrate the capacity of the network to leverage social capital for triple-loop learning - network managers recognized member tension and were responsive to member requests for increased agency in the direction of the network. The FACLN development of the additional CoPs further exemplifies the network's dedication to strengthening network connections, developing (and curating) trust relationships, as well as decentralizing decision-making components identified by Plastrik et al. (2014) as critical for effective social impact networks and by Olsson (2010) and Wilson et al. (2013) for bringing about transformation.

In Short Introduction to Networks, Caldarelli and Catanzaro (2012) indicate robust networks seem to "tolerate a certain amount of dysfunction without too many problems," largely due to alternative paths for information flow. While the authors do not describe what they mean by "dysfunction", they reference it in relation to tensions and common problems networks experience. The FACLN's relatively flat organizational structure and presence of multiple netweavers, however, essentially creates a variety of routes through which information (e.g., learning and knowledge) flows. While network weavers are typically thought of 
as individuals that are well connected (superconnectors), we might think of the network itself as a superconnector as it leverages and builds upon the success of other existing fire-related programs and networks, bridging gaps in the rural/urban divide (the wildland-urban interface; WUI) and bringing together resource managers, city officials and planners, landowners, and policymakers in a learning environment to share experiences and knowledge (what works, what doesn't) with the larger network and those outside the network (potential network members). Thus, the network as a superconnector, combined with its existing capacities and shared vision, may itself act as a pathway to transformation, although this has not yet been examined in FACLN.

The presence of transformative capacity in a network in and of itself does not necessarily translate into transformation. Yet, there do seem to be some transformations occurring, primarily at the local levels of the network. The FACLN appears to be bridging some of the gaps between fire-adapted efforts that traditionally have occurred in a single sphere (e.g., city fire departments, federal fuels reduction efforts, etc.). The combining fire-related efforts into a single fireadaptation effort seems to be bridging the gaps in awareness levels among the general public and resulting in increased actions that are increasing community fire adaptation (e.g., increased community networking for emergency preparedness, fuels reductions on private lands, post-fire responses, CWPPs, etc.). Whether these "local" transformations result in a network-wide transformation or transform the way in which humans interact with wildfire has yet to be seen.

While there does not seem to be any "secret sauce" to enabling and sustaining transformative capacity building, it seems necessary there be a number of communicative, feedback, trust/agency building and bridging components in place that allow for transformation to occur, whether intentionally as a stated objective of the network, organically as an emergent property of the network, or some combination of the two (as is the case with the FACLN). Given the literature indicates there seem to be a number of factors at play in transformation of systems (via networks), it would seem that to study transformation of/by/within a network, coding the interactions and documents of the network and analyzing for the presence of these factors may provide enough evidence for the presence of transformative capacity. Whether transformation itself occurs would seem to be an interpretive research endeavor while viewing the network from the outside. Additionally, after coding network documents and interactions (e.g., interviews) for literature- established transformative capacity factors, there are typically additional themes and patterns that emerge, leading to additional thematic coding. Examination of 
these additional themes/codes may yield a secondary level of data aggregation (a sort of super code) that emerges as additional factor(s) important for recognizing or understanding transformation.

\section{Organizational Learning}

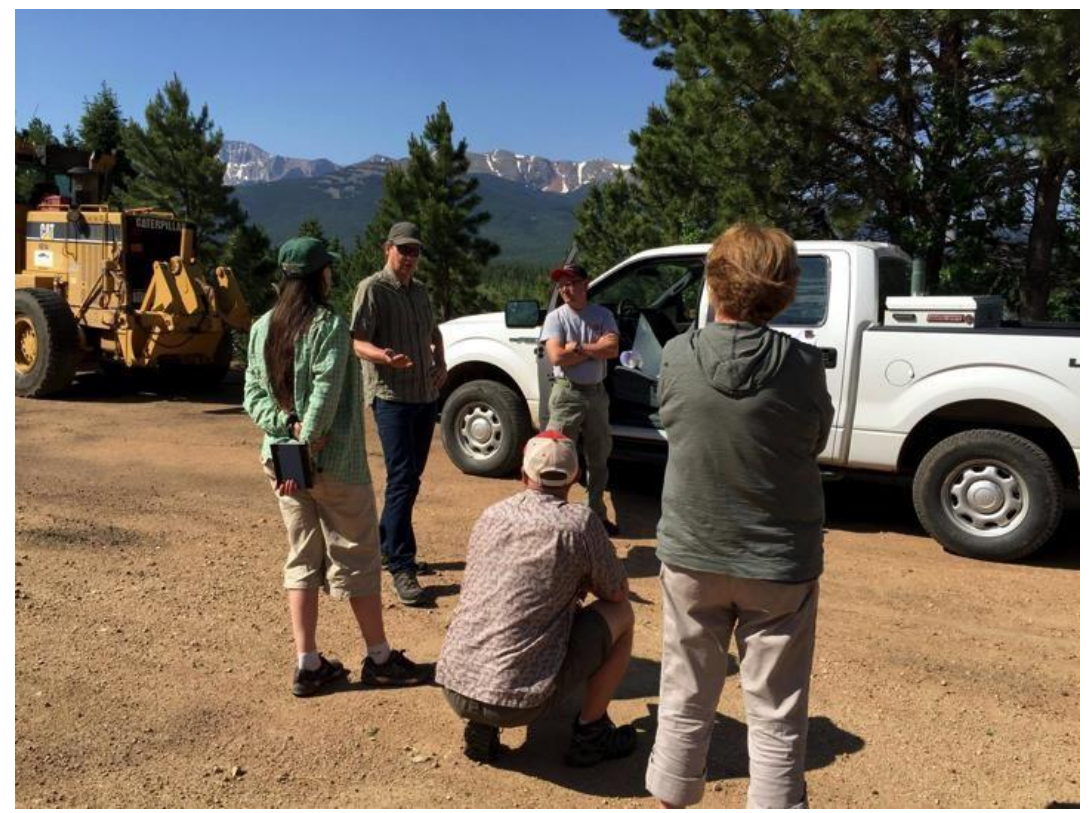

Figure 10. Members from two different Fire-Adapted Community Learning Network sites participate in a learning exchange in Teller County, Colorado, in June 2016. Retrieved from https://www.facebook.com/FACNetwork/.

It is clear the FACLN has positioned itself well for organizational learning. Not only was the network formation organized around learning concepts (i.e., a learning network) but the organization itself experiences and seems to be responsive to third order learning (i.e., triple-loop learning; Tosey, Visser, \& Saunders, 2012). Organizational learning within the FACLN is principally embodied at two different levels: regular network member interactions and episodic network evaluation. Cross-discipline and intra-network learning happens regularly and naturally during trainings and skills exchanges (e.g., TREX program), monthly conference calls, quarterly webinars, regular workshops, and annual regional and network meetings of all members in the region/network. While neither fully address overall network learning, both appear to be important components for network learning as these various events and activities facilitate learning by network members - in essence, the development of an institutional (network) memory (capacity). Episodic network evaluation happens as the network coordination team - responsible for aggregating learning, disseminating knowledge to network members, and 
bringing learning to policymakers - responds to member-derived input and feedback. This third order learning was exemplified by the network when, after hearing from network members they wanted additional input on the strategic directions of the network, the network coordinating team initiated a survey of its members and incorporated/addressed the results of the survey by developing member-derived core operating principles of the network.

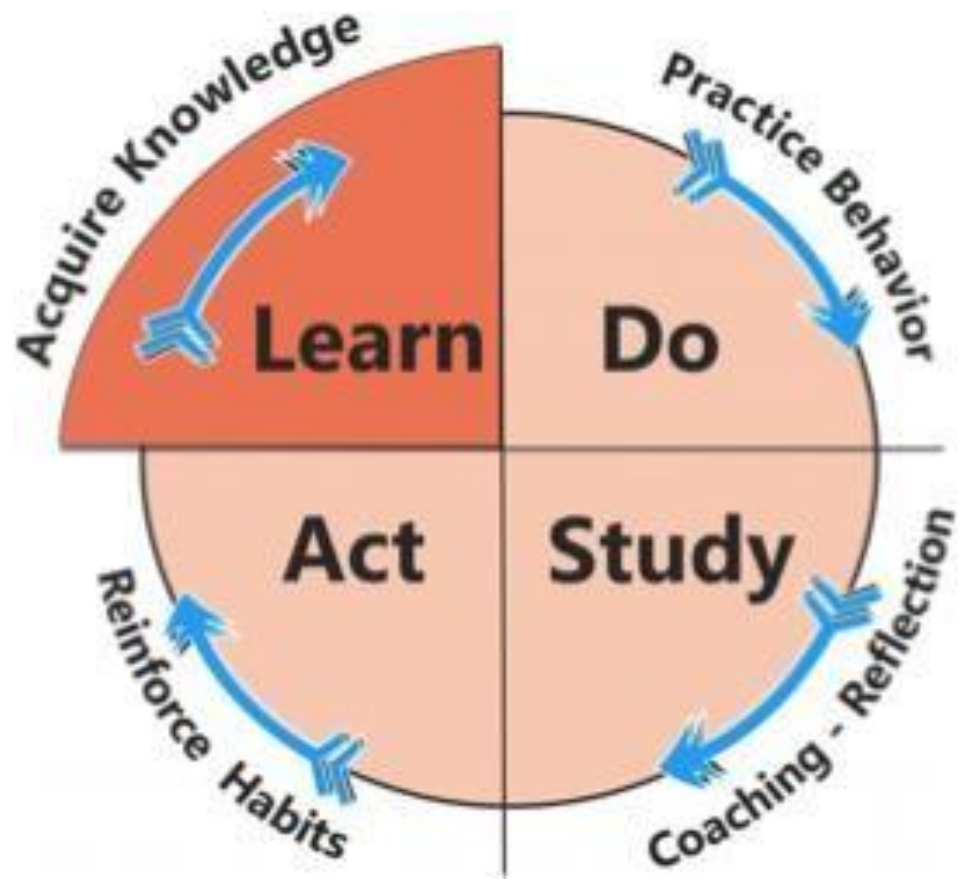

Figure 11. Key components of organizational learning. Retrieved from http:/ /www.lmmiller.com/build-lean-system-organizational-learning/.

Routine feedback (member-to-member, member-to-manager, network-topolicymakers) through established channels seems to be a critical mechanism for organizational learning. Perhaps more importantly, the responsiveness of the network managers to the feedback and tensions in the network is critical to organizational learning (at the member-to-manager level). Feedback that is critical can be difficult to hear, let alone act upon. But perhaps because the network coordinating team was committed to network learning and responsiveness, the organization was able to adapt in response to the "learning", demonstrating the nimbleness of the organization. Additionally, members of the network routinely express concerns (tensions?) about continuation of funding from the network. As the network matures, other tensions may arise, potentially resulting in additional opportunities for network development. In this sense, organizational learning can be thought of as an ongoing course correction process, not a static event. Nevertheless, it is unclear what keeps the 
Coordinating Team from being defensive or resistant to critical member feedback but this should be examined further as it may prove to be key to effective thirdloop learning - indeed, to transformation.

\section{CONCLUSION}

Despite being a relatively young learning network, the FACLN, its membership and leadership have experienced tremendous growth in their first three years, growing from eight initial communities to eighteen communities by early in the network's second year. This rapid growth created some tensions within the network - primarily with how to deal with members that were not participating in active knowledge and innovation sharing with the rest of the network - but the network and its leadership appear to have built in capacities that 1) allow for flexibility in how the network achieves its mission, 2) provide effective network evaluation, feedback and learning loops that help the network stay on track with their mission yet responsive to unique member needs across the landscape, 3) allow information sharing (and learning) at multiple levels and scales within and outside the network, and 4) may facilitate transformation in how wildfire is both seen (accepted) and done (managed) across the United States.

\section{REFERENCES}

Armitage, D. (2005). "Adaptive Capacity and Community-Based Natural Resource Management." Environmental Management 35 (6): 703-15. doi:10.1007/s00267-004-0076-z.

Bradshaw, B. (2003). "Questioning the Credibility and Capacity of CommunityBased Resource Management." Canadian Geographer / Le Géographe Canadien 47 (2): 137-50. doi:10.1111/1541-0064.t01-1-00001.

Caldarelli, G., and Catanzaro, M. (2012). Networks: A Very Short Introduction. Oxford: Oxford University Press. http://eprints.imtlucca.it/1189/.

Foster-Fishman, P. G., Berkowitz, S., Lounsbury, D. W., Jacobson, S. \& Allen, N. A. (2001). "Building Collaborative Capacity in Community Coalitions: A Review and Integrative Framework." American Journal of Community Psychology 29 (2): 241-61. doi:10.1023/A:1010378613583.

Goldstein, B. E., and Butler, W. H. (2010). "The U.S. Fire Learning Network: Providing a Narrative Framework for Restoring Ecosystems, Professions, and Institutions." Society \& Natural Resources 23 (10): 935-51. doi:10.1080/08941920903012494. 
Goldstein, B. E., Butler, W. H., \& Hull, R. B. (2010). "The Fire Learning Network: A Promising Conservation Strategy for Forestry." Journal of Forestry 108 (3): 120-25.

Holley, J. (2012). Network Weaver Handbook: A Guide to Transformational Networks. Network Weaver Publishing.

Olsson, P., Bodin, O., \& Folke, C. (2010). "Building Transformative Capacity for Ecosystem Stewardship in Social-ecological Systems.” Adaptive Capacity and Environmental Governance, 263-85.

Olsson, P., Bodin, Ö., \& Folke, C. (2010). "Building Transformative Capacity for Ecosystem Stewardship in Social-Ecological Systems." In Adaptive Capacity and Environmental Governance, edited by Derek Armitage and Ryan Plummer, 263-85. Springer Series on Environmental Management. Springer Berlin Heidelberg. http://link.springer.com/chapter/10.1007/978-3-642-12194-4_13.

Olsson, P, \& Galaz, V. (2012a). "Social-Ecological Innovation and Transformation." In Social Innovation, edited by Alex Nicholls and Alex Murdock, 223-47. Palgrave Macmillan UK http://link.springer.com/chapter/10.1057/9780230367098_10.

Olsson, P, \& Galaz, V. (2012b). "Social-Ecological Innovation and Transformation." In Social Innovation, edited by Alex Nicholls and Alex Murdock, 223-47. Palgrave Macmillan UK http://link.springer.com/chapter/10.1057/9780230367098_10.

Plastrik, P., Taylor, M., \& Cleveland, J. (2014). Connecting to Change the World: Harnessing the Power of Networks for Social Impact. http://site.ebrary.com/id/11026072.

Plummer, R., \& Armitage, D. (2007). "A Resilience-Based Framework for Evaluating Adaptive Co- Management: Linking Ecology, Economics and Society in a Complex World." Ecological Economics 61 (1): 62-74.

Pyne, S. (2004). Tending Fire: Coping With America's Wildland Fires. Island Press.

Tosey, P., Visser, M., \& Saunders. M. N. (2012). "The Origins and Conceptualizations of "triple-loop" learning: A Critical Review." Management Learning 43 (3): 291-307.

Wenger, E. (1998). Communities of Practice: Learning, Meaning, and Identity. Cambridge University Press. Wilson, S., Pearson, L. J., Kashima, Y., Lusher, D., \& Pearson, C. (2013). "Separating Adaptive

Maintenance (Resilience) and Transformative Capacity of Social-Ecological Systems." Ecology and Society 18. http://hdl.handle.net/10535/8817. 


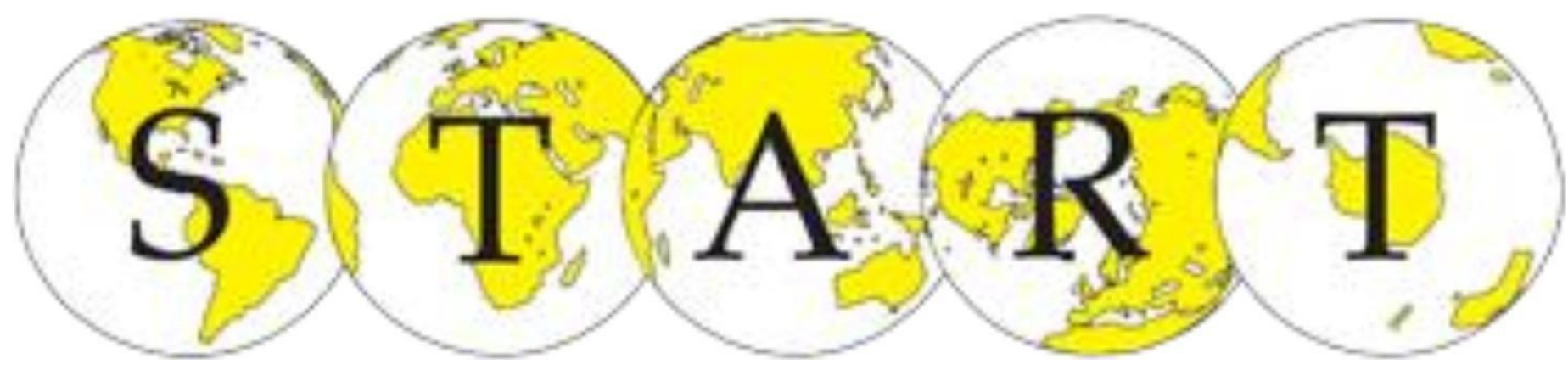

global change SysTem for Analysis, Research \& Training

Global Change SysTem for Analysis,

Research and Training

Sarah Schweizer, University of Colorado

Denver

sschweizer@start.org 
CASE STUDY - GLOBAL CHANGE SYSTEM FOR ANALYSIS, RESEARCH AND TRAINING BY SARAH SCHWEIZER, UNIVERSITY OF COLORADO DENVER

PART 1 - CASE INTRODUCTION AND PROFILE

\section{Network Origins}

To appreciate the historical underpinnings and urgent call for START's creation, it is necessary to have a cursory understanding of the evolving landscape of global change science. In the mid-1980s, a concerted effort through the formation and implementation of global change science programs was made to understand global environmental change processes and the Earth as an integrated system. Communities of scientists, predominately from the developed world, revealed that many of the world's challenges were characterized by uncertainty around global environmental change, which manifests through multiple drivers including climate change, globalization, population growth, and degradation and depletion of ecological services. These unprecedented challenges posed significant risk to human well-being and ecosystem function both of which critically underpin sustainable development. Due to the urgency of their findings, it became apparent to some scientists that they had an obligation to act beyond their roles as scientists by transforming how science was conducted and used in order to help inform policy decisions for these societal challenges.

In 1987, the World Commission on Environment and Development acknowledged this new emphasis in their report, Our Common Future:

A major reorientation is needed in many policies and institutional arrangements at the international as well as national levels because the rate of (global) change is outstripping the ability of scientific disciplines and our current capabilities to assess and advise... A new international programme for cooperation among largely nongovernmental organizations, scientific bodies, and industry groups should therefore be established for this purpose.

Given increasing calls from scientists and advocates for immediate actions and societal changes in order to avoid threatening impacts, many important questions emerged about individual, national, and regional capacities to conduct global change science to inform purposeful actions of adaptation and systems transformation. In the 1990 s, several reports signaled a need to involve 
developing country scientists in conducting regionally based research to help inform critical gaps in knowledge of vulnerabilities and impacts at all scales in the developing world.

Building on Our Common Future report, the International Council Science Union's (ICSU) Special Committee for the International Geosphere-Biosphere Programme (IGBP) released a plan in June of 1990, describing major Core Projects, designed to carry out global change research. The plan specifically highlighted the need to mobilize research in all parts of the world to form a better understanding of global change. The Special Committee noted:

The scientific understanding concerning global change processes and impacts is generally not well advanced in less-developed countries, where available scientific manpower and financial resources are especially limited. There is an urgent need for the IGBP to stimulate global change research in these regions to ensure that their scientists are involved in all aspects of data collection, synthesis and global change predictions. In addition, outputs from climate and global Earth system models must be made available to the science community in less developed countries and interpreted in a national and regional context. (IGBP, 1990, p. 3)

This plan emphasized the need for a substantial increase in the number and capacity of developing country scientists and their participation in international science agendas in order to gain a better understanding of the complexity of global change.

In recognition of the need for new institutional governance arrangements and active participation from developing countries, the workshop Global Change Research Centres: From the Concepts to Reality was held at the Rockefeller Foundation's conference facility in Bellagio, Italy. The Bellagio workshop was organized by the International Council Science Union's Scientific Committee for International Geosphere-Biosphere Programme and brought together 18 leading scientists to consider the means for stimulating global change research at regional levels, especially in developing countries, that would enhance greater understanding of global change processes thereby facilitating the development of strategies for responding effectively to such change. The Bellagio workshop proposed a global system of regional networks for analysis, research and training as "an essential component of the total programme" of global change research; thus, START was born (IGBP, 1991, p. 6). 
START was created to support systemic change and inclusive participation and to accomplish what other existing global environmental change institutional arrangements had failed to do. Looking back, Roland Fuchs, former Executive Director of START, reflects on the workshop, "It was by all accounts an extraordinary gathering: old men dreamed dreams and the young saw visions" (1995, p. 397). START was international endeavor to promote regional networks of scientists and institutions engaged in global environmental change research. A regional approach was seen as necessary for two reasons. First, regional differences in such characteristics as biogeography, socioeconomic systems, and climate must be considered to obtain a truly global perspective and understanding of change in the earth system, including global-regional linkages that define planetary boundaries most prone to significant change. Second, responding effectively to the challenges of global change requires that capacity be developed at regional to local scales that support informed decision-making by society.

A key aim of the proposed network was to contribute to existing global change science programs such as the World Climate Research Programme (WCRP), International Geosphere-Biosphere Programme, and the International Human Dimensions Programme (IHDP) to ensure global programs addressed regional needs and to encourage partnerships between scientists in developed and developing countries and between scientists and policy makers. START provided a mechanism to challenge historical science power dynamics by encouraging developing country inclusion. To implement the bold vision, The International START Secretariat was established in 1992 in Washington, D.C., to serve as the operating arm of START. The following section discusses the intertwined relationship of START's history, now in its $24^{\text {th }}$ year of operation and its evolving network design.

\section{Network Design and History}

Participants at the Bellagio workshop determined that START, would be cosponsored by International Geosphere-Biosphere Programme, World Climate Research Programme, and the International Human Dimensions Programme under the aegis of the International Council for Science (ICSU). It was international initiative spurred by the insights of the global change research programs with a specific aim to transform global change science from predominately Western focused into a "truly global network of research activities" (IGBP, 1991, p. 13). 
As a result, START's networks were developed to promote global change science and strengthen the capacity of scientists, practitioners, and institutions in developing countries to lead research. More specifically the regional networks intended to: 1) conduct research on regional aspects of global change; 2) assess the impacts of the regional findings; and 3) provide regionally important integrated and evaluated information to policy-makers and governments (IGBP, 1998).

The next section describes four key governance transitions and network design adaptations within START's 24 year history (see figure 1).

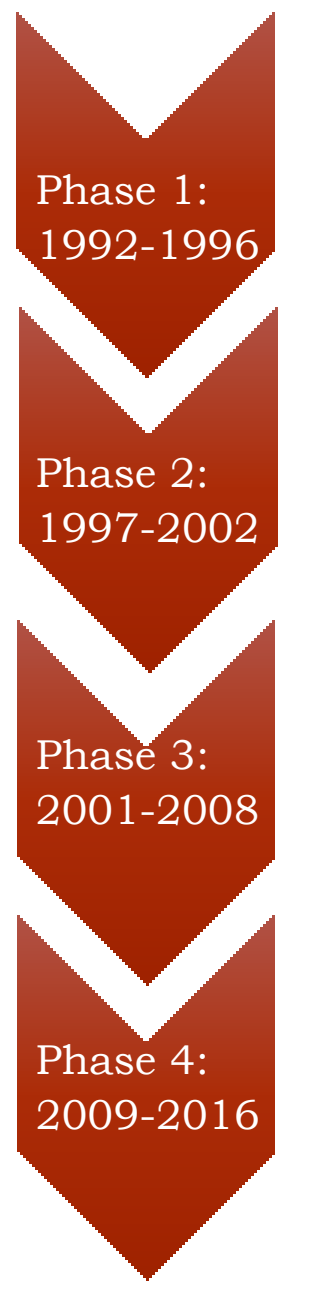

- An internationally sponsored program of the global environmental change research family

- Initial phase of scoping START's regional networks

- START Standing Committee (1992-1997)

- An internationally sponsored program of the global environmental change research family

- START's first Implementation Plan for 1997-2002

- START Scientific Steering Committee (1998-2008)

- An internationally sponsored program of the global environmental change research family

- Earth System Science Partnership (ESSP) formulation and maturing of START

- START International, Inc. formalized as a 501c3 non-profit organization

- Board of Directors established

- No longer formerly sponsored by the global environmental change research family

Figure 1. START's primary governance transitions.

Phase 1: 1992-1996. Following the establishment of the International START Secretariat in 1992, an initial phase was dedicated to scoping START's regional networks through support from several national contributions. The 
International START Secretariat serves as the central hub of the network and coordinates formal activities and programs with regional networks in Africa and Asia. Despite original global ambitions, START concentrated network formation within Africa and Asia due to the counterpart establishment of the intergovernmental Inter-American Institute (IAI) in South America. It was clear that IAI would receive considerable funding and be capable of addressing START's remit in the Americas therefore START's energies and resources were focused in underserved areas of Africa and Asia. This geographic focus has remained consistent through START's history.

A fundamental purpose of these regional networks, as envisioned in Bellagio, was "to mobilize scientific manpower and resources to address the scientific questions concerned with global change" and to provide a framework to support regional syntheses and scientific assessments of relevance to policy development (IGBP, 1991). In addition, regional research networks were seen as critical for promoting regional cooperation in global change research; developing coherence and greater efficiency among national, regional and international research agendas; enhancing exchange of data and communication of research results; and more rapidly providing scientific knowledge to the public and inputs to policymakers. Furthermore, each region prioritized capacity building that would enhance regional scientific and technical capabilities and research infrastructures.

In the networks design, START attempted to create a regional structure based on geopolitical rather than bio-climatic regionalization. This was reflected in the development of a regional structure with components in Sub-Saharan Africa, the Mediterranean, Southeast Asia, South Asia, Temperate East Asia, and Oceania. Subsequent regional science planning meetings were convened in each area to identify regional research needs and objectives to guide the network. Figure 2 below depicts the boundary space in which START operated during this timeframe. START was the broker of knowledge sharing and action between the global environmental change organizations at the top of the figure and the regional networks and centers that were developed in Asia and Africa featured at the bottom of the figure. 


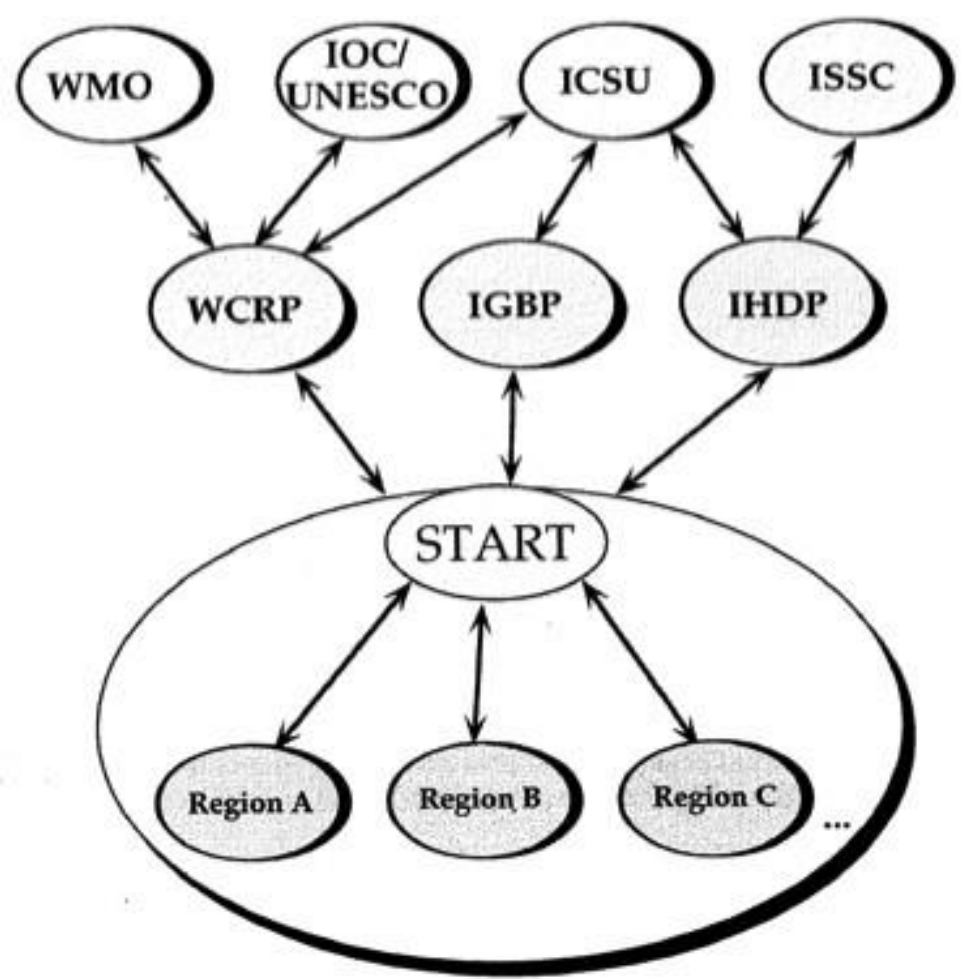

Figure 2. START Network Relationships (IGBP, 1998, p. 11). Retrieved from http://www.igbp.net/download/18.1b8ae20512db692f2a680006373/137638 3118375/report_44-START.pdf.

\begin{tabular}{|l|l|}
\hline ICSU & International Council of Scientific Unions \\
\hline IGBP & International Geosphere-Biosphere Programme \\
\hline IHDP & International Human Dimensions Programme on Global \\
\hline IOC & Intergovernmental Oceanographic Commission \\
\hline ISSC & International Social Science Council \\
\hline WCRP & World Climate Research Programme \\
\hline UNESC & United Nations Educational, Scientific and Cultural \\
\hline WMO & World Meteorological Organization \\
\hline
\end{tabular}

Phase 2: 1997-2002. After an initial experimental and start-up period during 1992-1996, the START Implementation Plan was developed to address the needs of the regional science community and to strategically outline START's future contributions. The plan captured the intent and heart of the Bellagio report, which served as the "founding document" for START, yet differed substantially in the approach and mechanisms to carry out the vision. For example, the Bellagio report called "for a broad range of START activities in large-scale, multipurpose, regional research centers" that would be responsible and capable to conduct research and modeling, synthesis and data management, and conduct capacity building trainings. With the exception of the TEA-START Center in 
Beijing, these expectations and model has proven difficult and impractical due to the dependence on finding sufficient financial resources. The lack of core support, with its ramifications in terms of limited staff and low levels of material resources, has constrained START's potential in the regions to more fully develop networks and programs. START's experience and experimentation has shown that flexible distributed networks and "virtual centers" provide an easier and more sustainable approach. Phase one and Phase two transitions and experiences also reiterated that a one-size-fits all approach was doomed for failure.

In addition to changing regional models and expectations, the implementation plan defined and laid out clear objectives, activities, and expected outputs for the period of 1997-2002. It also addressed funding requirements, leadership and management, and monitoring and evaluation measures to be considered during the timeframe. The plan identified five cross cutting themes to be emphasized in the network:

1. Regional climate variability and change, including its prediction and impacts

2. Changes in composition of the atmosphere and its impacts

3. Land use/cover change and its impacts; including land degradation, deforestation and desertification

4. Impacts of global change on terrestrial ecosystems and biodiversity

5. Global change and costal zones, land-ocean interactions and impacts on national and international waters

The network structures were transformed in order to foster linkages across the five cross cutting themes that served as priorities since they embodied a range of research interests from START's sponsors and regional scientists. The network design also explicitly focused on mechanisms to link global change science with policy makers and international arenas. Each regional network varied in structure but maintained a few common design elements (START, 2008):

1. Regional coordinating committees have the responsibility for planning, endorsing and overseeing implementation of scientific activities within the concerned region. Members are appointed in their individual capacity but with the expectation that they will also represent the interests and priorities of their national global change science communities.

2. A regional secretariat supports the regional committee, prepares reports and is responsible for communications. 
3. Regional centers have the responsibility for leading one or more major scientific activities within the region, and related capacity building, and typically host the regional secretariat. Affiliated centers, whether formally designated or not, are institutions within the region serving as the lead institutions for specific collaborative regional activities.

Phase 3: 2002-2008. START's strategy and functions changed over time as a result of lessons learned during early years of operation and changing contexts including global change scientists' advancements in understanding global changes, and the evolving institutional structures of international science programs that support and conduct global change science. While three international global science programs originally sponsored START, it was recognized as a formal project in 2001 when the Earth System Science Partnership (ESSP) was formed. The Earth System Science Partnership encompassed four of International Council Science Union's international global change research programs: DIVERSITAS, International Geosphere-Biosphere Programme, International Human Dimensions Programme, and World Climate Research Programme. Figure 3 illustrates the Earth System Science Partnerships' structure and goal of enabling integrative sciences and international scientific assessments through partnerships with individual global change research programs. START was designated to support a cross cutting function to facilitate capacity building, communication, and iterative engagement to inform society and advance integrative science through interactions with Earth System Science Partnership's partners, programs, and projects. In 2003, Earth System Science Partnership conducted a formal review of START and concluded: "START fills an important and unique role in ESSP; START is highly successful in meeting goals in developing regional research networks and research driven capacity building." 


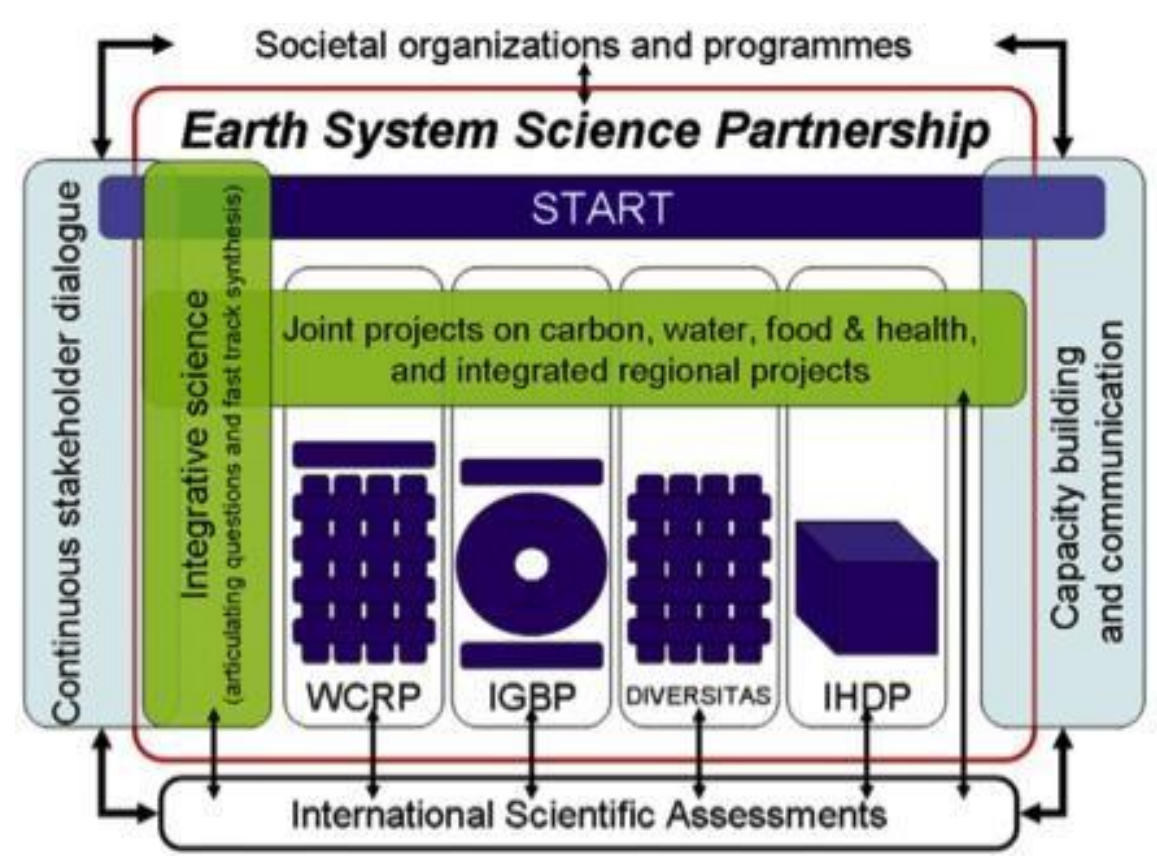

Figure 3. Earth System Science Partnership's structure for integrative science. START's role is cross cutting through ESSP and the GEC research programs (WCRP, IGBP, DIVERSITAS, and IHDP) to facilitate capacity building and iterative engagement to inform society

For the first decade of START, the Bellagio Report and the Implementation Plan served as guiding documents to inform planning and development of START's regional networks. Network activities and coordination were also highly influenced by regional context and priorities, partnership and implementation of Earth System Science Partnership's core projects, capabilities and interests of regional scientists, and funding opportunities. During the envisioning process for START, parties explicitly discussed the importance of the network to be adaptable and nimble for future needs, “... and with a built-in capability to evolve in a way that considers all relevant dimensions of the driving forces of global change...." (IGBP, 1991, p. 3). With this inherent built-in capability to evolve, START strategically modified the network design numerous times and went through waves of expansion and intentional downsizing to meet present challenges and needs.

Phase 4: 2009-2016. By 2009, START was comprised of the International START Secretariat coordinating START's programs and activities, six regional committees, centers, and secretariats hosted at universities and government institutions, and three regional nodes facilitating regional research (see Figure 4). Further changes were implemented in 2009 when START officially incorporated as an independent nonprofit corporation with US 501(3)@ status. 
This change came from the recommendation of an ad hoc START Development and Strategic Planning group organized to advise the International START Secretariat. The Development and Strategic Planning group considered the action necessary to secure formal "brand name" recognition of START and to enable a more streamlined process for applying and securing funding from nonUS-based funding sources. As a result, the governing structure was revised to meet an increased demand for START to serve capacity building needs of the broader global environmental change community outside of International Council Science Union supported global change programs. Therefore START's relationship with the Earth System Science Partnership and the global change reach programs transitioned to that of partners rather than sponsorship. In addition a Board of Directors was created and two standing committees, the START Scientific Steering Committee and the START Development Committee, were appointed.

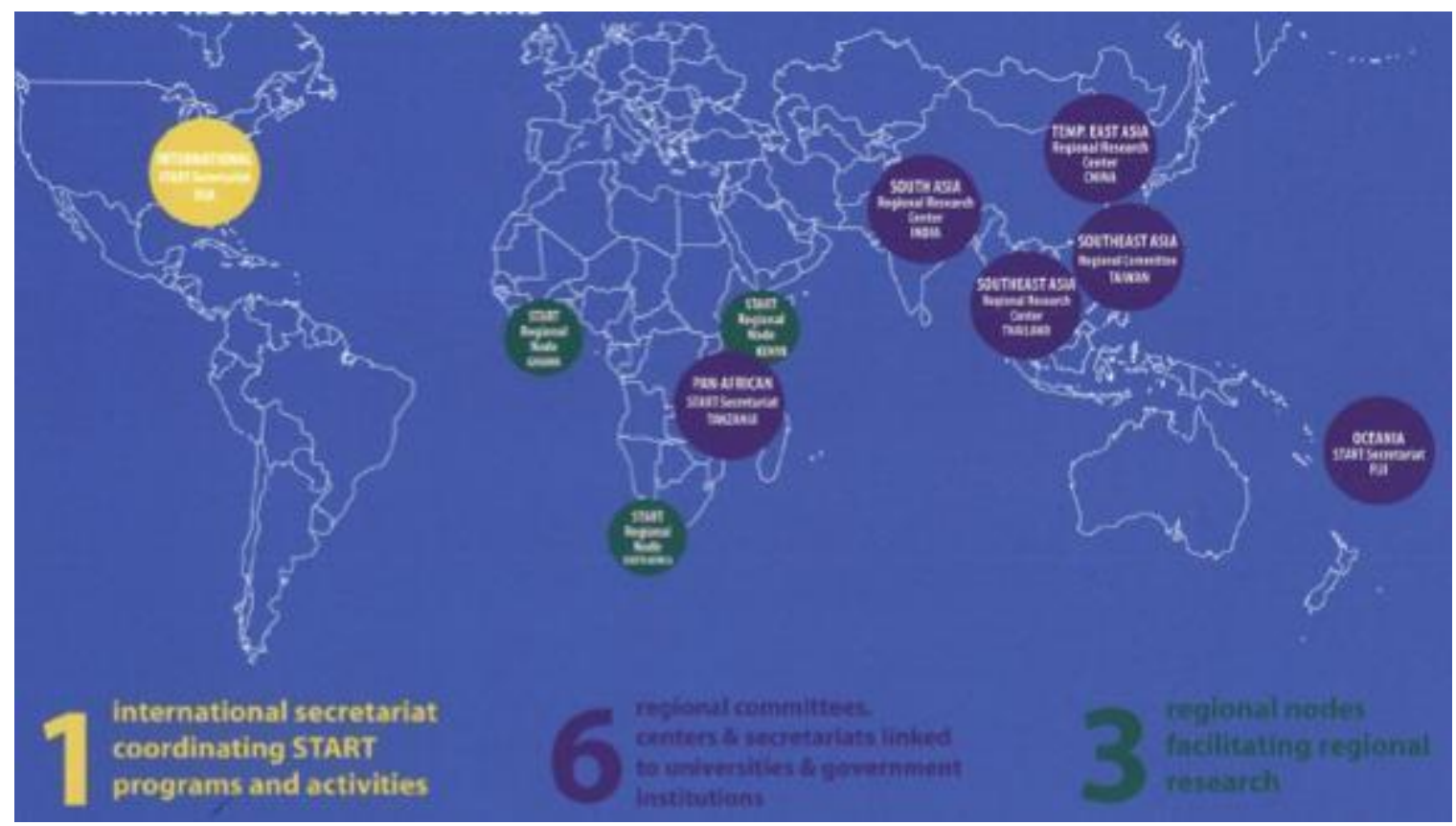

Figure 14. START network structure during beginning years of Phase 4. Retrieved from http://start.org/download/publications/start09-web.pdf.

In recent years (2013-2016), the context in which START's regional structures were initially established has changed, as evident in the growth of large global initiatives that offer opportunities for new kinds of partnerships, and the challenge of securing donor interest in funding core activities of physically based centers. This new landscape prompted a review of what a nimble and effective START structure should look like, resulting in a transformation from brick and mortar regional centers to a system of START Regional Affiliates in Africa and 
an examination of its potential in Asia. The structure still supports a 'hub and spoke' approach that is South-South and North-South in nature but the system is characterized by an actions-based coordination model under which the International START Secretariat collaborates with Affiliates and other implementation partners - rather than physical START centers - to carry out joint initiatives and advance common goals. The fundamental changes through a START Regional Affiliate structure intends to allow START to more effectively meet its objectives under their three strategic priority areas: promoting excellence in research, strengthening communication between research, policy and practice, and engaging university partners to foster innovation in teaching, curricula and research. Adopting this light structure has allowed for learning and adaptation as new constraints and opportunities are presented. The International START Secretariat still coordinates START programs and activities as done since inception but this emergent structure serves as the foundation for the network and promotes collaboration at various spatial scales to achieve more than START could in isolation.

\section{Learning and Capacity Building}

Capacity building is a critical component for how START functions and promotes learning among regional networks. Capacity building can be defined as the knowledge-intensive process of generating, mobilizing, utilizing, improving, and transferring individual, institutional, and country level skills/expertise for address a specific problem or multitude of challenges (Mugabe et al. 2000). The main objective of START's capacity building efforts is to contribute to reducing vulnerabilities while enhancing resilience and adaptive capacities in developing countries. As a result, START developed a framework for capacity building that prioritizes development and implementation of programs and network activities that integrate knowledge generation with knowledge sharing in ways that aim to effectively inform, and be informed by, action (see Figure 5). The approach supports capacity among individuals and institutions while strengthening robust, collaborative, and interdisciplinary regional networks. 


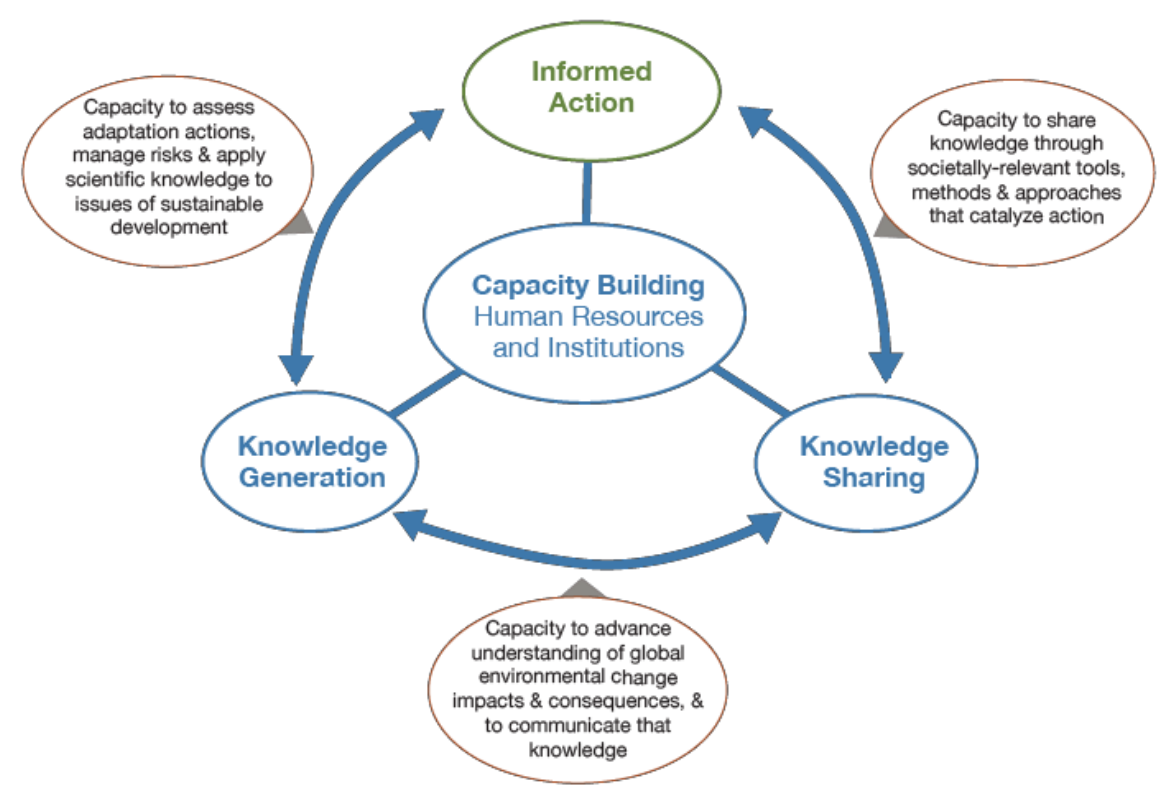

Figure 15. START's Framework for Capacity Building. Retrieved from

Reflecting on over twenty years of capacity building experience, START leadership published an article to share best practices and principles for longterm capacity building (Virji et al., 2012):

- Be research-driven and context specific, and adapt its approach and priorities to the widely varying scientific capacities across countries;

- Be country driven not donor driven: countries must determine and drive activities from conception to evaluation;

- Be issue and place-based: activities should be determined by the country's development priorities to be addressed, rather than determined by a specific tool, program, or expertise;

- Emphasize active participation in long-term research initiatives and international science programs that are relevant to the country's priorities. However, capacity building works best if it first achieves local benefits on local priorities, and then addresses participation in global climate research, rather than the reverse;

- Seek to achieve a multiplier effect by engaging with early-career to midcareer scientists, and by encouraging active networks of individuals and institutions;

- Promote gender parity and support the participation of women in climate research, decision- making and sectoral interests;

- Not be targeted solely at the scientific community, but rather be done in a holistic, integrated manner that fosters capacity for interaction and 
dialog among scientists, policy makers, and other societal decisionmaking groups, where the scientific community's role is to provide the science-base for a rational, constructive dialog among stakeholders with different views; and,

- Occur within a framework of integrated, interdisciplinary problem solving that reaches across a broad swath of sectoral and livelihood interests, including agriculture, forestry, fisheries, water resources management, meteorology, and climatology, energy, public health, disaster management, urban and rural development.

As referenced above, strong and well-supported scientific networks are an imperative element of capacity building, as they are a crucial source for new knowledge that enables continual and dynamic learning (Virji, 2012). In order to foster networks, START has made assertions that capacity building is a continual process whereby START alumni are engaged and re-engaged in multiple activities that build leadership in their respective fields and regions and create opportunities for them to be key actors in strengthening their own institutions while also encouraging relevant partnership and exchange between institutions (START, 2013a). This continual engagement is an approach that START has emphasized since its foundation:

Once-off training exercises are easy to organize, but are the least effective method of capacity enhancement and result in large cost/benefit ratios. In contrast, sustained development of human capacity through continual involvement with research maximizes efficiency and minimizes the cost/benefit ratio ... The need is to catalyze the involvement of talented scientists in on-going and new initiatives. Passive participation in training activities should be minimized; active participation in long-lasting initiatives should be maximized (IGBP, 1991).

Two specific examples of learning-by-doing methods that enhance learning and capacity building with START networks include: 1) City and Social Learning Labs in the Future Resilience for African Cities and Lands (FRACTAL) initiative and 2) Transformative Scenario Planning in the Adaptation at Scale in SemiArid Regions (ASSAR) program.

\section{City and Social Learning Labs}

Future Resilience for African Cities and Lands (FRACTAL) is a four-year initiative examining the water-energy-climate nexus in eight Southern African cities with the aim of better understanding pathways for integrating multi-decade climate 
information into decision making in the urban context. The FRACTAL team has created City Learning and Social Labs as a critical mode of co-exploration to support learning and innovative solutions for complex challenges.

The process begins when a city identifies their pressing issues in collaboration with an embedded researcher and FRACTAL team members. The embedded researcher entails immersing a researcher in the working world and practices of the people shaping and making these decisions in a city region (e.g., in a public institution such as a municipality, ministry or treasury). In this context, mutually beneficial research is undertaken to better understand public decision-making at the city regional scale with a specific focus on what scientific climate information is needed and how this information can most effectively be brought to bear within these local decision-making processes. Once the pressing issue is identified, the team invites diverse stakeholders with an interest in the topic to attend what is considered the first Learning Lab.

The Learning Labs encourage a process that engage a variety of stakeholders on finding solutions for a question or problem that they all perceive as relevant and urgent. The Learning Labs are designed to encourage all participants to share their insights, needs, and research finds on an identified problem. While sharing perspectives, all participants are asked to listen and consider others' perspectives. The Learning Labs embrace core concepts from Scharmer's (2009) Theory $\mathrm{U}$ such as the process of presencing, to let go as much as possible to ensure understanding of a complex problem from various and diverse viewpoints to inspire discussions around possible solutions, ideas of how to test these solutions, allowing space to improve and dismiss previously held ideas, and encourage further reflection among the group. This type of learning is an iterative process that requires skilled facilitation in order to ensure that deeper learning leads to improved action on the city level. Each Learning Lab can have different formats - provided there is a mechanism for regular interaction (e.g., a learning workshop every 3 months, a monthly discussion forum, etc.). However, the implementation of the Learning Lab approach always involves: a) the coexploration of deep case studies in cities b) building capacity and communication channels for better informed decision making, and c) monitoring the impact and change in policy and decision making.

\section{Transformative Scenario Planning}

The Adaptation at Scale in Semi-Arid Regions program (ASSAR) aims to improve understanding of climate change in semi-arid areas across Africa and Asia. START's research involvement focuses on understanding key barriers to and 
enablers of adaptation in northern Ghana and southern Mali through examining issues relating to governance, social differentiation (including gender), and natural resources. A collaborative transformative scenario planning (TSP) process is used to co-develop adaptation pathways for positive livelihood trajectories, evaluate important material and non-material costs and benefits, and identify political- economic-institutional enablers for advancing adaptation efforts. The scenario planning methods engages a broad range of stakeholders in the construction of particular scenarios in West Africa. Successful elements of a TSP process include:

- the ability to convene an initial team from the whole system (coinitiating),

- observe what happens within the system (co-sensing),

- construct stories about what could happen (co-presencing),

- discover what can and must be done (co-creating), and finally

- act to transform the system (co-evolving).

A simulation exercise was conducted on the possible futures for managing natural resources under agriculture intensification in semi-arid areas of Mali and Ghana, using the TSP process. The exercise produced four optional future scenario pathways using rainfall variability and the nature of the governance system as the two most uncertain driving forces in the region. Participants had the opportunity to construct four storylines under each scenario which evaluated options on the timescale of present day-2035, at the intersection of low or high impacts arising from rainfall variability and a centralized, versus decentralized, governance system. Stories went from meager futures characterized by land grabs by central government, migrating youth, fortress conservation approaches in protected areas, increasing disparities and political uprising - to more upbeat futures, where traditional authorities release more land for farming and investments are made in drought- resistant varieties, community-based silos and school feeding programs, thus increasing resilience, education and food security. From these stories, participants then decide what can and must be done, and what role they could play in order to influence the system - thus bringing to life the "transformative" defining feature of a TSP process. 


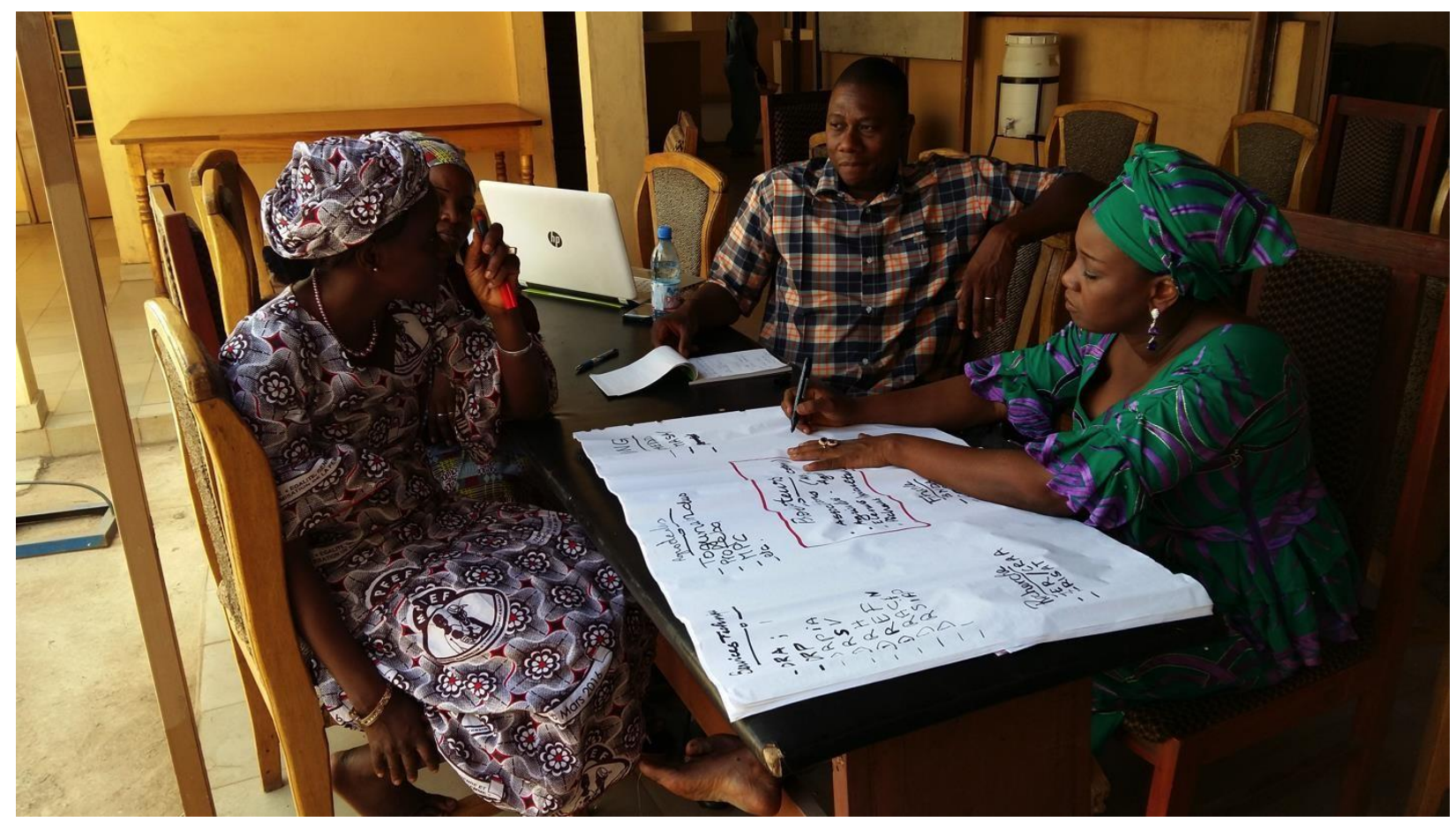

Figure 6. ICRISAT Mali participating in the Adaptation at Scale in Semi-Arid Regions Program. Image courtesy of ICRISAT Mali.

The Learning Labs and TSP process provide two examples of learning and capacity mechanisms. START has a variety of learning and capacity building modalities that aim to strengthen scientific skills, knowledge and connectivity of early and mid-career scientists and practitioners through experiences that are embedded at the interface of science, policy, and practice.

PART 2 - EXAMINING THE CASE

The second part of this case study builds on Part one and outlines network experiences and practices related to concepts of cross-scalar integration, netweaving, organizational learning, and transformative capacity. While each section is presented independently, these concepts are highly interrelated and difficult to separate in the context of START. The discussion is exploratory in nature and based primarily on participant observation, document analysis, and preliminary interviews.

\section{Cross-Scalar Integration}

Linkages between and among various levels and scales are gathering increased attention as potentially enhancing the adaptive capacity of social systems and 
organizations (Pelling et al., 2008; Diduck, 2010). The International START Secretariat serves as the hub of the network and stimulates learning processes and exchanges in scale-spanning activities and programs of individuals, organizations, and networks. Presently START has a loose and flexible multiscalar design and structure focused in Africa and Asia.

When asked what START does, one network member replied, "START leverages limited resources to build up leadership, relationships, and partnerships for facilitating cross-cutting capacity building." Initial analysis indicate START's ability to facilitate this cross scalar integration and cross- cutting capacity building is demonstrated in terms of 1) supporting a two way connection for network members between their home institutions and regional/global arenas and 2) promoting collaboration with diverse groups of people and research disciplines.

In the first example, START actively fosters networks and communities of practice at the intersection of global environmental change and sustainability including disaster risk reduction, land- use/land-cover change, biodiversity conservation, urban resilience, water resources management, agriculture and food security, regional climate modeling, and climate services. A network member illustrates their involvement and benefit from such engagement, "The organization and mentoring offered by START was incredible and changed my perspective of international collaboration and scientific training. In addition, it offered me a network in which to interact with world class scientists..." START offers opportunities to engage in such networks and communities of practice but it also relies on network champions to mentor young scientists through their own institutions and work. The same network member emphasized this ripple effect, "Through my academic work, [START's] vision is being spread out to touch all the graduates and colleagues that work with me." The regional networks aim to foster critical skills in network members so they benefit professional and strengthen capacities at their own institutions. This confidence in network member's ability to transfer knowledge is demonstrated, "I am ready to facilitate a similar training in my regional GOFC South Asia network."

The second example is supported through START's network activities and programs that aim to create opportunities for diverse groups of individuals and sectors to come together for exchange and collaboration. START facilitates exercises that stimulate dialogue and debate and guide participatory processes of investigation, discovery, and reflection. These shared experiences among participants form a strong foundation to strengthen networks and inform followon collaboration. One network member recalls their participation in an 
Advanced Institute, “...the...Institute was an invaluable training experience. I think it has done a good job of getting the next generation of scientists to think outside their traditional disciplinary boundaries and move beyond their comfort zones to create more meaningful collaborations." Equally important is START's integration and broker role of linking varying spaces of geography, institutional type, and disciplinary fields to address global environmental challenges. Network leaders play an important role in connecting enduring differences and highlighting similarities among diverse groups that have potential to foster science innovation and actions related to science with society as opposed to science for society.

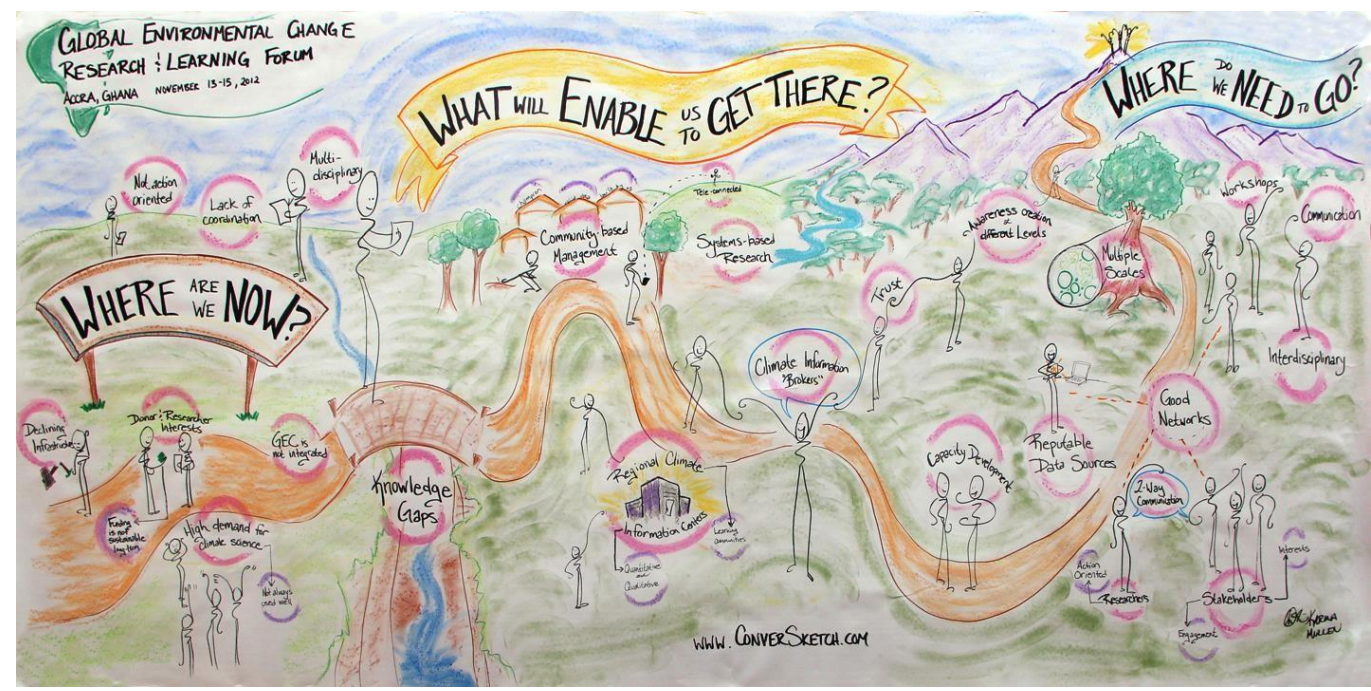

Figure 7. Graphic recordings were used to capture participants' ideas and ways forward at the 2012 Global Environment Change Learning Forum in Accra, Ghana. Image courtesy of Karina Mullen Branson.

\section{Netweaving}

Embedded in networks are leaders representing various stakeholder groups (Agranoff, 2006) with the aim to facilitate collaboration and cross-scale linkages within the network. These leaders have been referred to in the literature as netweavers, boundary spanners, policy entrepreneurs, social innovators, network facilitators, collaborative capacity builders, and activists (Agranoff, 2006, Weber \& Khademian, 2008, Westley et al., 2007). What they all have in common is a focus on capacity building activities, such as knowledge sharing and learning, through collaborative exchange across organizational boundaries. In START, netweaving is not a role that belongs to any one person; instead netweaving responsibilities are dispersed and seen as "collective". In this case, 
it seems netweaving becomes a capability of the network where it lives and grows through relationships as much as it does through specific individuals.

START Program Specialists are essential netweavers within individual projects and programs. Program Specialists custom-design integrative network activities in ways that inform and enhance network-supported research, education, and training while also aiming to encourage participants to take the next step by applying knowledge and skills learned. They also play a connecting role as referenced by a network member: "START brings together people, ideas, organizations and resources. It focuses these on critical questions about our future. The results are enhanced capabilities, relationships and dispositions for collaborative global change science. No one does this better." One Program Specialist spoke about their netweaving approach, "It is important to foster trust and encourage people to explore outside of their comfort zones. I try to lead by example and leave all assumptions at the door". A similar notion was mentioned by another netweaver, "I lead with questions and not answers."

There are ample examples of netweavers facilitating connections among individual program participants and also between the broader START network and relevant global initiatives as was demonstrated in the cross-scalar integration section. Maintaining and fostering new relationships to span boundaries and to forge new opportunities for the network itself is key component of success for these netweavers. One network member specifically referenced this trait in START staff, "START is so well connected to international organizations and individual experts in their fields that it becomes a magnet to bring together international intellectual pools."

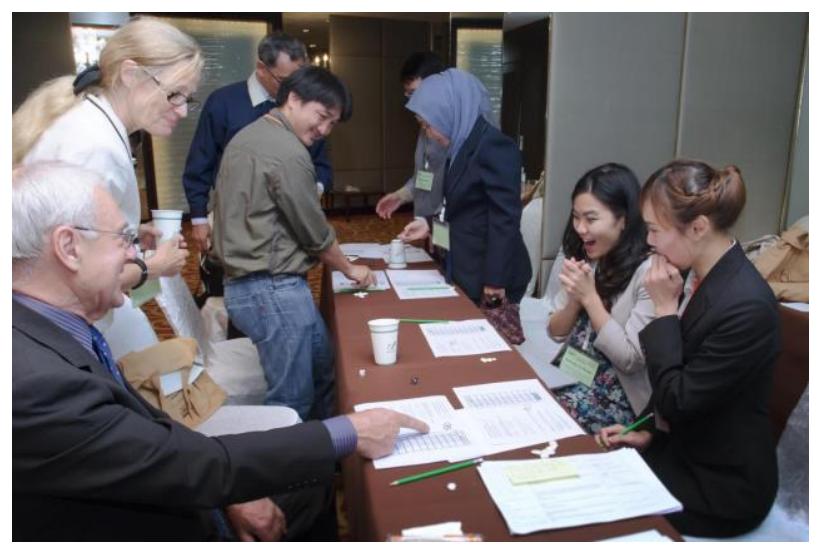

Figure 8. A series of highly interactive games were played to help individuals understand complex issues facing communities and decision-makers in relation to a changing climate. Image courtesy of START. 
START also has "big picture" netweavers that work to balance autonomy that individual programs and networks require with the need for overall coordination to fulfill START's goal of advancing capacity across various geographic sites and organizational scales. These big picture netweavers, consisting of the Board of Directors and Management Team, are responsible for ensuring impact and evolution of network structures and the vitality of START as an organization.

\section{Organizational Learning}

Organizations and networks are established when there is a clear purpose for their existence. Once that need is satisfied it is generally agreed that the organization should phase out. On numerous occasions, START's current Executive Director has stated, "The biggest accomplishment will be if START ceases to exist because we are no longer needed. There is nothing that would make me happier." While this is the ambition, an external review conducted by the Norwegian Agency for Development Cooperation determined that a permanent START governance structure could be necessary for some time:

There is...still a need for an organization that can contribute to building network in the scientific community in the field of global change, support in developing research proposals and provide both long and short-term fellowships and grants across the (African) region. The Pan-African START programme has proved to be an efficient organization in this regard, with a well-developed network and necessary credibility in the scientific community. There is a need for continued support of the program, particularly to ensure a stable and predictable funding of fellowships and a working secretariat. It is recommended that support for the START programme continues (NORAD, 2002).

Like any organization or network, it is important for START to learn and evolve over time to most effectively carry out its mission. The evolving landscape of global environmental change science has produced challenges and opportunities for adaptive organizations over the past two decades since START's inception. Changes include the expanding number and diversity of organizations competing for funding in the field and the growing need to operationalize transdisciplinary collaborative partnerships. These challenges require nimble organizations and networks with high levels of adaptive capacity. Adaptive capacity is the capability of a system to adjust to changing internal and external demands. Organizations with high levels of adaptive capacity are capable of learning at individual scales and across multiple scales through collective learning (Armitage, 2005; Folke et al., 2003; Walker et al., 2002). Furthermore, organizations with high levels of adaptive capacity are flexible in problem 
solving, creative in generating solutions, and responsive to social and environmental feedback.

START has activated its capacity to adapt to such variables by modifying the organization's structure and design; engaging with broader groups of stakeholders such as policymakers, civil society representatives, and other societal decision-makers alongside scientists and educators; and adopting new ways and means of operating in order to remain responsive and effective in its work. In START's biennial report, the organization pledged:

START has always advocated for capacity building as a critical component of development-it motivates and sustains the leadership required for social change and informed decision making. As such, we encourage a focus on capacity building on all scales and by all partners and institutions. This advocacy also presents a constant challenge to us in keeping ourselves relevant and maintaining our reputation as an innovative thought leader in the field. We take this challenge very seriously and endeavor to remain at the cusp of innovation and creativity in our programs and activities. Our promise to you is that we will continue to encourage and to challenge ourselves and others in this respect for years to come (START, 2013b).

This communication with network members and partners indicate that START embraces the responsibility of continual learning in order to best serve their networks.

The concept of organizational learning has roots in March and Simon's (1958) study of decision- making and efficiency in an organization. The assumption that organizations embody human attributes is often discussed (Weick \& Daft, 1983), however it is broadly accepted that it is an individual, and not an organization itself, who learns (Miner \& Mezias, 1996). Hence, developing the capacity for individuals to reflect upon and learn from experiences is vital in building a body of organizational knowledge and skills, thereby promoting the organization's capacity for adaptive operation (Kleiman et al., 2000; Salafsky et al., 2002). Yet these learning processes and knowledge will be isolated to the individual within the organization unless processes of collaboration are encouraged and set into practice. Interaction and sharing between individuals is, therefore, necessary in order to better understand and drive the learning process to determine ways in which the overall organization can learn. The social process of learning is further emphasized in the literature on organizational learning (Westley, 1995) and the social perspective (Gherardi, 2006; Gherardi et 
al., 1998; Lave \& Wenger, 1991), which view learning as inseparable from social interaction and engagement in work practice.

In 2012, START held their first annual retreat in an attempt to foster social learning processes that may have the ability to enhance the capacity of the organization to respond to feedback from the landscape in which it is situated (Berkes et al., 2003). The retreat was designed to allow for reflection on current practices and operations and to redefine possibilities for the future. The retreat facilitated a process of self-assessment and discovery by asking key questions such as: What do we want to accomplish? How do we know if we are making progress? How do we define success? (Friedman, 2005). Flexibility and learning within organizations is a determinant of adaptive capacity (Armitage, 2005; Fazey et al., 2007; Pelling et al., 2008), and as a result, learning is advanced by organizations that experiment, monitor processes and outcomes, and adapt practices as new knowledge is gained (Carpenter et al., 2001). Through reflection, discussion, and mapping exercises, the organization worked to identify steps to catalyze desired changes. The retreat also enabled all staff to collaboratively review their roles and responsibilities in the context of START's current programs and projected growth areas. Staff worked collaboratively to identify gaps in expertise and create action plans for more effectively achieving personal and organizational goals.

In September 2013, the second annual retreat brought together all Board members, staff, and a select number of regional representatives, for intensive discussions about START impact. Priorities for discussion included how to increase impact in strategic and manageable ways and how to tell the story of previous and ongoing impact in more compelling ways. The Retreat produced detailed recommendations that informed development of a Results Based Management logframe to increase effectiveness and efficiency and a revised mission to guide the future of START. 


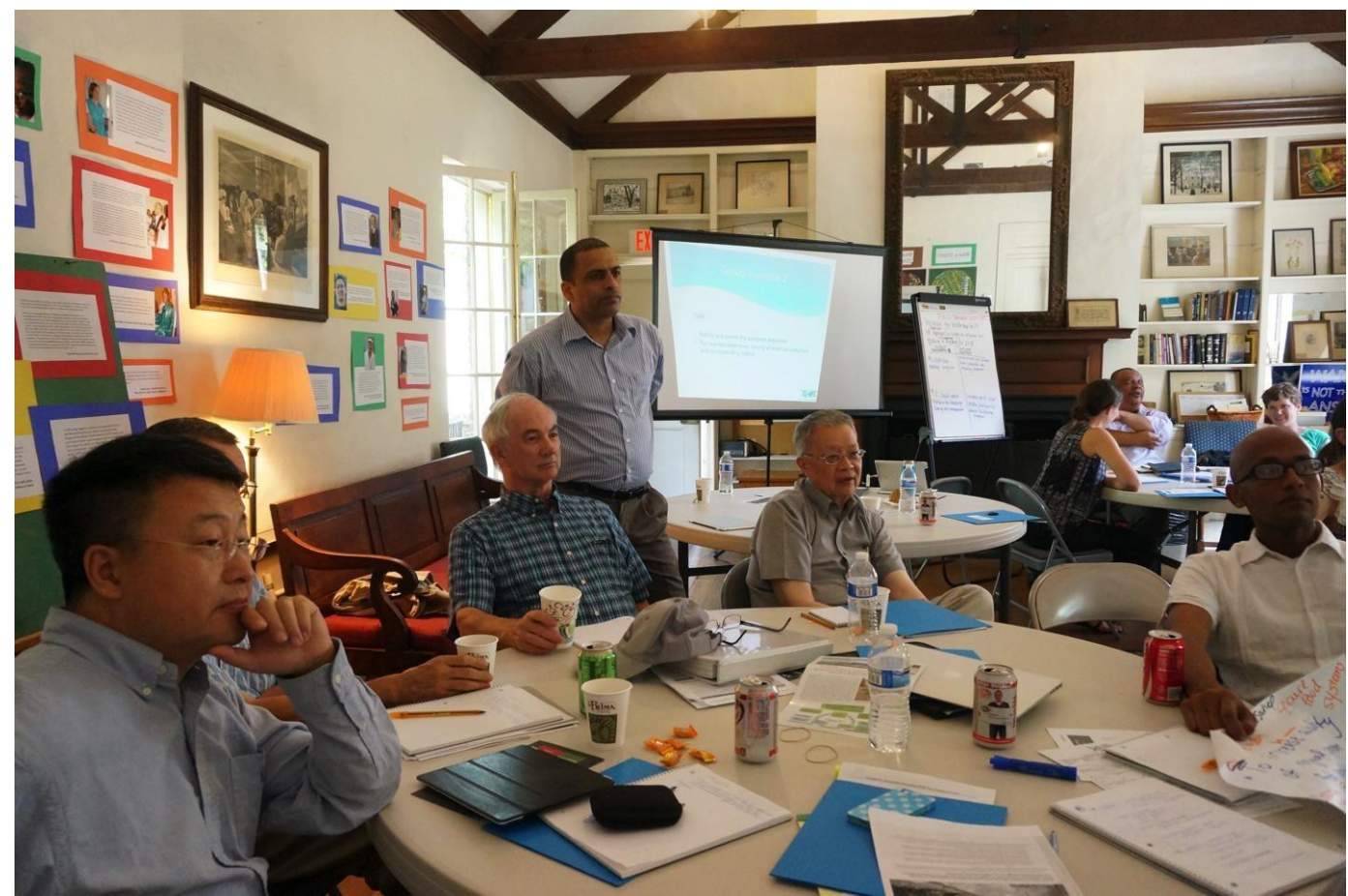

Figure 9. START staff, board, and regional representatives gather for a retreat in 2013. Image courtesy of START.

\section{Transformative Capacity}

In considering transformative capacity in networks it is important to examine Argyris and Schön's (1978) multi-loop learning, which demonstrates how organizational learning, and social learning overlap. Multi-loop social learning goes much further than just learning in a group setting, as Woodhill (2003) points out it involves "understanding the limitations of existing institutions and mechanisms of governance and experimenting with multi-layered, learning oriented and participatory forms of governance" (p. 143).

The three levels of looped learning are often characterized as follows: Are we doing things right? (single-loop learning); Are we doing the right things? (doubleloop learning); What are the right things to do? (triple-loop learning). The questioning and reflection that occurs at the level of triple- loop learning leads to a deeper understanding of the context, power dynamics, and values that influence the capacity to operate in a system (Keen et al., 2005). Triple-loop learning supports a process to frame questions in a reflective and iterative manner as a way to address challenges in complex systems by questioning and potentially transforming rules, structures, programs, decision- making processes, and nested governing values of behaviors (Nielsen, 1993). Research suggests triple-loop learning can foster change in institutional contexts and 
governance arrangements (Yuen et al., 2013; Bos et al., 2013) and therefore it is necessary for networks to build and enable capacities to support change.

Triple-loop learning, or "transformational learning," is multilayered and requires continuous iterative processes in which groups engage in critical reflection to examine processes of single- and double- loop learning and to foster changes within these existing governance rules and norms (Flood and Romm, 1996; Snell and Man-Kuen Chak, 1998). The triple-loops is about learning how to learn; why individuals and groups learn the way they learn; and what norms and values inform their learning and decision-making. Triple-loop learning may therefore involve a process of transformation by creating a shift in context or perspectives.

Preliminary analysis of present day START indicates that network activities and practices are potentially fostering capacity for change at three scales: individual, organizational, and systems level. In addition, there are examples of activities and partnerships that support integration across these three scales. In-depth research should be conducted to examine START by way of this deeper, transformational, third-loop level of learning before stronger claims are made. The proposed research design to carry out this research is described in the following section.

At the individual scale, capacity development takes numerous forms including technical, academic, and professional skills as well as strengthening of complementary soft skills. In the context of START, individual capacity development is largely focused on advancing skills and knowledge that facilitate and mobilize transdisciplinary approaches to knowledge co-design and coproduction, enhance futures literacy in research and in societal communications, and nurture experiential confidence to create new networking opportunities within and across regional networks. Early career researchers are a priority group for capacity strengthening at the individual level. Nurturing communities of practice able to address complex sustainability challenges requires that individual capacity development expand beyond the research community to consider capacity development and mobilization needs and priorities within policy and practice domains.

At the organizational scale, the approach to capacity development focuses on strengthening organizations, which include nonprofit, for profit, governmental, academic, and research, as well as coordinated networks with interest in policy, sustainability science, and development. This level of capacity development also includes strengthening of educational institutions and curricula, supporting 
institutional transformation, and strengthening institutional governance. Strengthening institutional/organizational capacities ensures that investments in individual-level capacity development are allowed to flourish rather than dissipate. Strengthening organizations and networks towards systems-oriented science is fundamental to the success of the emerging global initiatives such Future Earth's Knowledge Action Networks.

At the systems scale, capacity development represents an important strategic opportunity as indicated by START employees but one that will require a concerted effort towards building strategic partnerships within regions and across START. The three scales (individual, organizational and systems) are nested, and thus achieving effective action at the systems level depends on capacity strengthening at individual and organizational levels. Systems level capacity development is anchored in specific geographic regions and integrates across spatial scales and societal domains. The systems level necessarily includes multiple sectors and numerous interacting drivers of change, and takes into account political dynamics, agency, and power structures. The systems level is distinguished from individual and organizational levels by a loosely configured associations of individuals and institutions, sometimes organized into networks, and the lack of a single 'owner', and thus the need to mobilize capacity in a coordinated, collaborative, and frequently voluntary manner. As expressed by the Overseas Development Institute (2006), "Capacity-building efforts need to be considered from a systems perspective that recognizes the dynamics and connections among various actors and issues at the different levels, as part of a broader unit rather than as loosely connected factors."

The following initiatives (see Table 1) are not an exhaustive list of all current START network activities but rather represent a synthesis demonstrating change at three different scales: individual, organizational, and systems level. It also includes STARTs efforts to contribute to the Future Earth platform, a 10year initiative bringing the global environmental change community together to support transformations to a sustainable world. 


\begin{tabular}{|c|c|c|c|c|}
\hline $\begin{array}{l}\text { START } \\
\text { Initiatives }\end{array}$ & $\begin{array}{l}\text { Individual level } \\
\text { capacity building }\end{array}$ & $\begin{array}{l}\text { Organizational } \\
\text { level capacity } \\
\text { building }\end{array}$ & $\begin{array}{c}\text { Systems level } \\
\text { capacity building }\end{array}$ & $\begin{array}{c}\text { Future Earth } \\
\text { Knowledge Action } \\
\text { Network } \\
\text { contribution }\end{array}$ \\
\hline $\begin{array}{l}\text { Transdiscipl } \\
\text { inary } \\
\text { Training }\end{array}$ & $\begin{array}{l}\text { Workshops to } \\
\text { promote skill } \\
\text { development in and } \\
\text { strengthening of } \\
\text { TD research and } \\
\text { communications } \\
\text { and networking }\end{array}$ & $\begin{array}{l}\text { Workshops }(2016) \\
\text { target national and } \\
\text { regional } \\
\text { representatives to } \\
\text { inform their } \\
\text { organization's } \\
\text { approaches to TD }\end{array}$ & $\begin{array}{l}\text { Strengthen a } \\
\text { community of } \\
\text { practice of TD } \\
\text { experts for } \\
\text { understanding co- } \\
\text { design and co- } \\
\text { produce }\end{array}$ & $\begin{array}{l}\text { Transformations to } \\
\text { Sustainability } \\
\text {-Food-Energy- } \\
\text { Water Nexus } \\
\text {-Urban } \\
\text { And others, TBD }\end{array}$ \\
\hline $\begin{array}{l}\text { FRACTAL \& } \\
\text { Global } \\
\text { Environmen } \\
\text { tal Change } \\
\text { Grants }\end{array}$ & $\begin{array}{l}\text {-Cohort of early } \\
\text { career scientists } \\
\text { embedded in city } \\
\text { government } \\
\text { agencies develop } \\
\text { TD skills } \\
\text {-GEC grants target } \\
\text { research capacity } \\
\text { and targeted } \\
\text { training }\end{array}$ & $\begin{array}{l}\text { - Increase } \\
\text { understanding \& } \\
\text { use of multi- } \\
\text { decadal climate } \\
\text { information in } 8 \\
\text { Southern Africa } \\
\text { municipalities } \\
\text {-Enhance the } \\
\text { capacity of } \\
\text { institutions \& GEC } \\
\text { recipients to } \\
\text { manage grants }\end{array}$ & $\begin{array}{l}\text {-Offer lessons from } \\
\text { co- exploration } \& \\
\text { co-design research } \\
\text { projects } \\
\text {-Strengthen a } \\
\text { community of } \\
\text { practice on water- } \\
\text { energy- climate } \\
\text { nexus } \\
\text { - Increase regional } \\
\text { understanding of } \\
\text { multi-decadal } \\
\text { climate information } \\
\text { in decision making }\end{array}$ & $\begin{array}{l}\text {-Food-Energy- } \\
\text { Water Nexus } \\
\text {-Urban }\end{array}$ \\
\hline $\begin{array}{l}\text { Pan-Asia } \\
\text { Risk } \\
\text { Reduction } \\
\text { Fellowship }\end{array}$ & $\begin{array}{l}\text {-Research, } \\
\text { training, } \\
\text { networking \& } \\
\text { educational } \\
\text { opportunities to } \\
\text { enhance fellow's } \\
\text { capabilities for } \\
\text { advancing \& } \\
\text { applying knowledge } \\
\text { on risk reduction } \\
\text { in Asia. } \\
\text {-Enhance the } \\
\text { capacity of PARR }\end{array}$ & $\begin{array}{l}\text {-Fellows foster } \\
\text { relationships } \\
\text { between Home and } \\
\text { Host Institutions } \\
\text { for ongoing } \\
\text { partnerships } \\
\text {-Enhance the } \\
\text { capacity of } \\
\text { institutions to } \\
\text { manage grants }\end{array}$ & $\begin{array}{l}\text { Strengthen the } \\
\text { PARR Alliance } \& \text { a } \\
\text { community of } \\
\text { practice on risk } \\
\text { reduction in Asia }\end{array}$ & $\begin{array}{l}\text {-Urban } \\
\text {-Risk \& Disaster } \\
\text { Prevention }\end{array}$ \\
\hline
\end{tabular}


Future Earth

Organizational

START

Initiatives

IRDR

Advanced

Institutes \&

Follow-on

Grants
Global

Observation

of Forest

Cover \&

Land

Dynamics

(GOFC-

GOLD)
Individual level

capacity building

-Advanced

promote skill

development of TD

$\&$ disaster risk

research

-Enhance the capacity of fellows

to manage grants
Institutes to

level capacity

building

-AI participants

transfer skills to

their home

institutions

-Competitive

follow-on grants

strengthen capacity

on AI themes

-Enhance the

capacity of

institutions to

manage grants

-Enhance skill

development on

interpretation \&

application of

Earth observation

data

-Improve
institutional access
to NASA's Earth
observation data

observation data

-Knowledge

exchange between

US and developing

country

institutions
Knowledge Action

Network

contribution

capacity building

Risk \& Disaster

Prevention
- Foster regional

networks on land

use/cover change

research, including

forestry, fire

disturbance,

agriculture, \& the

carbon cycle

dynamics

-Promote access

$\&$ application of

Earth observation

data in research

The strong

emphasis on

research into use

strengthens a

community of

practice on

adaptation
-Natural Assets

-NewTechnologies
Adaptation

at Scale in

Semi-Arid

Regions

(ASSAR) gain experience

through

participation in a

large research

consortia understanding of

research agendas

related to

governance, social

differentiation and

ecosystem services
Sustainable

Development Goals

Table 1. START's efforts to foster individual, organizational, and systems level change 


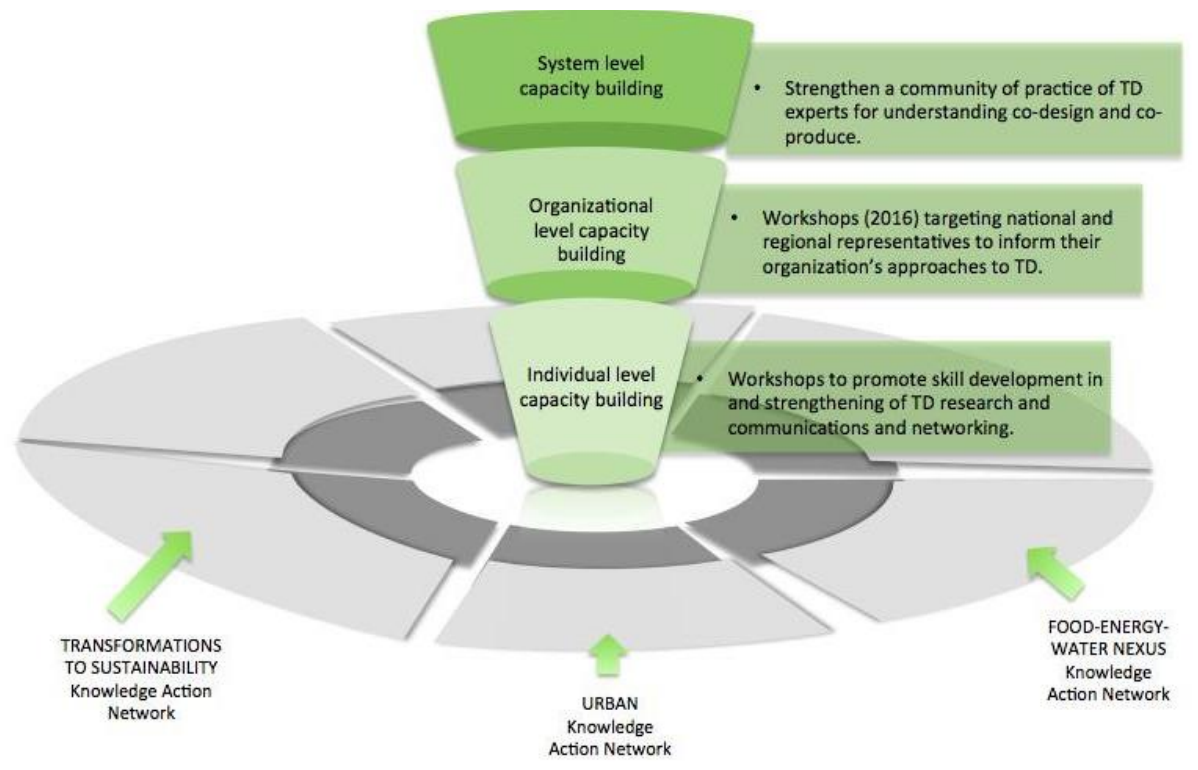

Figure 10. An example of transdisciplinary training activities striving for transformation.

\section{CONCLUSION}

This case study provides a glimpse of START's 24 years of experiential learning and efforts to foster network transformation through adaptation and evolution of network design, capacity building, cross-scalar and organizational learning. Part one has laid out the network origins and history as well as network design and capacity building philosophy. Part two has built on these descriptions to consider cross-scalar integration, netweaving, organizational learning, and transformative capacity within START.

While literature offers theories on the potential of networks and adaptive governance arrangements to overcome challenges through flexible organizations and collective action, the question in practice remains: What features of network or organizational design and social learning constitute the capacity to adapt and transform through multi-level interactions? Operating in this gap, START provides a valuable research opportunity to conduct a retrospective longitudinal analysis to investigate how START has adapted its capacity for learning and foresight to deal with new and challenging situations over time. This analysis into START's 24 years of intensive experimentation and transformation as an adaptive organization and network would create opportunity for rich and detailed narratives of practice to inform other networks. 
Agranoff, R. (2006). Inside Collaborative Networks: Ten Lessons for Public Managers. Public Administration Review, 66(Special Issue), 56-65.

Argyris, C., \& Schön, D. (1978). Organizational Learning. Addison-Wesley, Readin08.

Adaptive co-management and the paradox of learning. Global Environmental Change 18, 86-98.

Armitage, D. (2005). Adaptive capacity and community-based natural resources management. Environmental Management 35,(6), 703-15.

Berkes, F., Colding, J., \& Folke, C. (2003). Navigating social-ecological systems building resilience for complexity and change. Cambridge University Press, Cambridge, UK.

Bos, J.J., Brown, R.R., \& Farrelly, M.A. (2013). A design framework for creating social learning situations. Global Environmental Change. Retrieved from http:/ / dx.doi.org/10.1016/j.gloenvcha.2012.12.003

Carpenter, S. R., Walker, B., Anderies, J.M., \& Abel, J. (2001). From metaphor to measurement: resilience of what to what? Ecosystems 4, 765-781.

Diduck, A., (2010). The learning dimension of adaptive capacity: untangling the multi-level connections. In: Armitage, D., Plummer, R. (Eds.), Adaptive Capacity and Environmental Governance. Springer, Berlin, Germany.

Flood, R., \& Romm, N. (1996). Contours of diversity management and triple loop learning. Kybernetes 25(7/8), 154-163.

Folke C, Colding J, Berkes F. (2003) Synthesis: building resilience and adaptive capacity in socio- ecological systems. In: Berkes F, Folke C, Colding $\mathrm{J}$ (eds) Navigating social- ecological systems: building resilience for complexity and change. Cambridge University Press, Cambridge, 352387.

Friedman, V. J., Lipshitz, R., \& Popper, M. (2005). 'The Mystification of Organizational Learning', Journal of Management Inquiry 14(1), 19-30.

Fuchs, R.J. (1995). START - the road from Bellagio. Global Environmental Change 5(5), 397- 404. Gherardi, S., Nicolini, D., \& Odella, F. (1998). Toward a social understanding of how people learn in organizations: The notion of situated curriculum. Management Learning, 29(3), 273-297.

Gherardi,S. (2006). Organizational knowledge: the texture of workplace learning. Malden, MA, Oxford, UK, Victoria, Australia: Blackwell publishing.

IGBP. (1998). Global Change Report 44 - START Implementation Plan 19972002, Stockholm: International Geosphere-Biosphere Programme.

IGBP. (1990). Global Change Report 12 - The International GeosphereBiosphere Programme: A Study of Global Change The Initial Core 
Projects. Stockholm, Sweden: International Geosphere-Biosphere Programme.

IGBP. (1991). Global Change Report 15 - Global change System for Analysis, Research and Training (START): report of a meeting at Bellagio, December 3-7, 1990. Boulder Colo.: International Geosphere-Biosphere Programme.

Keen, M., Brown, V., \& Dybal, R. (2005). Social Learning in Environmental Management. Earthscan, London.

Kleiman, D. G., Reading, R. P., Miller, B. J., Clark, T.W., Scott, J. M., Robinson, J., Wallace, R. L., Cabin, J., \& Felleman, F. (2000). Improving the evaluation of conservation programs. Conservation Biology 14:356-365.

Lave, J. and E. Wenger. (1991). Situated Learning: Legitimate Peripheral Participation. University of Cambridge Press, Cambridge, UK.

Leemans, R., Asar, G., Busalacchi, A., Canadell, J., Ingram, J., Larigauderie, A., Mooney, H., Nobre, C., Patwardhan, A., Rice, M., Schmidt, F., Seitzinger, S., Virji, H., Vorosmarty, C., \& Young, O. (2009). Developing a common strategy for integrative global environmental change research and outreach: the Earth System Science Partnership (ESSP). Current Opinion in Environmental Sustainability, 1, 1-10. doi:10.1016/j.cosust.2009.07.013.

Miner, A., \& Mezias, S. (1996). Ugly duckling no more: Past and futures of organizational learning research. Organization Science, 7(1), 88-99.

Mugabe J. 2000. Capacity development initiative. Scientific and technical capacity development: needs and priorities. GEF-UNDP.

Nielson, R. P. (1993). Woolman's "I Am We" Triple Loop Action Learning: Origin and Application in Organization Ethics. The Journal of Applied Behavioral Science, 29(1), 117-138. Pelling, M., High, C., Dearing, J., \& Smith, D. (2008). Shadow spaces for social learning: a relational understanding of adaptive capacity to climate change within organizations. Environmental Planning A, 40, 867-884.

Salafsky, N., Margoluis, R., Redford, K.H., \& Robinson, J.G. (2002). Improving the practice of conservation: a conceptual framework and research agenda for conservation science. Conservation Biology 16, 1469-1479.

Snell, R. \& Chak, A. M-K. (1998). 'The Learning Organization: Learning and Empowerment for Whom?', Management Learning 29(3), 337-364. START (2008). START: The Next Decade, A Strategic Plan.

START (2013a). Advancing Knowledge for Action on Global Environmental Change: Reflecting on Progress and Strategizing for the Future. Retrieved from http://start.org/publications/start-strategy-publication START (2013b). Biennial Report 2012-2013. Retrieved from http://start.org/publications/12-13- biennial-report 
Virji, H., Padgham, J., \& Seipt, C. (2012). Capacity building to support knowledge systems for resilient development - approaches, actions, and needs. Current Opinion in Environmental Sustainability, 4(1): 115-121.

Walker, B., Abel, N., Anderies, J., Carpenter, S., Cumming, G., Janssen, M., Lebel, L., Norberg, J., Peterson, G. D., \& Pritchard, R. (2002). Resilience management in social- ecological systems: a working hypothesis for a participatory approach. Conservation Ecology 6(1):14. Retrieved from http://www.consecol.org/vol6/iss1/art14/.

Weber, E. P., \& Khademian, A. M. (2008). Wicked Problems, Knowledge Challenges, and Collaborative Capacity Builders in Network Settings. Public Administration Review, 68(2), 334-349.

Weick, K. E. \& Daft, R.L. (1983). The Effectiveness of Interpretation Systems. In Organizational Effectiveness: A Comparison of Multiple Models, ed. Kim S. Cameron and David A. Whetten, 71-93. New York, NY: Academic Press.

Westley, F. (1995). Governing design: The Management of Social Systems and Ecosystem Management. In: Gunderson, L., Holling, C.S., Light, S.S. (Eds.), Barriers and Bridges to the Renewal of Ecosystems and Institutions. Columbia University Press, NY.

Woodhill, A. J. (2003). Dialogue and transboundary water resources management: towards a framework for facilitating social learning. Pages 44-59 in S. Langaas and J. G. Timmerman, editors. The role and use of environmental information in European transboundary river basin management. IWA Publishing, London, UK.

Yuen E., Jovicich, S.S., \& Preston, B.L. (2013). Climate change vulnerability assessments as catalysts for social learning: four case studies in southeastern Australia. Mitigation and Adaptation Strategies for Global Change, 18(5):567-590. 


\section{ACKNOWLEDGEMENTS}

This project was initiated to help inform the design of NSEC, a network of campusbased centers and offices that serve as catalysts for educational transformation in science, technology, engineering, and mathematics (STEM).

This material is based upon work supported by the National Science Foundation under Grant No. 1524832. Any opinions, findings, and conclusions or recommendations expressed in this material are those of the author(s) and do not necessarily reflect the views of the National Science Foundation.

\section{A REPORT FROM THE NETWORK OF STEM EDUCATION CENTERS, HTTP://SERC.CARLETON.EDU/STEMEDCENTERS/INDEX.HTML.}

